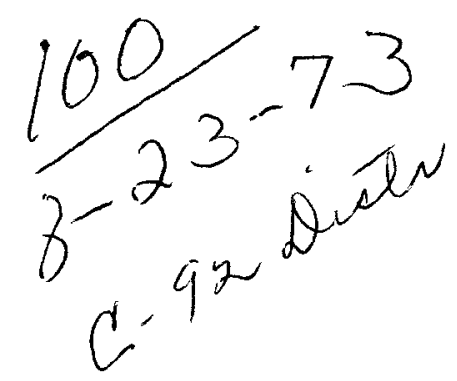

WANL-TME-1906A NASA-CR-121225

JUNE 18, 1973

Westinghouse Astronuclear Laboratory

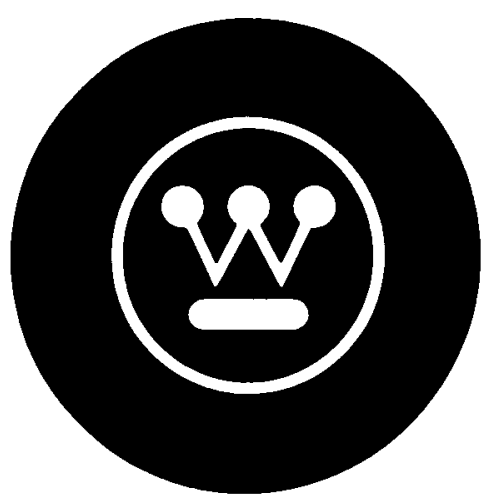

\title{
AN UPDATE OF
}

\section{INPUT INSTRUCTIONS TO TEMOD}




\section{DISCLAIMER}

This report was prepared as an account of work sponsored by an agency of the United States Government. Neither the United States Government nor any agency Thereof, nor any of their employees, makes any warranty, express or implied, or assumes any legal liability or responsibility for the accuracy, completeness, or usefulness of any information, apparatus, product, or process disclosed, or represents that its use would not infringe privately owned rights. Reference herein to any specific commercial product, process, or service by trade name, trademark, manufacturer, or otherwise does not necessarily constitute or imply its endorsement, recommendation, or favoring by the United States Government or any agency thereof. The views and opinions of authors expressed herein do not necessarily state or reflect those of the United States Government or any agency thereof. 


\section{DISCLAIMER}

Portions of this document may be illegible in electronic image products. Images are produced from the best available original document. 
Westinghouse Electric Corporation Astronuclear Laboratory

P. O. Box 10864

Pittsburgh, Pennsylvania 15236 
FORWARD

The work described herein was performed at the Westinghouse Astronuclear Laboratory under subcontract to the Atomics International Division of Rockwell International Corporation. The work was performed for the Space Nuclear Systems Division, a joint AEC-NASA office with project management provided by NASA-Lewis Research Center and the AEC-SNAP Project Office. 
TABLE OF CONTENTS

A. MAIN PROGRAM: TEMOD

B. BLOCK DATA SUBPROGRAM

C. PHONY SUBROUTINE

D. SUBROUTINE COUPLE

E. SUBROUTINE OPTIM

F. SUBROUTINE PUMP

G. SUBROUTINE LIFE

D- 4

H. SUBROUTINE RITE

D- 4

I. FUNCTION SUBPROGRAM SI

D- 4

J. FUNCTION SUBPRO GRAM DK2FK

D- 4

K. FUNCTION SUBPROGRAM WATE

D- 4

III INPUT TO THE TEMOD CODE

A. GENERAL

D- 5

B. BULK MATERIALS PROPERTIES

D- 5

C. FIXED POINT CONTROL CONSTANTS

D- 6

D. FLOATING POINT INPUT PARAMETERS

D-14

E. DATA CARDS, ORDER AND FORMATS

1. Comment Card

2. Fixed Point Data for NZ Array

3. Floating Point Data for Z Array

D-21

4. Temperature Data

D-22

5. Multiple Case Runs

D-24 
TABLE OF CONTENTS

SECTION

PAGE

IV

PARAMETRIC CALCULATIONS

D-25

A. GENERAL D-25

B. TEMPERATURE PARAMETRIC WITH SPECIFIED D-25 GEOMETRY

C. LOAD RESISTANCE PARAMETRIC WITH SPECIFIED D-26 MODULE

D. TEMPERATURE PARAMETRIC WITH SPECIFIED D-27 VOLTAGE AND CIRCUIT LENGTH

E. PARAMETRIC ON NUMBER OF COUPLES WITH D-27 SPECIFIED LOAD VOLTAGE AND CIRCUIT LENGTH

F. PARAMETRIC ON N-LEG/P-LEG AXIAL THICKNESS D-28 RATIO WITH SPECIFIED CIRCUIT LENGTH

G. PARAMETRIC ON NUMBER OF COUPLES WITH D-29 SPECIFIED LOAD VOLTAGE HEAT INPUT OR POWER OUTPUT

H. PARAMETRIC TO DETERMINE OPTIMUM SEGMENTING D-29 RADIUS, $r_{5}$

I. TEMPERATURE DERIVATIVE CALCULATIONS D-31

J. RADIAL GEOMETRY PARAMETRICS D-32

1. Inner Radius/Outer Radius Parameters D-33

2. Inner Radius/Thermoelectric Washer Radial D-34 Thickness Parametrics

K. PUMP MODULE PARAMETRIC STUDIES D-34

L. CALCULATIONS OF PERFORMANCE AS A D-35 FUNCTION OF TIME

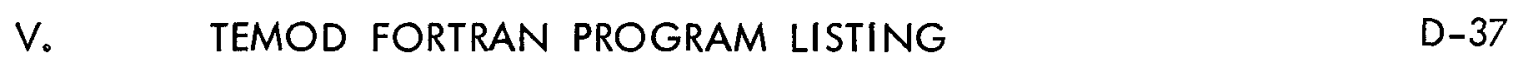




\section{LIST OF ILLUSTRATIONS}

FIGURE

1

CROSS SECTIONAL

VIEW OF A "UNIT" COUPLE

PAGE

D- 3

\section{LIST OF TABLES}

TABLE

1

TEMOD INPUT FIXED POINT CONTROL PARAMETER

PAGE

DEFINITIONS

2

TEMOD INPUT FLOATING POINT CONTROL

D-15

PARAMETER DEFINITIONS 
W Astronuclear

Laboratory

WANL-TME-1906A

NASA CR-121225

\section{AN UPDATE OF INPUT INSTRUCTIONS TO TEMOD}

\section{INTRODUCTION}

The theory and operation of a Fortran IV computer code, designated as TEMOD*, used to calculate tubular thermoelectric generator performance is described in WANL-TME1906. The original version of TEMOD was developed under AEC Contract AT(29-2)-2638 in 1969. This report which is written as Appendix D of WANL-TME-1906, describes additions to the mathematical model and an update of the input instructions to the code which have been developed under AEC Subcontract N854-0051, in the period 1969 - 1973.

Although the basic mathematical model described in WANL-TME-1906 has remained unchanged, a substantial number of input/output options have been added to allow completion of module performance parametrics as required in support of the Compact Thermoelectric Converter System Technology Program conducted at Westinghouse Astronuclear Laboratory. The report, then, basically replaces Section IV of WANL-TME-1906 entitled "Input to the TEMOD Code."

Section $V$ of this report contains a Fortran listing of the code.

* C. M. Rose, "A Numerical Model for Tubular Thermoelectric Generator Performance Analysis", WANL-TME-1906, April 1969. 


\section{BASIC DESCRIPTION OF CODE SETUP}

The TEMOD code consists of a main program, referred to as TEMOD, seven subroutines and three function subprograms. Although a complete Fortran listing of the code is given in Section $V$ of this report, a brief discussion of the code sections is given below:

\section{A. MAIN PROGRAM: TEMOD}

Contains read statements for input quantities. Lists input parameters and module dimensions unless list is suppressed by input control parameter $N Z(5)$. Also directs flow of logic between each of the individual subroutines and subprograms.

B. BLOCK DATA SUBPROGRAM

Contains compiled tables of all applicable material properties. Selections of thermoelectric material combinations, clad and conductor ring materials can be made by specification of control parameters at input.

C. PHONY SUBROUTINE

Assigns thermoelectric, clad and conductor ring properties as specified by input control parameters. Also adjusts thermoelectric material properties by percentages specified during input. Outputs all material properties used in each calculation unless output is suppressed by input control parameter $\mathrm{NZ}(5)$.

\section{SUBROUTINE COUPLE}

Performs heat balance/radial temperature profile/electrical output calculations for each thermoelectric couple. The mathematical model used for these calculations is discussed in WANL-TME-1906. A cross sectional view of a unit couple is shown in Figure 1.

\section{E. SUBROUTINE OPTIM}

Performs temperature, dimensional and load resistance incrementations specified. Also contains output statements which are restricted to one line of parameters for each set of conditions. 


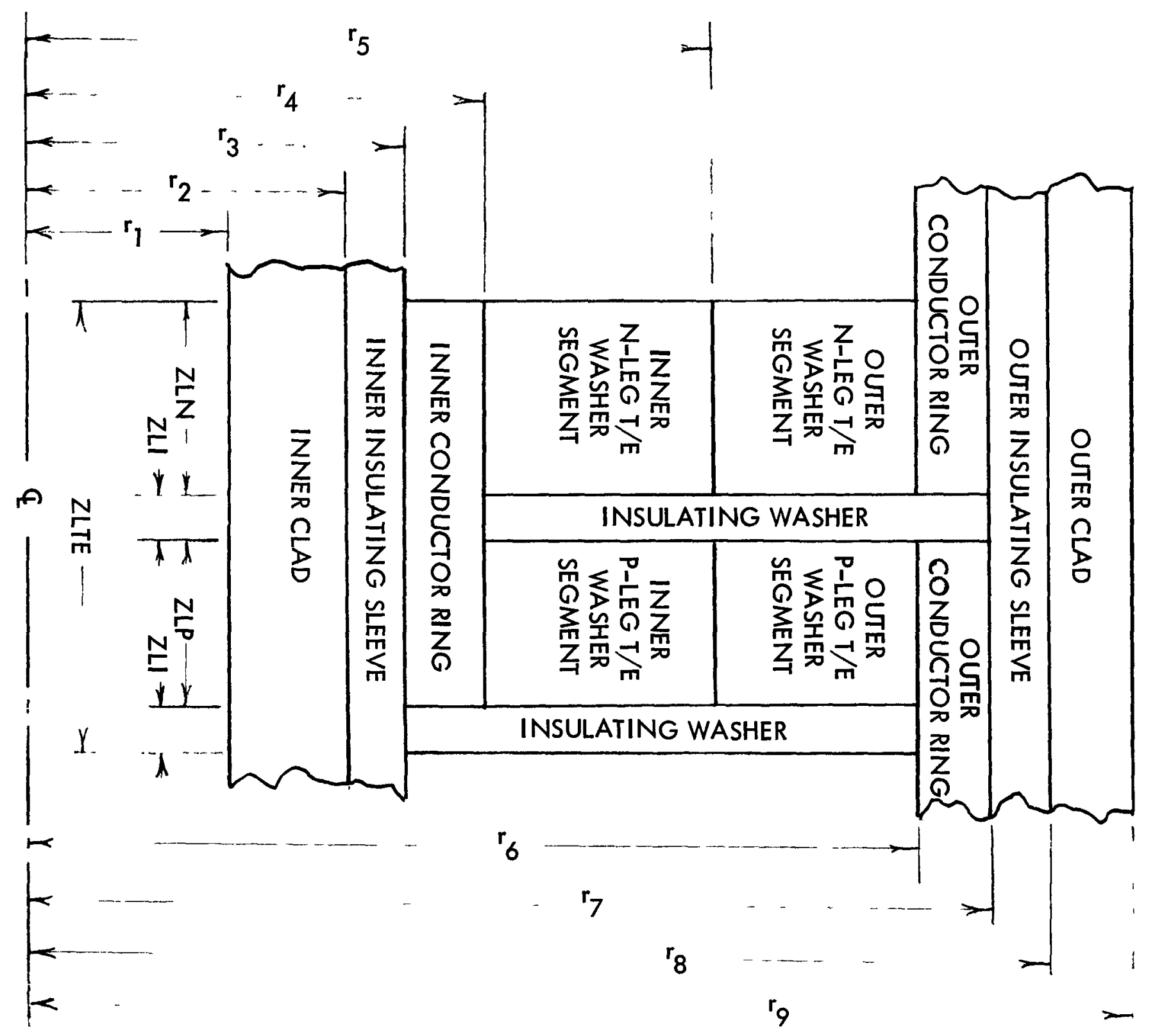

FIGURE I. CROSS SECTIONAL VIEW OF A "UNIT" COUPLE 


\section{F. SUBROUTINE PUMP}

Performs dimensional incrementations specified for pump module parametric calculations in which electrical power and required load vol tage have been set.

G. SUBROUTINE LIFE

Performs performance as a function of time calculations in which operating conditions and degradation rates are specified.

H. SUBROUTINE RITE

Combines the results of the individual couple calculations to determine module performance for any specified number of couples (see $N Z(10)$ below) operating in thermal parallel and electrical series. Also contains write statements to list results of module and individual couple calculations.

1. FUNCTION SUBPROGRAM SI

Performs all interpolation or extrapolation calculations. Primarily used to evaluate material properties which are contained in the program as temperature table values.

J. FUNCTION SUBPROGRAM DK2FK

Performs all temperature unit conversions. Performance calculations are done in Kelvin units, but input/output may be specified in either Fahrenheit or Kelvin units (see $N Z(8)$ ).

K. FUNCTION SUBPROGRAM WATE

Calculates module weight based on input module dimensions. Weight calculations will include contribution of end closures if appropriate entry is made in $Z(61)$. 


\section{INPUT TO THE TEMOD CODE}

\section{A. GENERAL}

There are four categories of input data required to operate the TEMOD code. The formats used to read these parameters have not been modified from the description given in WANL-TME-1906. The basic categories of input data are: (1) bulk material properties, (2) fixed point (integer) control constants; (3) floating point data, and (4) operating temperatures.

\section{B. BULK MATERIALS PROPERTIES}

Bulk materials properties include thermal conductivities and densities of all materials in the generator, Seebeck coefficients of all thermoelectric materials, and electrical resistivities of all materials in the electrical circuit. These properties with the exception of densities, are introduced as tables with the property evaluated at $50^{\circ} \mathrm{K}$ increments from $300^{\circ} \mathrm{K}$ up to $1000^{\circ} \mathrm{K}$ (15 values).

A listing of the material property subroutine, DATAIN is given in Appendix $A$ along with the complete program listing. Properties for six types of thermoelectric materials (TEGS-3N, TEGS-2N or GE-nl, TEGS-3P, TEGS-2P, ternary n-type, and ternary p-type) have been built into the code and calculations can be made using any combination of these materials by proper selection of the control constant, discussed below. In addition properties are entered for three types of cladding materials (stainless steel, inconel and tantalum) and three types of conductor ring materials (iron, tungsten, and molybdenum) are also entered and can be selected by an input control constant.

The sixteenth entry in the thermal conductivity table for each material in the DATAIN subroutine listed in Appendix $A$ is the density of the material (in pounds per cubic inch). These densities are used in weight calculations.

Also note that Seebeck coefficients for all thermoelectrical materials are entered using absolute values. The negative Seebeck coefficients of n-type materials is handled internally by the program logic. 


\section{FIXED POINT CONTROL CONSTANTS}

All fixed point data is read into a list called NZ. The list is dimensioned 50 although not all of the 50 locations are used. This list below gives the instructions that correspond to each location in the NZ array. The method of entering numbers into this array is unchanged from the procedures specified in WANL-TME-1906.

Table I lists fixed point control parameter definitions for each entry in the NZ array. As shown in the table, the first four entries in the NZ array refer to thermoelectric materials which must be specified for the inner and outer radial segments of both the $n$ and p-legs of the thermoelectric couples. A schematic of a "unit couple" is shown in Figure 1. This option allows performance calculations for modules incorporating radially segmented thermoelectric washers. By specifying the same thermoelectric material to the inner and outer segment of either leg, results will correspond to modules in which no radial segmenting has been incorporated.

As discussed above, property tables for six types of thermoelectric materials have been built into the code. By specifying an input control constant ranging from one to six, the material property tables for any of the six types of thermoelectric materials can be used in either radial segment of either leg.

All entries designated by an asterisk in Table 1 refer to parameters which are zeroed at the beginning of each calculational case to avoid potentially expensive (in terms of computer time) errors. If non-zero entries are desired in change cases for any of these parameters, the values must be reset in each change case. All other entries in the NZ array will maintain their previous values for all change case, unless changed by entering new values in subsequent cases. 


\section{TABLE 1}

\section{TEMOD INPUT FIXED POINT CONTROL PARAMETER DEFINITIONS}

$N Z=\mathrm{J}:$

$N Z(2)=J:$

$N Z(3)=J:$

$N Z(4)=\mathrm{J}:$

$N Z(5)=$ IRITE:
The integer $J$ specifies the material properties to be used for the inner n-leg thermoelectric washer segment (See Figure 1). The code numbers corresponding to each type of thermoelectric material whose properties are built into the code are as follows:

$J=1$; TEGS-3N material.

$J=2$; TEGS-2N material.

$J=3$; TEGS-3P material.

$\mathrm{J}=4$; TEGS-2P material.

$\mathrm{J}=5$; Ternary $n$-type material.

$J=6$; Ternary p-type material.

The integer $\mathrm{J}$ specifies the materials properties to be used for the outer $n-\operatorname{leg} T / E$ washer segment ( $J$ defined as for $N Z(l)$ above).

The integer $J$ specifies the materials properties to be used for the inner $p-\operatorname{leg} T / E$ washer segment ( $J$ defined as above). The intejer $J$ specifies the materials properties to be used for the outer $p-\operatorname{leg} T / E$ washer segment of the $P-\operatorname{leg}(J$ defined as above).

Output control parameter. Standard output format used except if:

IRITE $=1 ; N Z$ and $Z$ array output suppressed.

IRITE $=2$; Radial temperature profile and temperature drop which are standard output for non-parametric calculations, are suppressed. 
TABLE 1 (Continued)

IRITE $=3 ; N Z$ and $Z$ array; Radial temperature output suppressed.

IRITE $=4$; Output restricted to one page of input temperatures and calculated parameters per case.

$N Z(6)=N C L D H:$

$N Z(7)=N C L D C:$

$N Z(8)=$ KFTEMP:

$N Z(9)=1 Z 9:$

$N Z(10) \quad=N C:$

$N Z(11)=N G T 1:$
Parameter specifying inner clad material.

NCLDH $=1$; Stainless Steel 316 properties used.

$\mathrm{NCLDH}=2$ or 0 ; Inconel 718 properties used.

$\mathrm{NCLDH}=3 ; \mathrm{Ta}-10 \mathrm{~W}$ properties used.

Parameter specifying outer clad material.

NCLDC $=1$ or 0 ; Stainless Steel 316 properties used.

NCLDC $=2 ;$ Inconel 718 properties used.

Parameter used to specify input and output temperature units.

KFTEMP $=0$; Temperatures specified and listed in $\mathrm{OK}$.

KFTEMP $\neq 0$; Temperatures specified and listed in ${ }^{\circ} \mathrm{F}$.

Dimension input control parameter.

$1 Z 9=0$; Module outer radius to be specified in $Z(9)$ - See Table 2.

IZ9 $\neq 0$; Radial thickness of outer $\mathrm{T} / \mathrm{E}$ washer segment $\left(r_{6}-r_{5^{\prime}}\right.$ in Figure 1) to be specified in $Z(9)$ - See Table 2. Number of axial sections (complete unit couples as shown in Figure 1 ) in the module ( 300 maximum). NC $=1$ for all parametric studies in which module performance is based on resul ts of a unit couple operating at average clad temperature conditions.

Parameter specifying type of calculations to be done.

NGT1 = 0 ; Open circuit and matched load calculations for a module in which all axial sections (see $N Z(10)$, above) are connected in electrical series and thermal parallel. 


\section{TABLE 1 (Continued)}

NGT1 = 1; Open circuit calculations only for a module in which all axial sections (see $N Z(10)$, above) are connected in electrical series and thermal parallel.

NGT1 = 2; Matched or fixed load calculations only for a module in which all axial sections (see $N Z(10)$, above) are connected in electrical series and thermal parallel.

NGT1 = 3; Open circuit calculations made for each individual couple (axial section) with no electrical or thermal connections between couples.

NGT1 = 4; Matched load or fixed load (see $Z$ (19) below) calculations made for each individual couple (axial section) with no electrical connections between couples.

NGT1 = 5; Matched or fixed load (see $Z(19)$ below) and open circuit calculations made for each individual couple as in NGTl = 3 and NGTl = 4 above.

NGT1 = 6; Optimum load calculations (for maximum efficiency) made for each individual couple (axial section) with no electrical or thermal connections between couples. NGTI = 7, Optimum load and matched load calculations made for each individual couple as in NGTI $=6$ and NGT1 = 4 above.

$N Z(12)=$ PCMULT: Number of couples in the module for which individual couple calculations have been specified $(N Z(11) \geq 3$, above). Module performance is determined by multiplying appropriate parameters calculated for individual couples by PCMULT. 


\section{TABLE 1 (Continued)}

Results are strictly valid only for modules operating with uniform hot and cold clad temperatures.

$\mathrm{NZ}(13)=\mathrm{INT}:$

Method by which hot and cold clad temperatures are to be read as input.

INT $=0$; Input hot and cold clad temperature pairs for each of the NC axial sections (see $N Z(10)$ above).

INT $=1$; Axial hot and cold clad temperature profiles specified in previous case are used (for use in parametric studies).

INT $>$ 1; Input INT hot and cold clad thermocouple readings and interpolation will be performed based on axial locations (see $N Z(14)$ ) to determine hot and cold clad temperatures at the midpoints of each of the axial sections. This option can be used only if $N Z(11)<3$.

$\mathrm{NZ}(14)=$ INTTC:

Parameter specifying method of reading axial locations of thermocouples (used only if $N Z(13)>1$ ).

INTTC $=0$ Input INT see $(N Z(13))$ hot and cold clad thermocouple readings. Individual thermocouples assumed to be uniformly spaced along circuit length of module with the first and last couples located at either end of the circuit. INTTC $\neq 0$ Input an axial distance corresponding to each thermocouple pair. Axial distances to be entered as specified in Section E below.

$\mathrm{NZ}(15) \quad=\mathrm{ICRH}: \quad$ Parameter specifying inner conductor ring material. ICRH $=1$ Iron properties used.

$I C R H=2$; Tungsten properties used.

ICRH $\neq 1$ and $\neq 2$ : Molybdenum properties used. 


\section{TABLE I (Continued)}

$N Z(33) \quad=$ IPUN:

Parameter specifying punched output in perturbation calculations.

IPUN = 0; No punched output.

IPUN $=1$; A card of output parameters punched for each calculational case. Parameters listed are: Inner and outer diameters, average inner and outer clad temperatures, circuit length, load voltage, internal resistance, overall efficiency and power output in a 1X, 2F7.3, 2F7.1, 5E10.3 format.

NZ(34) $\quad=$ IPDWT:

Parameter specifying power density or weight calculation output in perturbation routine calculations.

IPDWT $=0$; Power density (watt/cc) calculations printed.

IPDWT $\neq 0$; Weight calculations printed.

$N Z(35) \quad=$ ITHQ: $\quad$ Parameter specifying operating conditions for life test calculations (See Section IV).

$I T H Q=0$ or 1 ; Fixed inner (hot) clad temperature.

$I T H Q=2$; Fixed or decaying heat input.

$N Z(36) \quad=$ ITCR: $\quad$ Parameter specifying heat rejection conditions for life test calculations (See Section IV).

$I T C R=0$ or 1; Fixed outer (cold) clad temperature.

$I T C R=2$; Fixed radiator. 


\section{TABLE I (Continued)}

$N Z(16)=I C R C$

$N Z(17)$

$N Z(18)=$ IPIN:

$N Z(19), N Z(20), N Z(21)$

$\mathrm{NZ}(22)^{*} \quad=$ NODUMP:
Parameter specifying outer conductor ring material.

ICRC $=1$ Iron properties used.

$I C R C=2$; Tungsten properties used.

ICRC $\neq 1$ and $\neq 2$; Molybdenum properties used.

Not used.

Parameter specifying material used for power lead pins (pins extending through retainer rings at each end of module, to which load circuit is connected).

IPIN = 1; Iron properties used.

IPIN = 2; Tungsten properties used.

IPIN = 3; Molybdenum properties used.

IPIN = 4 or $0 ;$ Nickel properties used.

Not used.

Control parameter used to request intermediate calculated parameters as output.

NODUMP $=0$; No intermediate information printed out. NODUMP $=1$; A page of intermediate parameters (interface resistances, Joule heat, etc.) printed out after each pass through subroutine couple.

NODUMP $=2$; Intermediate parameters are printed out after the final pass through subroutine couple for each axial section.

$\mathrm{NZ}(23) \quad=$ MAXIND: If module current closure is not obtained after MAXIND iterations, calculation will be terminated. If zero is entered, MAXIND is set equal to 10 . 


\section{TABLE 1 (Continued)}

\begin{tabular}{|c|c|c|}
\hline$N Z(24)$ & $=$ MAXTEM: & $\begin{array}{l}\text { If the criterion for temperature closure is not met for any } \\
\text { couple after MAXTEM iterations, calculations will be } \\
\text { terminated for this case and a dump of selected parameters } \\
\text { will be given. If zero is entered, MAXTEM is set equal to } 10 .\end{array}$ \\
\hline$N Z(25)$ * & $=$ NPUMP: & $\begin{array}{l}\text { Parameter used to specify pump module parametric calculations } \\
\text { (See section IV). }\end{array}$ \\
\hline$N Z(26)^{*}$ & $=$ NPERT: & $\begin{array}{l}\text { Increment on number of couples to be used in parametric } \\
\text { calculations (See Section IV). }\end{array}$ \\
\hline$N Z(27)$ & $=\mathrm{NR} 5 \varnothing \mathrm{PT}$ & $\begin{array}{l}\text { Parameter used to allow direct calculation of optimum } T / E \\
\text { washer segmenting radius }\left(\mathrm{r}_{5} \text { in Figure } 1\right) \text { in parametric } \\
\text { calculations. }\end{array}$ \\
\hline$N Z(28)$ & $N Z(29), N Z(30)$ & Not used. \\
\hline$N Z(31)^{*}$ & $=$ NOPTIM & $\begin{array}{l}\text { Parameter used to specify temperature, load resistance, or } \\
\text { geometry parametric calculations. (See Section IV). } \\
\text { NOPTIM }=0 \text { Perturbation subroutine (OPTIM) not entered. } \\
\text { NOPTIM }=1 \text { Standard value for perturbation calculations. } \\
\text { One line of output listed for each set of temperatures, load } \\
\text { resistance and dimensions. } \\
\text { NOPTIM }=2 \text { Used for T/E washer segmenting radius } \\
\text { perturbations. Output listed only for optimum valve of } r_{5}{ }^{\circ} \\
\text { NOPTIM }=3 \text { Temperature derivative option (See Section IV). }\end{array}$ \\
\hline$N Z(32)$ & $=$ DRINCR & $\begin{array}{l}\text { Parameter specifying T/E washer segmenting radius pertur- } \\
\text { bations. DRINCR corresponds to the increment to be applied } \\
\text { to the inner segment thickness (in percent of the total } \\
\text { specified } T / E \text { washer thickness). }\end{array}$ \\
\hline
\end{tabular}




\section{FLOATING POINT INPUT PARAMETERS}

All floating point input, except for axial temperatures, are read into a list labeled $Z$. Table 2 lists the parameter to be read into each location and the method of entering data into this array is given in the section entitled DATA CARDS. The radii $\left(r^{\prime} s\right)$ and axial dimensions referred to in the table are shown in Figure 1.

All dimensions are in inches, resistances are in ohms and temperatures are in ${ }^{\circ} \mathrm{K}$ or ${ }^{\circ} \mathrm{F}$ depending on the value entered in $\mathrm{NZ}(8)$. Any exceptions are specified in Table 2.

All entries designated by an asterisk in Table 2 refer to parameters which are zeroed at the beginning of each calculational case to avoid potentially expensive (in terms of computer time) errors. If non-zero entries are desired in change cases for any of these parameters, the values must be reset in each change case. All other entries in the $Z$ array will maintain their previous values for all change case, unless changed by entering new values in subsequent cases. 
TABLE 2

\section{TEMOD INPUT FLOATING POINT CONTROL PARAMETER DEFINITIONS}

$$
\begin{aligned}
& z(1)=R(1) \\
& Z(2)=D R(1) \\
& Z(3)=D R(2) \\
& Z(4)=D R(3) \\
& Z(5)=D R(4) \\
& Z(6)=D R(6) \\
& Z(7)=D R(7) \\
& Z(8)=D R(8) \\
& Z(9)\left\{\begin{array}{l}
=R(9) \\
=D R(5)
\end{array}\right. \\
& Z(10)=Z L I \\
& Z(11)=Z \mathrm{LN} \\
& Z(12)=Z L P
\end{aligned}
$$$$
Z(13)=H H
$$$$
Z(14)=H C
$$$$
Z(15)=\text { TOLTEM: }
$$

Inside radius $\left(r_{1}\right)$ - inches.

Radial thickness of inner clad $\left(r_{2}-r_{1}\right)$. See also $Z(24)$.

Radial thickness of inner insulating sleeve $\left(r_{3}-r_{2}\right)$.

Radial thickness of inner conductor ring $\left(r_{4}-r_{3}\right)$.

Radial thickness of inner T/E segment $\left(r_{5}-r_{4}\right)$.

Radial thickness of outer conductor ring $\left(r_{7}-r_{6}\right)$.

Radial thickness of outer insulating sleeve $\left(r_{8}-r_{7}\right)$.

Radial thickness of outer clad $\left(r_{9}-r_{8}\right)$. See also $Z(25)$.

Outside radius $r_{q}$ if $N Z(9)=0$.

Radial thickness of outer T/E segment, $\left(r_{6}-r_{5}\right)$, if $N Z(9) \neq 0$.

Axial length of insulating rings.

Axial length of $n-l e g, T / E$ washer.

Axial length of $p-\operatorname{leg} T / E$ washer. If zero is entered in this location, the axial length of the p-leg is calculated to optimize efficiency. See also $z(29)$.

Thermal contact coefficients of hot insulating sleeves interfaces (Typically zero).

Thermal contact coefficients of cold insulating sleeves interfaces (Typically zero).

Tolerance to which temperatures must agree from one temperature iteration to the next to meet convergence requirement (TOLTEM $=.001$ if zero is entered) - See 
TABLE 2 (Continued)

Equation 41 of WANL-TME-1906.

$Z(16)=$ TOLCUR:

Tolerance to which current must agree from one current iteration to the next to meet convergence requirement. (TOLCUR $=.001$ if zero is entered) - See Equation 45 of WANL-TME-1906.

$Z(17)=$ TPIN:

Temperature at which electrical resistance of power lead pins $(Z(18))$ has been evaluated. $\operatorname{TPIN}=700^{\circ} \mathrm{K}\left(800^{\circ} \mathrm{F}\right)$ if $Z(18)=0$.

$Z(18)=$ RPIN:

Electrical resistance of power lead pins connecting $T / E$ circuit to external power leads.

$Z(19)^{*}=$ RLOAD: Load resistance. RLOAD = Internal generator resistance, i.e., matched load, if zero is entered and load calculations are specified.

$Z(20) \quad=$ RECONC:

Contact resistivity coefficient of cold iron connector interfaces (See $\mathrm{K}_{\text {INT }}$ in Equation 1 of WANL-TME-1906). Typically RECONC $=0$.

$Z(21)=R E C O N H: \quad$ Contact resistivity coefficient of hot iron connector interfaces (See $\mathrm{K}_{\text {INT }}$ in Equation 1 of WANL-TME-1906). Typically $\mathrm{RECONH}=0$.

$Z(22)=$ ZKEND: $\quad$ Overall conductance of both module end closures (watts $/{ }^{\circ} \mathrm{K}$ if $N Z(8)=0$; watts $/{ }^{\circ} \mathrm{F}$ if $\mathrm{NZ}(8) \neq 0$ ).

$Z(23) \quad=$ RRREF: Inner-to-outer clad radius ratio $\left(r_{9} / r_{1}\right)$ at which end closure conductance, ZKEND, is evaluated. RRREF is used to scale ZKEND in parametric analyses in which radial dimensions are varied. 


\section{TABLE 2 (Continued)}

$Z(24)=$ CID:

$Z(25)=C O D:$

$Z(26)=$ ZNPERT:

$Z(27)=Z N M I N:$

$Z(28)^{*}=$ QREQ:

$Z(29)=Z$ LNLP

$Z(30) \quad=$ PEREQ:

$Z(3 I)$ = VREQ:

$Z(32) \quad=$ ZLREQ:

$Z(33)=$ THINC:

$Z(34)=$ TCINC:
Ratio of inner clad thickness to module inner diameter. This parameter is used for parametric analyses in which the I. D. is being varied and is used to calculate $D R(1)$ for each case. $Z(2)$ must be set equal to zero.

Ratio of outer clad thickness at module outer diameter. This parameter is used for parametric analyses in which the module O.D. is being varied and is used to calculate $D R(8)$ for each case. $Z(8)$ must be set equal to zero.

Increment for the $n$-leg axial thickness, $Z \mathrm{LN}$, in parametric calculations (See Section IV).

Minimum n-leg axial thickness, $Z \mathrm{LN}$, in parametric calculations (See Section IV).

Required module heat input rate (watts) in parametric calculations in which total heat input is specified. Specified $Z L N / Z L P$ ratio, used only if $Z(12), Z L P$, is set equal to zero.

Specified power output for parametric calculations (See Section IV.

Specified module load voltage for parametric calculations. Specified total module length for parametric calculations. $(Z(32)=0$ if couple axial dimensions are specified). Increment for $\overline{\mathrm{T}}_{H}$ in temperature perturbation calculations. Increment for $\bar{T}_{C}$ in temperature perturbation calculations. 
TABLE 2 (Continued)

\begin{tabular}{|c|c|c|}
\hline$z(35)$ & $=$ THMAX: & Maximum $\bar{T}_{H}$ to be used in temperature perturbations. \\
\hline$z(36)$ & $=$ TCMAX: & Maximum $\overline{\mathrm{T}}_{C}$ to be used in temperature perturbations. \\
\hline$z(37)$ & $=$ DTMIN: & $\begin{array}{l}\text { Minimum radial temperature drop }\left(\bar{T}_{H}-\bar{T}_{C}\right) \text { for which } \\
\text { calculations are to be performed. }\end{array}$ \\
\hline$Z(38)$ & $=$ DRMIN: & $\begin{array}{l}\text { Minimum } T / E \text { washer radial thickness for which calculations } \\
\text { are to be performed. }\end{array}$ \\
\hline$z(39)$ & $=$ RIINC: & Increment for module inner radius. \\
\hline$z(40)$ & $=R \varnothing \mid N C:$ & $\begin{array}{l}\text { If } N Z(9)=0, R O I N C \text { is the perturbation increment } \\
\text { applied to the module outer radius, } r_{9^{*}} \\
\text { If } N Z(9) \neq 0, R O I N C \text { is the perturbation increment applied } \\
\text { to the outer } T / E \text { washer radial thickness, } \Delta R_{5} .\end{array}$ \\
\hline$Z(41)$ & $=$ RIMAX: & $\begin{array}{l}\text { Maximum module inner radius, } r_{1} \text {, for which calculations } \\
\text { are to be performed. }\end{array}$ \\
\hline$Z(42)$ & $=$ R9MAX: & $\begin{array}{l}\text { If } N Z(9)=0, R 9 M A X \text { is the maximum module outer radius, } \\
r_{9} \text { for which calculations are to be performed. } \\
\text { If } N Z(9) \neq 0, R 9 M A X \text { is the maximum outer } T / E \text { washer } \\
\text { radial thickness, } \triangle R_{5} \text {, for which calculations are to be per- } \\
\text { formed. }\end{array}$ \\
\hline$z(43)$ & $=$ PWRDEN: & $\begin{array}{l}\text { Fuel specific power density (watts/cc). Fuel is assumed to } \\
\text { fill volume enclosed by the I.D. of the module inner clad. } \\
\bar{T}_{H} \text { will be calculated for cases in which PWRDEN }>0 \text {. }\end{array}$ \\
\hline$Z(44)^{*}$ & $=$ QINPC: & $\begin{array}{l}\text { Specified heat input rate (watts) for each couple. } \bar{T}_{H} \text { will } \\
\text { be calculated for cases in which QINPC }>0 \text {. }\end{array}$ \\
\hline
\end{tabular}




\section{TABLE 2 (Continued)}

\begin{tabular}{|c|c|c|}
\hline$z(45)$ & $=$ QGAM: & $\begin{array}{l}\text { Amount of gamma heat generated within the lead telluride } \\
\text { of each couple in an internally fueled gamma emitting isotope } \\
\text { configuration. This parameter must be determined by an } \\
\text { independent gamma heat shielding analysis. }\end{array}$ \\
\hline$z(46)$ & $=$ RLPERT: & $\begin{array}{l}\text { Increment for load resistance }(Z(19) \text { applied in perturbation } \\
\text { subroutine. No perturbation performed if RLPERT }=0 \text {. }\end{array}$ \\
\hline$Z(47)^{*}$ & $=$ RLMAX: & $\begin{array}{l}\text { Maximum load resistance for which calculations are to be } \\
\text { performed in load resistance perturbation subroutine. }\end{array}$ \\
\hline$z(48), z(49)$ & & Not used. \\
\hline$z(50)^{*}$ & $=Z L I B R H$ & $\begin{array}{l}\text { Axial thickness of the tungsten foil diffusion barriers incorpor- } \\
\text { ated in the insulating washers in annulus } D \text { of Figure } 1 \text {. }\end{array}$ \\
\hline$Z(51)^{*}$ & $=Z$ ZLBRC & $\begin{array}{l}\text { Axial thickness of the tungsten foil diffusion barriers incorpor- } \\
\text { ated in the insulating washers in annulus } E \text { of Figure } 1 \text {. }\end{array}$ \\
\hline$z(52), z(55)$ & & Not used. \\
\hline$z(56)$ & $=$ HRINC: & $\begin{array}{l}\text { Increment (hours) to be used in time increment calculations } \\
\text { (See Section IV). }\end{array}$ \\
\hline$z(57)$ & $=$ HRMAX: & Maximum time (hours) to be used in time increment calculations \\
\hline$z(58)$ & $=\mathrm{HFLF}:$ & Half life (years) of isotope fuel in time increment calculations. \\
\hline$z(59)$ & $=$ TREJ : & $\begin{array}{l}\text { Ambient heat rejection temperature to be used in time } \\
\text { increment calculations performed for fixed radiator configur- } \\
\text { ation (See Section IV). }\end{array}$ \\
\hline$z(60)$ & & Not used. \\
\hline
\end{tabular}




\section{TABLE 2 (Continued)}

$Z(61)=$ WTCON: Ratio of module end closure weight to cross sectional area of module (pounds per in ${ }^{2}$ ).

$z(62), z(70)$

Not used.

$Z(70+\mathrm{J}) * *$

Percent increase desired in Seebeck coefficient of $J$ th thermoelectric material where $J=1$ to $6($ See $N Z(1))$.

$z(80+J)^{* *}$

Percent increase desired in resistivity of the $J$ th thermoelectric material where $J=1$ to $6($ See $N Z(1))$.

$Z(90=\mathrm{J})^{\star *}$

Percent increase desired in thermal conductivity of the $\mathrm{Jth}$ thermoelectric material where $J=1$ to $6($ See $N Z(1))$.

** These entries refer to percent increase per 1000 hours in life test calculations to account for module degradation as a function of time as discussed in Section IV of this report. 


\section{E. DATA CARDS, ORDER AND FORMATS}

\section{Comment Card}

The first data card read into the program is a comment card. This comment should identify the case being run and will print out at the top of each page of output. The card is read using a 18A4 format so that the comment is restricted to a maximum of 72 spaces and should be centered in the 72 space field on the data card.

\section{Fixed Point Data for NZ Array}

Immediately after the comment card, fixed point data are read. A maximum of eleven (11) entries in the NZ (fixed point data)list may be made on one card. The format used in reading fixed point data is FORMAT $(312,11(3 X, 13))$.

The first two digit integer refers to the number of pieces of data given on the card. This must be a number form 0 to 11. Any entry other than zero in card columns $3-4$ indicates that no more fixed point data will follow the card being processed. The two digit integer in card columns $5-6$ indicates the NZ subscript of the first piece of data on the card being processed. The remaining input data centered on each card are entered sequentially into the NZ array.

\section{Floating Point Data for Z Array}

After processing a fixed point data card with an entry in card columns $3-4$, the floating point data are read. A maximum of six ( 6 ) entries in the $Z$ list (floating point data) may be made on one card. The format used to read this data is: FORMAT $(312,6 F 12.6)$. The first two digit integer refers to the number of pieces of data given on the card. This must be a number from 0 to 6 . Any entry other than zero in card columns 3 - 4 indicates that no more floating point data is to be entered into the $Z$ list after the present card is processed. The two digit integer in card columns $5-6$ indicates the $Z$ subscript of the first piece of data on the card being processed. The remaining data on the card are entered sequentially into the $Z$ array. 


\section{Temperature Data}

The method used to input clad temperature data is determined by the control variable entered in NZ(13)。All temperatures must be entered in Kelvin units. Three options are available for specifying temperature data.

a. $N Z(13)=0$. If $N Z(13)$ has been set equal to $Q$, hot and cold clad temperature pairs for each axial section must appear immediately after the first floating point data card with a non-zero entry in card columns $3-4$. The number of temperature pairs to be read is the number previously entered in $N Z(10)$.

Six temperatures pairs are read per card using a $12 \mathrm{~F} 6.5$ Format. The first temperature of each pair must be the hot clad temperature. In the event that a zero is encountered in any of this temperature input data, an error message is printed and all calculations for the case are suppressed. Hence it is possible to make an input error for one case without affecting the following cases.

b. $N Z(13)=1$. In the event that the effects of geometry variations are being investigated (as in parametric studies), it is often desired to run many cases using the same clad temperatures. If the number entered in NZ(13) is 1, no further data cards are read after the final card entering data in the $Z$ array. The code uses the temperature data entered in the previous case.

c. $N Z(13)>1$. This option is used to calculate the performance of a module for which experimental clad temperature measurements have been made at various locations along each clad. If $N Z(13)$ has been assigned greater than 1, the computer will interpolate on input hot and cold clad thermocouple readings to determine the hot and cold clad temperatures of each axial section. The number entered in NZ(13) corresponds to the number of hot and cold clad thermocouple pairs (not to be confused with the number of thermoelectric couples in the module) to be read. 
In order to perform the interpolation, of course, it is necessary to specify the axial location of each of the thermocouples. These locations are specified as the distance (in inches) from the leading edge of the first axial section of the module.

Since standard thermocouple instrumentation is used for most modules tested in the Compact Thermoelectric Converter program, the axial locations of these standard thermocouples are built into the code. By assigning $N Z(14)=0$, the thermocouples are assumed to be uniformly spaced along the circuit length of the module with the first and last couples located at either end of the circuit. In this case, the first card (or set of cards) after the $Z$ array data cards must contain the hot clad temperature data. The next card (or set of cards) must contain the cold clad temperature data. All of these cards use a 12F6.5 Format. To specify externally the thermocouple locations, the number of thermocouple pairs must be the number entered in NZ (13). If $N Z(14)$ has been assigned any value other than zero (and if $N Z(13)$ has been assigned a number greater than 1) the computer will begin to read axial locations for each thermocouple pair immediately after reading the last floating point data card.

After reading the thermocouple locations, the computer will read INT (the number entered in $N Z(13)$ ) hot clad thermocouple temperatures and the INT cold clad temperatures. Each of the three lists begins on a new data card and each card uses a 12F6.5 Format.

A zero entry in either the hot or cold clad thermocouple data is used to indicate the absence of a thermocouple reading at a particular location. When performing the interpolation to determine the temperature at the mid-point of each axial section, all zero entries in the temperature lists are ignored. 


\section{Multiple Case Runs}

Multiple runs can be made using TEMOD by simply stacking sets of input data. After reading all the input data for a given case, the calculations are performed and the output listed. The computer returns to input to search for another comment card. If none exists, calculations are terminated.

With the exceptions noted in Sections $C$ and $D$ above, entries in the $Z$ array, NZ array and axial temperature profiles are not zeroed from one case to the next. Hence, it is normally not necessary to reread any data which has not changed from one case to the next. Only the parameters which are changed from the previous case need be read in.

Care must be taken, however, to include a comment card, at least one card with fixed point data and one with floating point data for each case. If, for example, no floating point parameters change from one case to the next, a dummy card with only an entry in card column 4 must be included in the data cards in place of the floating point data card. 


\section{PARAMETRIC CALCULATIONS}

A. GENERAL

The TEMOD code has been written to allow various type of parametric calculations to be performed. Incrementation of parameters (i.e. operating temperatures, load resistances and component geometries) is done automatically by the code eliminating the need for voluminous input data decks. In addition, the output for these types of calculations is restricted to one line per case. Provisions have been made to allow specifications of module operating parameters such as electrical power, voltage, and/or heat input to meet required module design operating conditions. These conditions are met internally using program logic to calculate the required number of thermoelectric couples and/or module circuit length.

In each case, the calculations are made on a unit couple (see Figure 1). Thus, in each parametric calculation case, the control parameter $N Z(10)$ should be set equal to 1 and one set of temperature pairs should be entered.

The control parameters, geometry and operating temperatures for the first case of each parametric calculation must be set in accordance with instructions given in Section III of this report. The pertinent control parameters which must also be set for each type of parametric calculation is discussed below.

\section{B. TEMPERATURE PARAMETRIC WITH SPECIFIED GEOMETRY}

This option is normally used to determined performance of a specific type of module operating over a wide range of average hot and cold clad temperatures. In addition to the control parameters required to specify the module component materials and dimensions, the following entries are required to perform this type of parametric:

1. Set $N Z(31)=1$.

2. Set $Z(31)=Z(32)=0$.

3. Set $Z(33)$ through $Z(36)$ equal to the appropriate values as listed in Table 2.

4. Set the initial temperature pair at the lowest hot and cold clad levels of interest in the parametric. 


\section{LOAD RESISTANCE PARAMETRIC WITH SPECIFIED MODULE}

This load is used to calculate load curve characteristics of a specific type of module at a specific set of operating temperatures. The results, of course, will show that the power output will approach zero as the load resistance approaches either limit (zero or infinity) and that maximum power occurs at the point where the load resistance very nearly equals the generator resistance, i.e. matched load. (For calculations performed at fixed hot and cold junction temperatures, maximum power would occur precisely at matched load. However since the module performance calculations are made at fixed clad temperatures and since the junction temperatures do vary as the load resistance varies, the maximum power point does not occur precisely at matched load. Since the deviation between matched load power and maximum power is extremely small, no distinction is made between the two and an option has been built into the code to allow a direct determination of the matched load performance eliminating the need for running a load parametric.)

The load parametric calculations will also indicate that the load resistance at which module efficiency is optimized (defined as "optimum load") is approximately 20 to 30 percent higher than the module internal resistance. An option has also been built into the code to allow a direct determination of optimum load performance without running a load parametric.

Load resistance parametrics may be specified over a narrow or a wide range of resistance values. A parametric with a step size and increment range resulting in more than 200 separate cases is considered a wide range parametric. In the wide range calculations, the increment size is increased by a factor of ten after every ten calculations. This allows the parametric to cover an extremely wide range of resistance with only ten calculations for each order of magnitude.

In addition to the control parameters and input data required to specify the module component materials and dimensions, the following entries are required to perform the two types of load resistance parametrics: 
1. Narrow range parametric:

a. Set $N Z(31)=1$

b. Set $Z(19)$ equal to the initial (lowest) load resistance level.

c. Set $Z(46)$ and $Z(47)$ equal to the appropriate values.

2. Wide range parametric: set all parameters as described in (1) above except $Z(46)=0$.

\section{TEMPERATURE PARAMETRIC WITH SPECIFIED VOLTAGE AND CIRCUIT LENGTH}

This option allows parametric calculations to be performed to determine optimum module dimension for applications in which a load voltage and total circuit length has been prescribed. For these calculations, the number of thermoelectric couples required to meet the voltage specification at either matched or optimum load conditions is determined internally for each set of operating temperatures.

In addition to the control parameters and input data required to specify the module component material and dimensions, the following entries are required to perform this type of parametric:

1. Set $N Z(11)=4$ or 6 (matched or optimum load calculations).

2. Set $N Z(31)=1$

3. Set $Z(12)=0$. to allow $p$-leg axial thickness to be optimized with respect to $n-l e g$ thickness for each set of operating temperatures.

4. Set $Z(19)=0$. (A specification of load resistance, length, and vol tage amounts to an overspecification of the module performance).

5. Set $Z(31)$ through $Z(36)$ equal to the appropriate values as listed in Table 2 .

\section{E. PARAMETRIC ON NUMBER OF COUPLES WITH SPECIFIED LOAD VOLTAGE}

\section{AND CIRCUIT LENGTH}

This type of parametric is very similar to $D$ above, except the load voltage specification is met in each case by setting the load resistance equal to the appropriate value. This, of course, is done internally for each case by the program. This option is intended for use in applications where operating temperatures have been established by 
system operating constraints, hence, temperature parametrics should not be attempted.

1. Set $N Z(12)=1$ (the minimum number of couples required to achieve the specified lead voltage is determined by program logic).

2. Set $N Z(26)=1$ (the normal desired increment on the number of couples).

3. Set $N Z(31)=1$.

4. Sef $Z(12)=0$. To allow p-leg axial thickness to be optimized with respect to $n$-leg thickness for each case.

5. Set $Z(27)$ equal to the minimum n-leg thickness to be considered (this corresponds to a specification of the maximum number of couples and determines when the parametric calculations will be terminated). $Z(27)=$ .020 inch if no value is input.

6. Set $Z(31)$ and $Z(32)$ equal to the appropriate values as specified in Table 2 .

7. Set $Z(33)$ through $Z(36)$ equal to zero.

F. PARAMETRIC ON N-LEG/P-LEG AXIAL THICKNESS RATIO WITH SPECIFIED CIRCUIT LENGTH

The code has been written to allow a direct determination of the optimum n-leg/ p-leg axial thickness ratio. This option, however, allows a determination of the effects of varying this ratio on module performance.

In addition to the control parameters and input data required to specify the module component materials and initial case dimensions, the following entries are required to perform this type of parametric:

1. Set $N Z(12)$ equal to the number of couples in the module.

2. Set $N Z(26)$ equal to the number of washer thickness perturbations required.

3. Set $N Z(31)=1$.

4. Set $Z(11)$ and $Z(12)$ equal to the initial $n$ - and $p$-leg washer axial thicknesses

5. Set $Z(25)$ equal to the length by which the $n$-leg washer thickness is to be increased and the $p$-leg washer thickness decreased in each perturbation. 


\section{G. PARAMETRIC ON NUMBER OF COUPLES WITH SPECIFIED LOAD VOLTAGE HEAT INPUT OR POWER OUTPUT}

In many module applications, system constraints govern the module vol tage and heat input or power output requirements. For a given set of operating temperatures, the optimum module meeting these requirements can be determined using a parametric routine built into the code. In this routine, the number of couples in the module is increased from the minimum number required to produce an open circuit vol tage greater than the required voltage to a maximum number which is determined primarily by fabrication limits (minimum thermoelectric washer thickness). The total thermoelectric circuit length is dictated, primarily, by the heat input or power output specification.

In addition to the control parameters and input data required to specify the module component materials and initial case dimensions, the following entries are required to perform this type of parametric:

1. Set $N Z(12)=1$ (the minimum number of couples required to achieve the specified load vol tage is determined by program logic).

2. Set $N Z(26)=1$ (the normal desired increment on the number of couples).

3. Set $N Z(31)=1$.

4. Set $Z(12)=0$ to allow $p$-leg axial thickness to be optimized with respect to $n$-leg thickness for each case.

5. $\left\{\begin{array}{l}\text { Set } Z(28) \text { equal to the desired module thermal power input, or } \\ \text { Set } Z(30) \text { equal to the required electrical power output. }\end{array}\right.$

6. Set $Z(31)$ equal to the desired load voltage.

7. Set $Z(32)$ through $Z(36)$ equal to zero.

H. PARAMETRIC TO DETERMINE OPTIMUM SEGMENTING RADIUS, $r_{5}$

For many applications, it is desirable to use radially segmented thermoelectric washers in either the $p$ - or n-legs of the module. Thermoelectric materials can be doped at different levels to provide maximum conversion efficiency in different operating temperature ranges. Using a material doped for optimum performance at high temperatures in the inner segment of each thermoelectric washer, and an alternate material composition 
providing optimum performance at lower temperatures in the outer segment of each thermoelectric washers can provide efficiency improvements. Given two types of $n$-type and/or two types of p-type material, then, there is an optimum radius at which the materials can be segmented. An option has been provided to allow a determination of this optimum segmenting radius.

Since the optimum segmenting radius is a function of the module operating temperatures, this parametric option may be used in conjunction with the temperature parametric option discussed in (B) above.

In addition to the control parameters and input data required to specify the module component materials and initial case dimensions, the following entries are required to perform this type of parametric:

1. Set $N Z(31)=0$.

2. Set $N Z(32)$ equal to the increment to be applied to the inner segment thickness in percent of the total specified $T / E$ washer thickness. Normally $N Z(32)=5$ provides adequate calculational resolution to determine the optimum segment radius.

3. Set $Z(5)=0$. This initializes the segmenting radius such that the radial thickness of the inner $T / E$ washer segment is zero.

4. Set $Z(28)$ through $Z(32)$ equal to zero.

5. Set $Z(33)$ through $Z(36)$ equal to the appropriate values listed in Table 2 to allow operating temperature perturbations.

6. Set the initial temperature pair at the lowest hot and cold clad levels of interest in the parametric.

With this deck setup, a line of output will be listed for each segmenting radius. The first case (or line of output) for each temperature pair will correspond to a zero thickness outer $\mathrm{T} / \mathrm{E}$ washer segment, i.e.

$$
\frac{100\left(r_{6}-r_{5}\right)}{r_{6}-r_{4}}=0 \text { pct. (See Figure 1). }
$$


or

$$
\frac{100\left(r_{5}-r_{4}\right)}{r_{6}-r_{4}}=100 \text { pet. }
$$

The final case for each temperature pair will correspond to a zero thickness inner $T / E$ washer segment.

$$
\frac{100\left(r_{6}-r_{5}\right)}{r_{6}-r_{4}}=100 \text { pct. }
$$

or

$$
\frac{100\left(r_{5}-r_{4}\right)}{r_{6}-r_{4}}=0 \text { pct. }
$$

Since normally interest is restricted to the optimum segmenting radius only, an alternate form of this parametric can be used to reduce both the amount of output and the required computer time to perform the parametric. This option is specified in a manner identical to that discussed above except $N Z(31)$ is set equal to 2 . With this option incrementing of the inner washer thickness is performed until a maximum efficiency has been obtained, a line of calculated parameters corresponding to this optimum geometry is printed, and the temperatures are then incremented and the procedures repeated.

\section{TEMPERATURE DERIVATIVE CALCULATIONS}

During the course of reduction and analysis of experimental data from modules being tested, it has been found necessary to eliminate performance variations resulting from minor temperature fluctuations. For each experimental data set, it is desirable to determine analytically what the performance parameters would have been if the module had been operated at the exact prescribed operating temperatures.

This determination can be made by determining the derivatives of the primary performance parameters (i.e. effective Seebeck coefficient, $\bar{\alpha}$, internal resistance, $\mathrm{Rg}$, and thermal impedance $\mathrm{TI}$ ) with respect to hot and cold clad temperatures. 
A routine has been provided in the code to allow this evaluation. Calculations are performed at $25^{\circ} \mathrm{F}$ increments on either side of the design hot $\overline{\mathrm{T}}_{\mathrm{H}^{\prime}}$ and cold $\overline{\mathrm{T}}_{\mathrm{C}^{\prime}}$ clad temperatures. The parameters

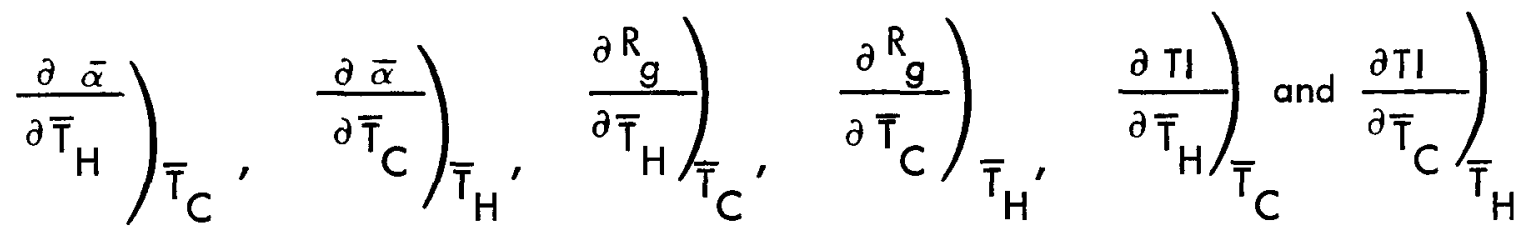

are computed and listed on the basis of these calculations. In these expressions, the effective Seebeck coefficient is defined:

$$
\bar{\alpha}=\frac{V_{o c}}{\bar{f}_{H}-\bar{T}_{C}}
$$

where $V_{o c}$ is the module open circuit voltage, and the thermal impedance is defined

$$
T I=\frac{\bar{T}_{H}-\bar{T}_{C}}{Q} \text {, }
$$

where $Q$ is the total module heat input.

In addition to the control parameters and input data required to specify the module component materials and initial case dimensions the following entries are required to perform this type of parametric:

1. Set $N Z(11)=4$. (The calculations are typically performed under matched load conditions except in the case of open circuit tests.)

2. Set $N Z(31)=3$.

3. Set $Z(28)$ through $Z(36)=0$.

4. Set the input temperatures at the design operating levels of the module.

\section{J. RADIAL GEOMETRY PARAMETRICS}

Quite often it is desired to perform any of the parametric options discussed above for a family of modules with varying overall radial geometries. For this reason an option is provided in the code to allow the radial geometry incrementation to be handled internally by the code. 
Provisions have been made to allow perturbation of the module inner radius and module outer radius or lead telluride radial thickness. Both of these geometry incrementing options may be used in conjunction with any of the parametric routines discussed previously.

\section{Inner Radius/Outer Radius Parameters}

In addition to the control parameters and input data required to specify the module component materials and initial case dimensions, along with the entries to perform any of the previously discussed parametric calculations, the following entries are required to perform the radial geometry parametrics:

a. Set $N Z(9)=0$ (See Table 1).

b. Set $Z(1)$ equal to the smallest inner radius of interest.

c. Set $Z(2)=0$. Inner clad thickness should be scaled linearly with module inner radius as specified by $Z(24)$.

d. Set $Z(8)=0$. Outer clad thickness should be scaled linearly with module outer radius as specified by $Z(25)$.

e. Set $Z(9)$ equal to smallest outer radius of interest.

f. Set $Z(23)$ through $Z(25)$ equal to the appropriate values as specified in Table 2.

g. Set $Z(38)$ equal to the minimum $T / E$ washer radial thickness for which calculations are to be performed. This is necessary since there may be $r_{1}, r_{9}$ combinations in the range of interest corresponding to negative or very small $\mathrm{T} / \mathrm{E}$ washer thicknesses. A substantial amount of computer time may be required to achieve temperature convergence on these cases of little or no interest.

h. Set $Z(39)$ through $Z(42)$ equal to the appropriate values as specified in Table 2.

i. Set $Z(61)$ equal to the appropriate value as specified in Table 2 . 
2. Inner Radius/Thermoelectric Washer Radial Thickness Parametrics

This option is very similar to (1) above except that the outer radius of the module is controlled by the specified T/E washer thickness. All parameters should be set as discussed in (1) above except the following:

a. Set $N Z(9)=1$ (See Table 1).

b. Set $Z(9)$ equal to the smallest $T / E$ washer radial thickness of interest.

c. $\operatorname{Set} Z(38)=0$.

d. Set $Z(42)$ equal to the maximum $T / E$ washer radial thickness of interest.

\section{K. $\quad$ PUMP MODULE PARAMETRIC STUDIES}

An option has been built into the TEMOD code to allow a determination optimum dimensions for tubular modules designed to provide electrical power for electromagnetic pumps. Since electromagnetic pumps require high current/low vol tage power, typical pump modules have extremely low internal resistances. For this reason, inner and outer conductor ring radial thicknesses are very critical and optimum thicknesses must be determined parametrically.

The parametric routine included in the code requires a specification of required current and load voltage along with operating temperatures. The radial thicknesses of the inner and outer conductors and thermoelectric washers are each varied independently. Axial dimensions for each case are calculated on the basis of meeting the required current and voltage specifications.

In addition to the control parameters and input data required to specify the module component materials and initial case dimensions, the following entries are made to perform this type of parametric:

1. Set $N Z(9)=0$. (See Table 1).

2. Set $N Z(25)$ equal to the desired number of perturbations to be performed on each conductor and $T / E$ washer radial thickness.

3. Set $Z(4), Z(5), Z(6)$ and $Z(9)$ equal to the appropriate minimum values of interest. 
4. Set $Z(8)=0$. Since module outer radius will vary in parametric, outer clad thickness should be scaled linearly with $r_{9}$ as specified by $Z(25)$.

5. Set $Z(12)=0$. Program logic will determine the axial thickness of the $T / E$ washers required to achieve voltage and current specifications for each case.

6. Set $Z(19)=0$. Although the input voltage and current specify a load resistance, this value is calculated internally.

7. Set $Z(23)$ and $Z(25)$ equal to the appropriate values as specified in Table 2 .

8. Set $Z(30)$ equal to the specified power output (the product of the specified current and voltage).

9. Set $Z(31)$ equal to the specified voltage.

10. Set $Z(40)$ equal to the radial increment to be applied to the conductor rings. The $T / E$ washer increment is half as large as the conductor ring increment.

11. Set $Z(61)$ equal to the appropriate value as specified in Table 2.

\section{CALCULATION OF PERFORMANCE AS A FUNCTION OF TIME}

During operation of thermoelectric generators various factors can produce performance variations as a function of time. Obviously, if the operating temperatures vary, the performance will be affected. These temperature variations can be caused by externally controlled modification or by a decay of the fuel in the case of an RTG application. In the latter case, the module cold clad temperature will vary as the amount of heat to be radiated is reduced.

In addition to operating condition variations, module performance is affected by a degradation process. The effects of this process can be simulated by modifying the thermoelectric material properties in the appropriate manner. In lead telluride generators these effects are simulated in increasing the resistivity of the n-type thermoelectric material to compensate for the diffusion of tellurium into the material. The rate at which the resistivity increases is a function of operating temperatures and washer axial thickness, and must be given as input to the calculations. Provisions are also included for modifying any of the other themoelectric properties in a similar manner. 
In addition to the control parameters and input data required to specify the module component materials and dimensions, the following entries are required to perform this type of calculation.

1. Set $N Z(35)$ equal to the appropriate value discussed in Table 1 to specify either constant $\overline{\mathrm{T}}_{H}$ or heat input conditions.

2. Set $N Z(36)$ equal to the appropriate value discussed in Table 1 to specify either constant $\overline{\mathrm{T}}_{\mathrm{C}}$ or fixed radiator calculations.

3. Set $Z(19)$ if fixed load resistance calculations are required $(Z(19)=0$ for matched load).

4. Set $Z(31)$ if fixed load voltage calculations are required.

5. Set $Z(56)$ equal to the desired time increment (in hours).

6. Set $Z(57)$ equal to the maximum time (hours).

7. Set $Z(58)$ equal to the isotope half life (in years) if heat decay calculations are desired.

8. Set $Z(59)$ equal to the heat sink temperature if fixed radiator calculations are desired.

9. Set $Z(71)$ through $Z(100)$ equal to the appropriate $T / E$ material property rate of change as specified in Table 2. Rates of change to specified as percent change per 1000 hours.

10. Set temperatures at the beginning-of-life levels. 
(w) Astronuclear Laboratory

V. TEMOD FORTRAN PROGRAM LISTING

PROGRAM TEMOD (INPUT, OUTPUT,PUNCH,TAPE $5=$ INPUT, TAPE GEOUTPUT, 1 TAPE 7:PUN(H)

C TEMOD................. CHARLES ROSE.

DIMENSTON NZ(50)

DIMENSTUN NZ(50), $2(100), X \operatorname{THERM}(30), \operatorname{THERMC}(30), \operatorname{THERMH}(30), H D(6,8)$

1 HO1 (8),HDZ (8),HD3 $(16,2), A S T A R I(2), Z O P M A X(5), Z O P T(5), Z O P T 1(5)$,

2 CKF 1 (2), CKF 2 (2), TMKF (2)

COMMON /TITLE/FETM(3), CASCAD $(8,2), \operatorname{SSIN}(3), \operatorname{CMT}(25), \operatorname{COND}(3,5), \mathrm{TEMKF}$,

1 CKMD $(2,2), I 3 N, I 2 N, I 3 P, I 2 P$

COMMON /MOLIF/HRS, HRINC, HRMAX, HFLF, RAOPCT, ITCR, ITHO

COMMON/TERIT/DTAV, DHM, DCV, RLDAD, QMDD, TCAV

COMMON /MDCPOP/RAD(9), DR (8), TEMP (9,300), VDC (300),RPC (300),PE(300),

1 OT (300), NOPTIM, VPC (300), RLPC (300), DTMOD (300), CUR (300), LNRAD (9),

2 LLP, ZLN, ZLI, ZLNLP, ZLPNI, ZLTE, NGTI, NGTZ, ITPERT, PCMULT, NODUMP, IVU,

3 OGEN, QGENL, OTE,OOUT,ZID, ZOD, ZKEND, ZK9,ZKR,RPPC,RPN, TDLTEM, TREJ,

4 VREO, PEREQ, ZLREQ, WTCON, ZLPN, IOUMZ, RN, DGRF, DGTRF, DGLRF, RADK, JDUMP,

$5 D P(30), N C$

COMMON /MODCPL/CURMOD (15), IT (300), DTTE, CONRN, CONRP, ZLIP, ZNC,

1 ALR64, MAXTEM,OGAM, CGAM, INDI,RINT 4,RINT6,RCON4,RCONG, CIFEH,CIFEC,

2 CUNST1, CONST2, CONST3, CONST4, CONST5, NRSOPT, SEGTE, ICRMDL, RADC

COMMON/TEFO/NCLDC, NCLDH, ICRH, ICRC, IPIN, ZLIBRH, ZL IBRC, TPIN, RPIN

COMMON /MODOPT/IPDWT, OR4, ORINCR, IRITE, ORTE, JOPTIM, IZ9, IENDK, IPUN,

1 RIINC, ROINC, RIMAX, R9MAX, DTMIN, DREO, THINC, TCINC, TCMAX, THMAX

2, NPERT, LNPERT, CKFP, CKF T, CTEOC, CTEIC, DEL 1L, RLPERT, RLMAX, ZNMIN, Z9SAV COMMON/TEPMP/NPUMP,DRO, CODZ

EOUIVALENCE (HO3(20), ASTARI (1))

DATA HD/4HINNE, 4HR CL, 4HAD .4H , 4H ,4H,

1 4HINNE, 4HR IN, 4HSULA, QHTING, 4H RIN, 4HG :

2 4HHOT, 4 SID, 4 HE CO, 4HNDUC, $4 H T U R$, ,HRING,

3 4H , 4HINNE, 4HR T/, 4HE WA, 4HSHER, 4HS ,

4 4H . 4 HOUTE, 4HR T/.4HE WA, QHSHER, 4HS ?

5 4HCOLD, 4H SID, 4HE CO, 4HNDUC, QHTOR, 4HRING,

6 4HOUTE, 4 HR IN, 4HSULA, 4HTING, 4H RIN, 4 HE

7 4MOUTE, 4HR CL, 4HAD IH I IH, IH /, TMKF/IHK, IHF/,KASE I/I/,

$8 H O L(2) / 2 H B N /, H D 1(7) / 2 H B N /, H D 2 / 3 * 1 H, 2 * 1 H=, 3 * 1 H /, H D 3 / 2 O \# 1 H, 1 H *$,

$96 * 1 \mathrm{H}, 2 * 1 \mathrm{H} *, 3 * 1 \mathrm{H} /, \mathrm{NZ} / 50 * 0 /, 2 / 100 * 0.1, \mathrm{CKF} 1 / 0, .459 .6 /, \mathrm{CKF} 2 / 1 ., 1.8 /$

REAL LNRAD

FK2K $(T)=(T+C K F P) / C K F T$

CID $=C L D C K(C M T(21), C M T(22), C M T(23))$

93 READ $(5,94)(C M T(K), K=3,20)$, ASTRP

94 FORMAT $(2 B A 4,7 X, A 1)$

$Z(19)=0$.

$Z(28)=0$.

$2(44)=0$. 


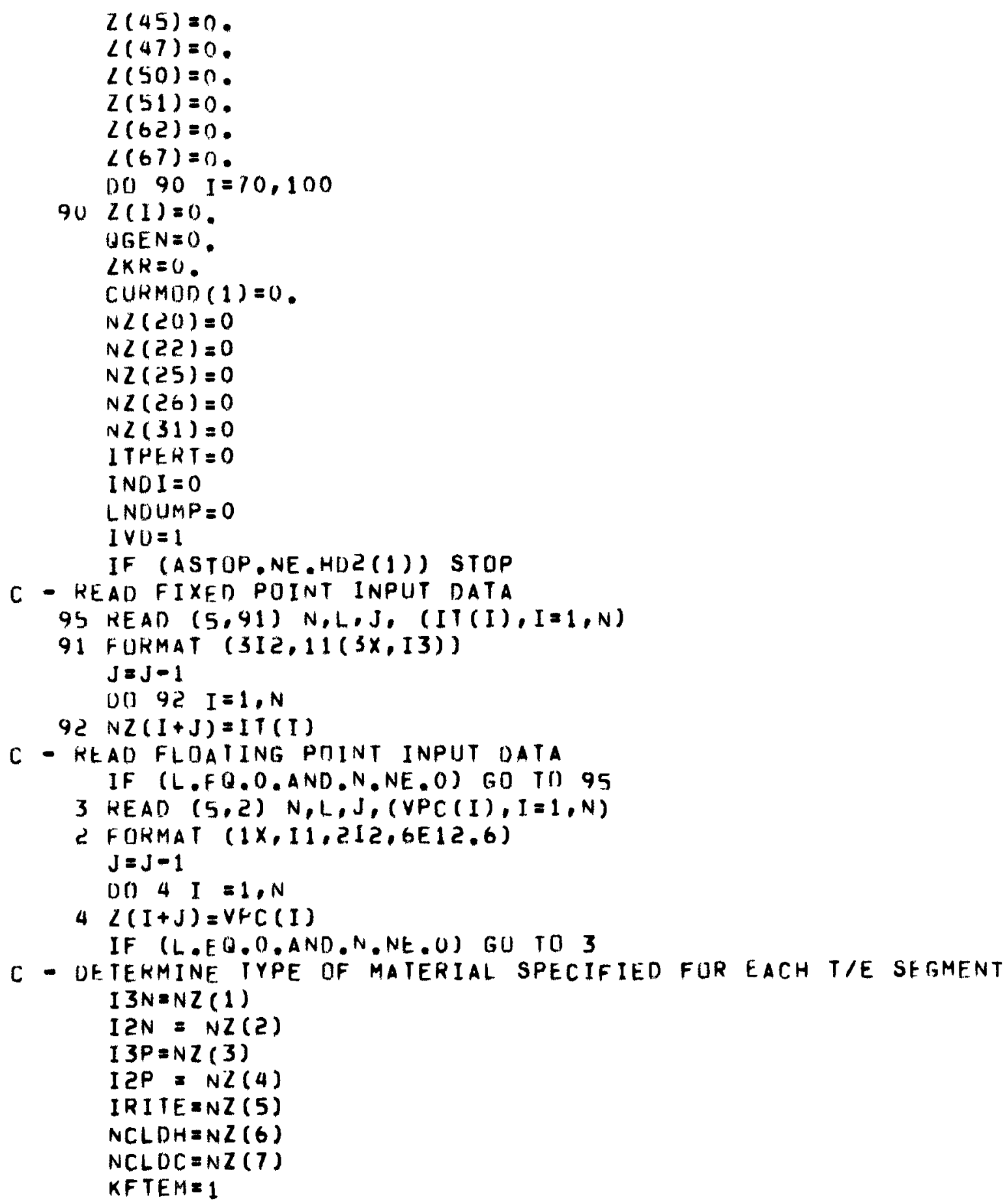




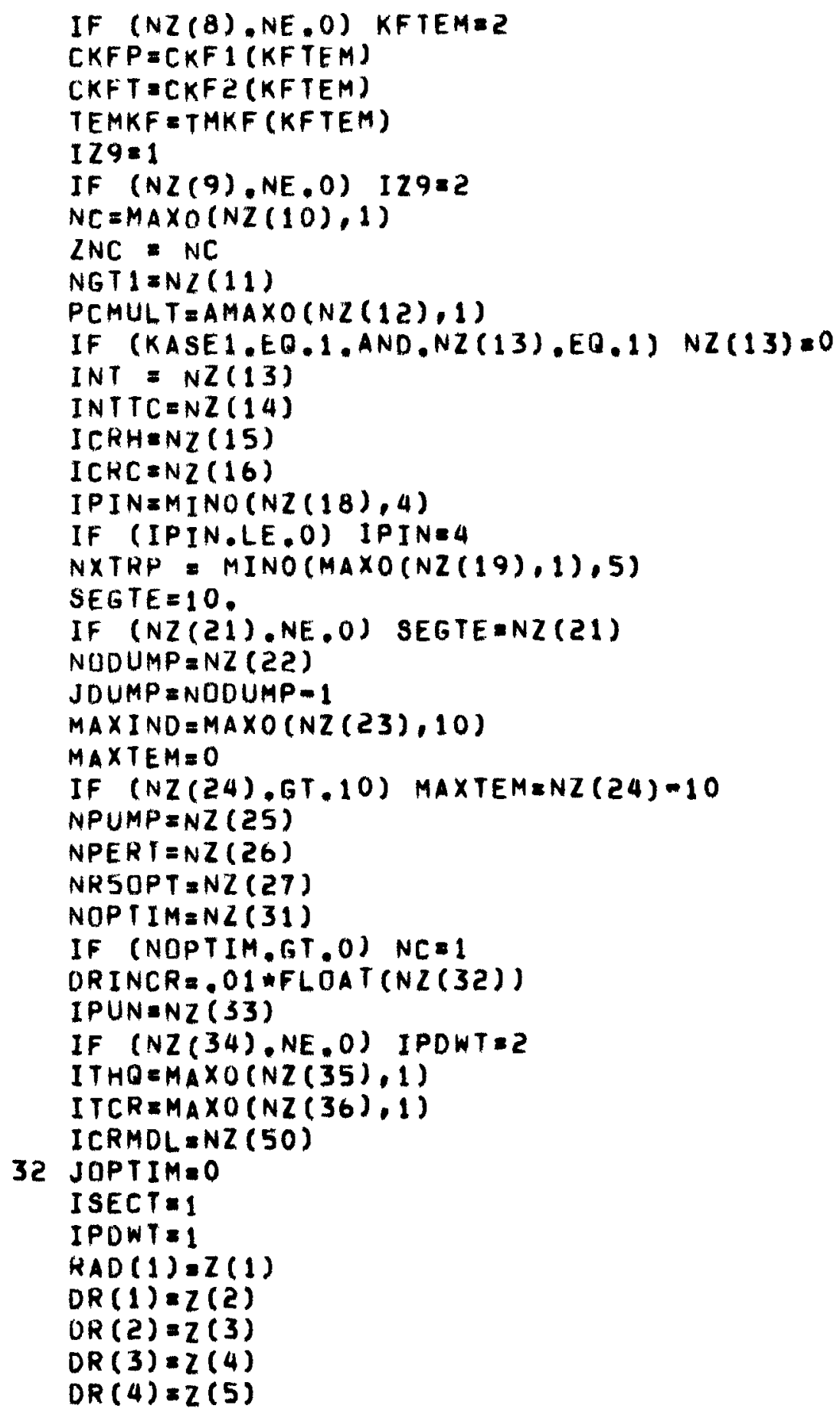




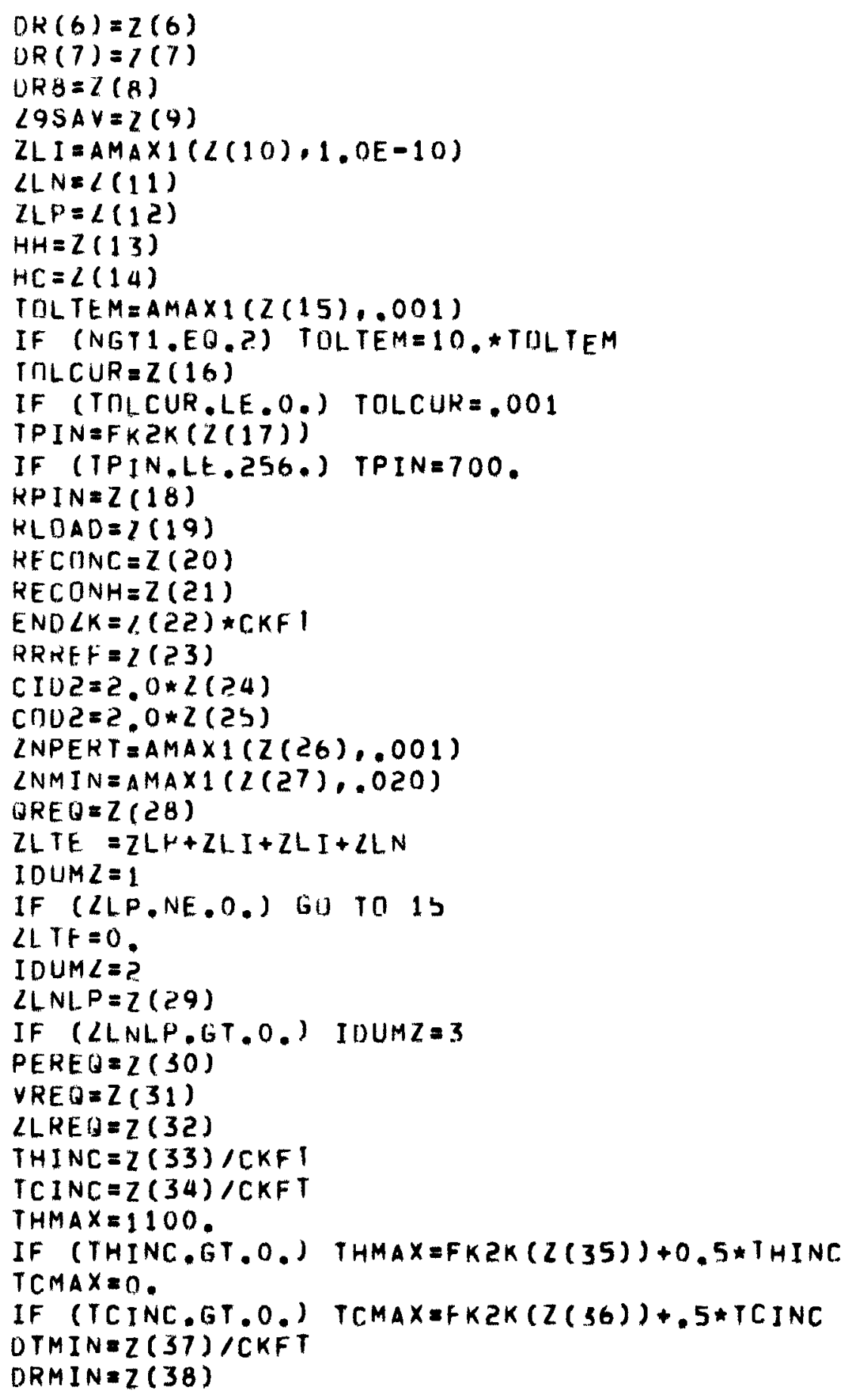




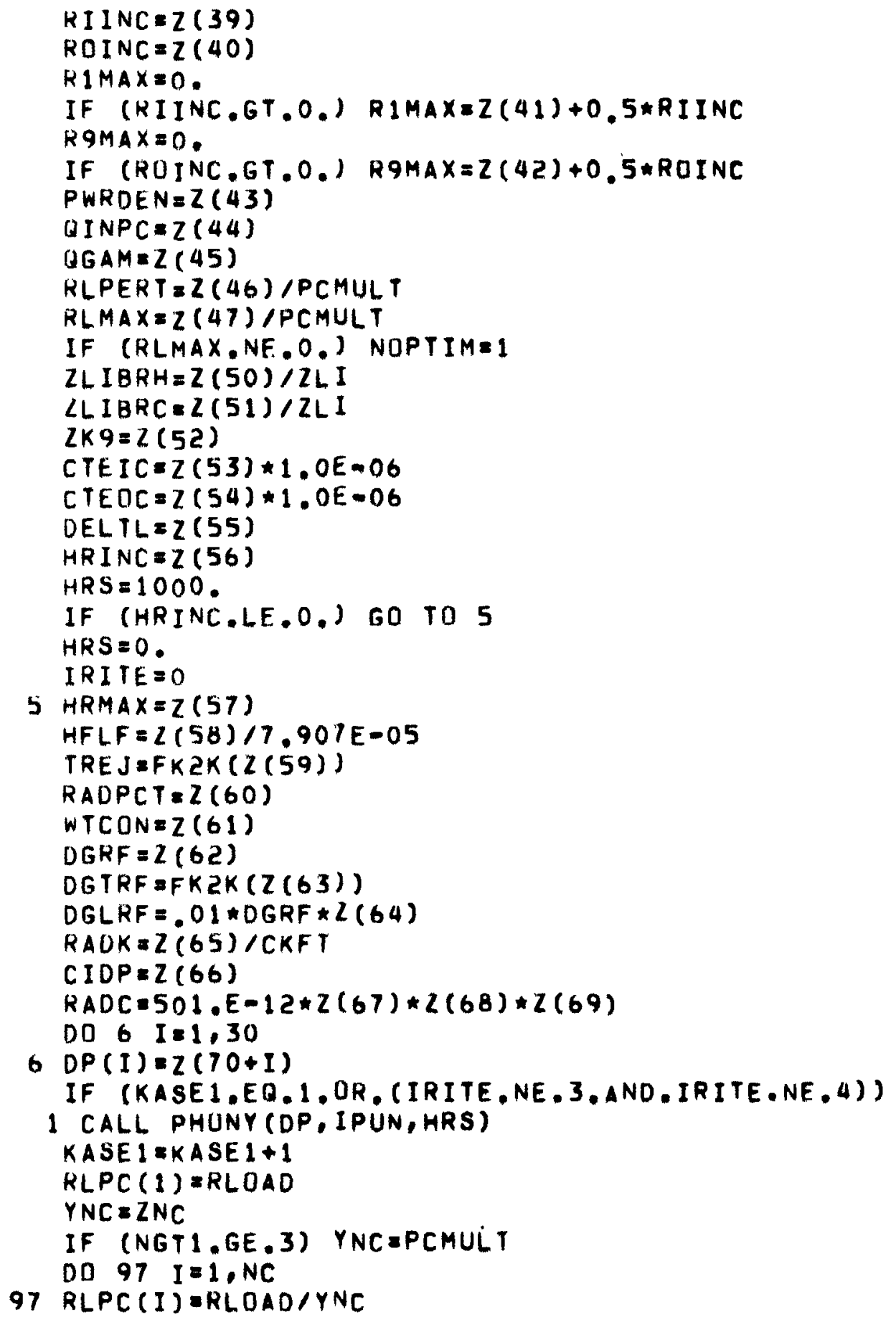




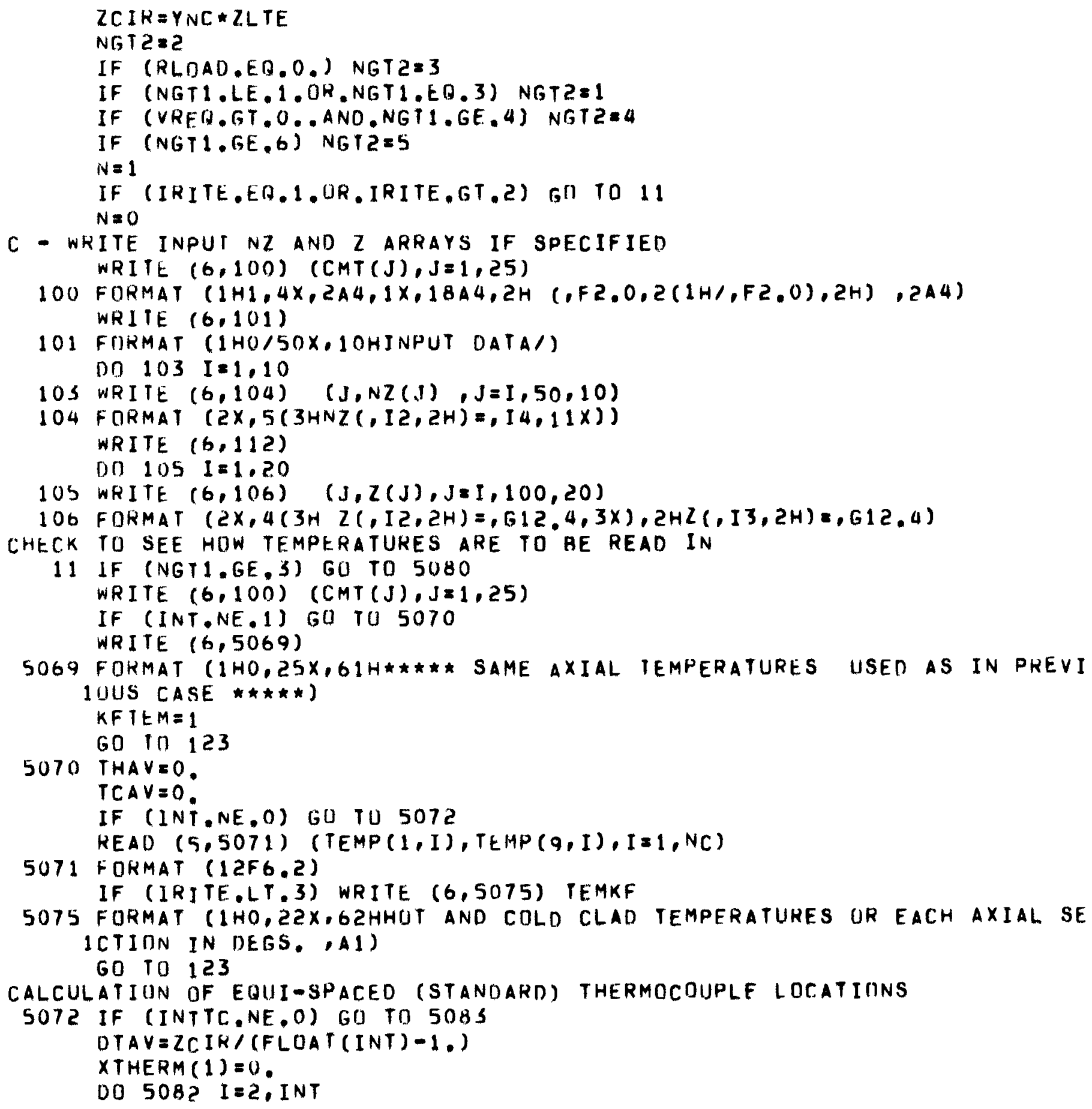


(W) Astronuclear

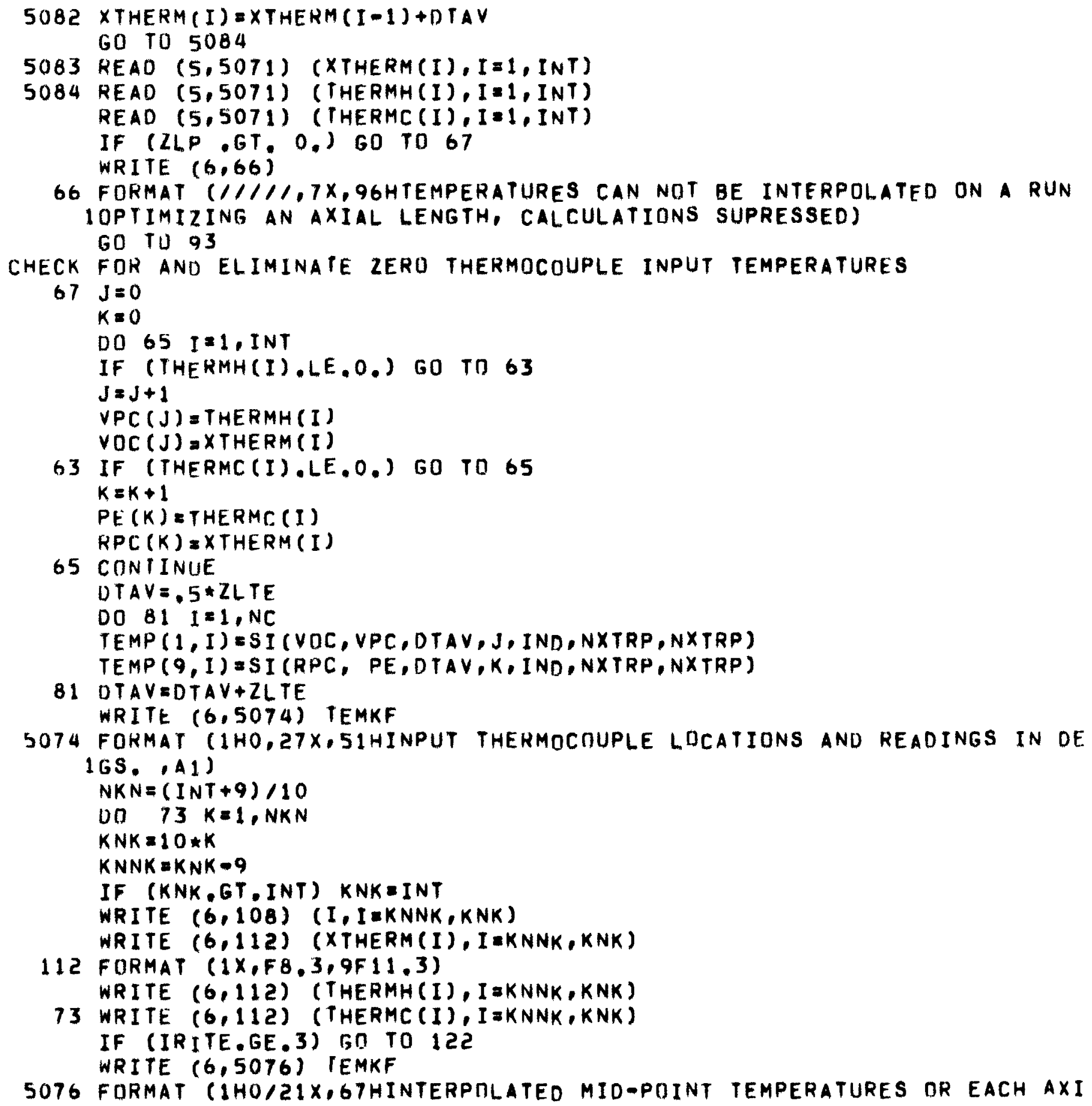


IAL SECTIUN IN DEGS. .A1)

$123 N K N=(N C+9) / 10$

DO $111 \mathrm{~K}=1, \mathrm{NKN}$

$K N K=10 * K$

$K N N K=K N K-9$

IF $(K N K, G T, N C) \quad K N K=N C$

WRITE $(6,108)$ (I,I $=K N N K, K N K)$

108 FURMAT $(1 H O, 3 \times, 10(13,8 X))$

WRITE $(6,112)$ (TEMP $(1, I), I=K N N K, K N K)$

111 WRITE $(6,112)$ (TEMP $(9,1), I=K N N K, K N K)$

122 IF (INT.EQ.1) GO TO 5073

DO $5077 \mathrm{I}=1, \mathrm{NC}$

$\operatorname{TEMP}(1,1)=F K 2 K(\operatorname{TEMP}(1,1))$

$\operatorname{TEMP}(9,1)=\operatorname{FK} 2 K(\operatorname{TEMP}(9,1))$

THAV $=T H A V+T E M P(1, I)$

SU7 I TCAV $=\operatorname{TCAV+TFMP(9,I)}$

THAV = THAV/LNC

$T C A V=T C A V / Z N C$

DTAV = THAV-TCAV

TMDDAV = TCAV+O,S\#DTAV

THAVF $=C K F Z(2) * T H A V-C K F I(2)$

$T C A V F=C K F 2(2) * T C A V-C K F 1(2)$

TMUDF $=[K K+2(5) \star T M U D A V-C K F 1(2)$

DT TAVF $=C K F Z(?) \star D T A V$

5073 WRITE $(6,5078)$ THAV, THAVF, TCAV, TCAVF, OTAV, DTAVF, TMODAV, TMDDF

5078 FORMAT (1HO/22X,3OHAVERAGE HOT CLAO TEMPERATURE =,F9.3, 9H DEG,K

$1($, F9,3,7H DEG,F)//21X,32HAVERAGE COLD CLAD TEMPERATURF $=, F 9.3$,

?. 9H DEG,K (,F9.3,7H DEG,F)//18X,34HAVERAGE RADIAL TEMPERATURE DR $3 U P=, F 9,3,9 H$ DEG.K (,F9,3,7H DEG.F)//24X,28HAVERAGE MODULE TEMPER

4ATURE $\equiv, F 9,3,9 H$ DEG,K (,F9,3,7H DEG,F))

GO TU 119

5080 IF (INT.EQ.1) GO TO 119

READ $(5,5071)(\operatorname{TEMP}(1, I), \operatorname{TEMP}(9,1), I=1, N C)$

IF $(N, F 0,0)$ WRITE $(6,62)$ TEMKF, (TFMP $(1,1), \operatorname{TEMP}(9, I), I=1, N C)$

62 FOKMAT (IHO/36H INPUT TEMPERATIIRF PAIRS (IN DEGS. .A1,1H)/

$1(6(2 X, F 7,2,1 H-, F 7,2,1 H))$,

IF (KFTEM.EQ.1) GO TU 119

DO $5081 \quad I=1, N C$

$\operatorname{TEMP}(1, I)=\operatorname{FK} 2 K(\operatorname{TEMP}(1, I))$

$50 B 1 \operatorname{TEMP}(9, I)=F K 2 K($ IEMP $(9, I))$

119 If (RLMAD.GE.0.) FO TO 118

READ $(5,5071) \quad(R L P C(1), I=1, N C)$

IF $(N, F, 0,0)$ WRITE $(6,117) \quad(R L P C(I), I=1, N C)$

111 FORMAT ( $74 \mathrm{H}$ INPUT LMAD RESISTANCE FOR EACH TEMPERATURE PAIR (IN MI 


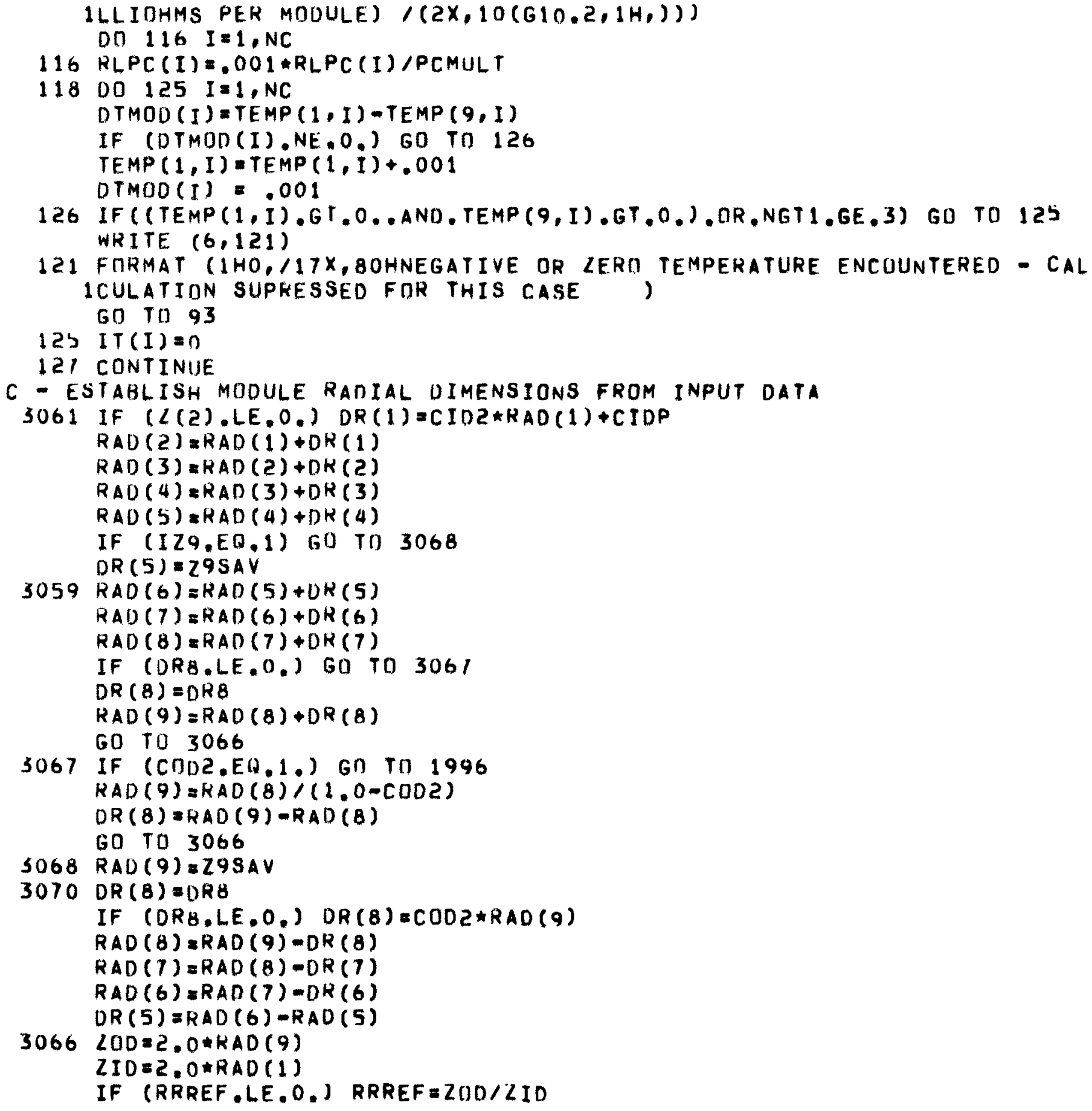


IENDK=I

IF (ENDZK.GT.O.) IENDK = 2

UGENL $=51.48 \star P W R D E N \star R A D(1) \star R A D(1)$

UGEN $=$ WGENL $\star Z L T E$

IF (IDUMZ,NE.1) QGEN=BGENL*Z,*(ZLN+ZLI)

IF (OINPC.GT.O,) QGENEOINPC

IF (IRITE.GT.3) GO TO 4004

C - WRITE RADIAL AND AXIAL DIMENSIONS IF SPECIFIED (NZ(5), EN. $0,1,2)$

WRITE $(6,100) \quad(C M T(J), J=1,25)$

$\operatorname{MDI}(1)=\operatorname{SSIN}(N C L D H)$

$H D 1(3)=F E T M(I C R H)$

HOI $(4)=\operatorname{CASCAD}(I S N, 2)$

$H D(1,4)=\operatorname{CASCAD}(I 3 P, 2)$

$H O 1(5)=C A S C A D(I 2 N, 2)$

$H D(1,5)=C A S C A D(12 P, 2)$

$H D 1(6)=F E T M(I C R C)$

HDI ( 8$)$ aSS IN (NCLDC)

WRITE $(6,2017)$

2017 FORMAT (1HO//,10X,17HRADIAL DIMENSIONS, 13X,18HRAOIAL THICKNESSES,

$17 X, 9 H C O M P \cap N E N T, /)$

$1=1$

IF (NOPIIM,NE,O.AND.DRINCR,GT,O.) I=2

DO $2019 \mathrm{~J}=1,8$

2019 WRITE $(6,2018) J, R A D(J), H D S(J, I), J, D R(J), H D 3(J+B, I), H D I(J), H D Z(J)$,

$1(H D(K, J), K=1,6)$

2018 FORMAT $(10 X, 4 H R A D(, I 1,3 H)=, F 10,6,5 H I N, . A 1 / 40 X, 3 H D R(, I 1,3 H)=$

$1 F 10,6,4 H I N, \ldots A 1,3 X, A 3, A 1,6 A 4)$

$J=9$

WRITE $(6,2018) \mathrm{J}$, RAD(J)

$\mathrm{J} 1=1$

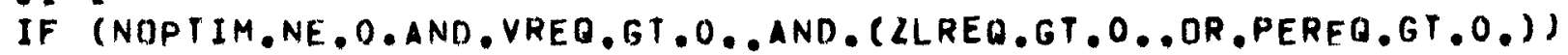

$1 \mathrm{~J} 1=2$

$J=(J 1+I D U M Z+1) / 2$

WRITE (6,2021) ZLN,ASTARI(J1),ZLP,ASTARI(J), ZLI,ZLTE,ASTAHI(J)

2021 FIIRMAT (1HO//46X,18HAXIAL DIMENSIONS ,///10X,8HZLN $\approx, F 9.5$,

$123 H$ IN. (N-TYPE WASHER),A2//10X,BHZLP $\because, F 9,5,23 H$ IN. (P-

2TYPE WASHER)AZ//10X,8HLLI $, F 9.5,24 H$ IN. (MICA THICKNESS)//

3 IOX,8HZLTE $=, F 9,5,32 \mathrm{H}$ IN, (TOTAL COUPLE THICKNESS),AR)

IF (J.EQ,1) WRITE $(6,2025)$ ZCIR,YNC

2023 FORMAT (IHO, 9X,BHZCIR $\$, F 9.5,30 \mathrm{H}$ IN. (TOTAL CIRCUIT LENGTH,.

1 F4.0.9H CUUPLES))

IF (J,EQ,2, OR,I,EQ,2) WRITE $(6,2022)$

2022 FORMAT ( 1 HO, 50X,51H* THIS DIMENSIMN OPTIMIZED OR CALCULATED INIERN (ALLY) 
(2) Astronuclear Laboratory

4004 DR4 $=0 R(4)$

$D R I E=R A D(6)-R A D(4)$

IF (URTE.LT.DRMIN.AND, (NOPTIM,GT.O,OR,NCLAD,GT.0)) GO TO 1996

3016 IF (RAD(1).LE.O..DR.ZLI.LE.0.) GO TO 1996

Dก $31 \mathrm{~J}=1,8$

$J 1 \approx J+1$

IF (RAD(J1).LE. O.) GO TO 1996

LNRAD (J) =ALDG (RAD(J1) /RAD(J))

31 IF $(\mathrm{J} / 2$.NE.2.AND.LNRAD(J),LE.0.) GD TD 1991

ISECT $=1$

GO $10 \quad 1999$

1991 CONTINUE

IF (NDPTIM,EQ.0.OR.ROINC.EQ.0.) GO TO 1996

I SEC $1=3$

GO IO 1999

1996 WRITE $(6,1992)$

1992 FIIRMAT ( 1 HO,21X,68HERRUR IN OIMENSIONS SPECIFIED - CALCULATIONS SU IPRESSED FOR THIS (ASE)

GO TU 93

$1999 Z K E N D=E N D Z K \star A L U G(R R R E F) / A L O G(Z D D / Z I D)$

IF (NOPTIM.EQ.0) GO TO 4002

CALL TPTIM(ISECT, J)

GU TO $(4002,4002,4002,3059,4002,3070,3061), \mathrm{J}$

CALCULATE ALL RECURRING PRODUCTS

4002 ALRG $=$ LNRAD (S) + LNRAD (4)

$C G A M=.5 / A L R 64-1 . /(\operatorname{EXP}(2, * A L R 64)-1$.

CONST1 $1=.062659 * A L R 64$

CONRN=CONST1/ZLN

RCON4 = RECONH/ $(40.5366 * Z L N * R A D(4))$

RCDNG $=$ KECDNC/ $(40,5366 * 2 L N \star R A D(6))$

CHECK FOR THERMAL CONTACT COEFFICIENTS EQUAL ZERO

CONST $3=0$.

CONST $4=0$.

IF (HH.NE.0.) CONST3 $=.3937 *(1.0 / R A D(2)+1.0 / R A D(3)) /(L N R A D(2) * H H)$

IF (HC.NE.0.) CUNST4 $=.3937 *(1.0 / R A D(7)+1.0 / R A D(B)) /(L N R A D(7) * H C)$

CHECK TO SEE IF P-LFG AXIAL LENGTH IS TO BE OPTIMIZED

IF (IDUML.GT.1) GO TO 78

CALCULATE RECURRING PRODUCTS IF PALEG IS NOT IO BE OPTIMIZED

$Z L P N=Z L_{L} P+Z L N$

$Z L P N I=Z L P N+Z L I$

$Z L T E=Z L P N I+Z L I$

$Z L N L P=Z L N / Z L P$

CONST $5=15.9593 * \angle L P$

$\angle L I P=2.0 * Z L I / Z L P$ 
CDNST $2=15.9593 * 2 L T E$

RTNT4 = RCONA ZLLN/ILP

$R I N T 6=R C U N G \star Z L P N / Z L P$

CONRP = CUNST $1 / Z L P$

IF (ICRMDL. NE. O) GO TO 4005

$C I F E H=15.9593 * D K(3) *(R A D(3)+R A N(4)) / Z L T E$

CIFEC $=15.9593 * D R(6) *(R A D(6) * R A \cap(7)) / 2 L T E$ GO TO 78

CALCULATE RADIUS DF CIRCULAR CONDUCTIR RING ELECTRICAL STREAMLINE

4005 KCHIIT $=A M I N I(D R(3), Z L N, \angle L P)$

$K C U L D=A M I N I(D R(6), Z L N, Z L P)$

CLFEH $=5.08 * R A D(4) * A L U G(3.14159 * R C H O T / Z L I+1.0)$

$C 1 F E C=5.08 * R A D(6) \star A L O G(3.14159 * R C \cap L D / Z L I+1.0)$

78 INDI $=I N O I+1$

C - ENTER SURRUUTINE COUPLE

CALL CNUPLE

IF (NUDUMP.EQ.5) 50 TO 93

C - ENTER SUGROUTINE LIFE, IF SPECIFIED

IF (HRINC,LE.O) 60 TO 3052

CALL LTFE (DAPERI)

IF (JMPIIM.LT.O) GO TO 93

GO 1078

3052 IF (NNPIIM.EQ.0) GO TO 3051

C - ENTEH SURRULITINE UPTIM FUR THOT, TCOLD, PCTZN PERTURBATION

CALL UPTIM $(2, J)$

$\operatorname{DTMUU}(1)=\operatorname{TEMP}(1,1)-\operatorname{TEMP}(9,1)$

GO TO $(93,4002,78,3059,78,3070,3061), \mathrm{J}$

3051 IF (NPIIMP.LF.O) IO TO 3053

CALL PIIMP(J)

GU TU $(4002,3061,93), J$

3053 IF (NUDUMP.EH. 3 ) 60 10 93

IF (NGT1.GE.3) GO TO 79

CALCULATE module VUl tage and Resistance for curRent ctinVergfnce check

UCV $=0$.

$U H M=0$.

DMOD $=0$.

DO $36 \quad j=1, N C$

$U C V=a C V+V O C(I)$

$B H M=U H M+R P C(I)$

$36 Q M O D=O M M O+Q T(I)$

$J=I N D I+1$

IF (NGT2-2) $79,37,22$

22 RLUAD $=$ UHM

CHECK FOR CONVERGENCE DN MODULF CURRENT 
(w) Astronuclear

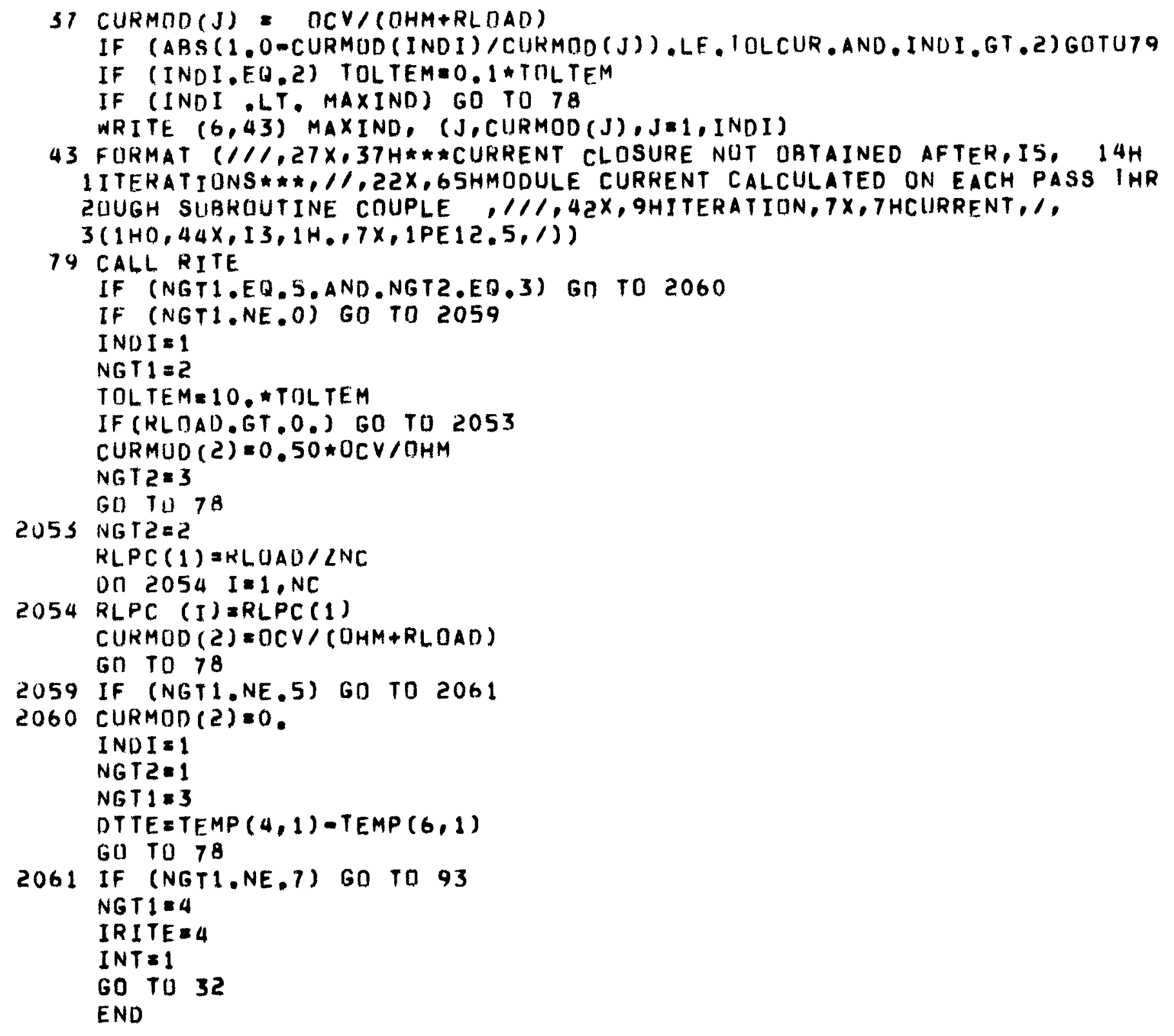


SUBRULITINE RITE

DIMENSIDN TAVG(300), ETAC (300), DTMF (300), TF $(9,300), \operatorname{TICUP}(300)$,

1 DTF $(9,300)$, CPMO $(12,2), A L P C U P(300), E T A(300)$

COMMON/TERIT/DTAV, OHM, OCV, RLOAD, QMOD, TCAV

COMMIN /MDCPOP/RAD (9), OR (8), TEMP $(9,300), V D C(300), R P C(300), P E(300)$,

1 QT (300), NOPTIM, VPC (300), RLPC (300), DTMOD (300), CUR (300), LNRAD (9),

2 LLP, ZLN, ZLI, ZLNLP, ZLPNI, ZLTE, NGT1, NGT2, ITPERT, PCMUI, T, NDDUMP, IVD,

3 QGEN, OJGENL, OTE, QOUT, ZID, ZOD, ZKEND, ZK9, ZKR, RPPC, RPN, TOLTEM, TREJ,

4 YREQ, PEREQ, ZLKEQ, WTCON, ZLPN, IDUMZ, RN, OGRF, DGTRF, DGLRF, RADK, JDUMP,

$S O P(S O), N C$

COMMUN /MODCPL/CURMDD(15), IT (300), DTTE,CONRN, CDNRP, ZLIP, ZNC,

1 ALRGG, MAXTEM, OGAM, CGAM, INDI,RINT4,RINTG, RCON4,RCONG, CIFEH,CIFEC,

2 CONST 1 , CONST 2, CONST3, CONST 4, CONSTS, NRSOPT, SEGTE, ICRMDL, RADC

CIMMON /MODOPT/IPDWT, DR4, DRINCR, IRITE, DRTE, JOPTIM, IZ9, IENDK, IPUN,

1 RIINC, ROINC, RIMAX, RQMAX, DIMIN, QREQ, THINC, TCINC, TCMAX, THMAX

2, NPFHT, ZNPERT, CKFP, CKFT, CTEOC, CTEIC, DELTL, RLPERT, RLMAX, ZNMIN, Z9SAV

COMMUN /TITLE/FETM(3), CASCAD $(8,2), \operatorname{SSIN}(3), \operatorname{CMT}(25), \operatorname{COND}(3,5)$, TEMKF,

1 CKMD $(2,2), I 3 N, I 2 N$, I 3P, I ZP

COMMUN /CPLRIT/DT $(8,300)$, OPTZLP (300), OPICPL (300)

DATA CPMO/4H CIR, 4HCUIT, 4H CA, 4HRNOT, 4H CUR, 4HRENT, 4H EFF, UH (AM,

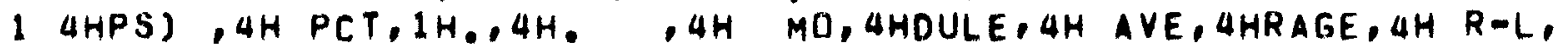

2 पHOAD, 4HTEMP, 4H(M-D, 4HHMS), 4HDEG . 4HMOHM, 1HS/

$\operatorname{CPMD}(1,2)=\operatorname{CRMD}(1,1)$

$\operatorname{CPMD}(2,2)=\operatorname{CRMD}(2,1)$

WRITE $(6,100)$ (CMT $(J), J=1,25)$

100 FIRMAT (1H1,4X,2A4, IX,18A4,2H (,F2.0,2(1H/,F2.0),2H), 2A4)

IF ( $2 K F N D . L E, 0$.$) GU TO 11$

$\operatorname{CPMD}(1,2)=\operatorname{CRMD}(1,2)$

$\operatorname{CPMD}(2,2)=\operatorname{CRMD}(2,2)$

11 IF (NGT1.LT.S.AND.IRITE.TT.2) GO 102005

DO $2001 I=1, N C$

$P=\operatorname{TEMP}(9, I)+0.5 \star D T M O D(I)$

TAVG (I) $=0 K 2 F K(P)$

$\operatorname{ETAC}(I)=100 . \star D T M O D(1) / T E M P(1, I)$

DTMF (I) $=$ CKFT $\star D T M U D(I)$

$\operatorname{TF}(9,1)=\operatorname{DK} 2 F K(\operatorname{TEMP}(9,1))$

TI $C U P(I)=D T M F(I) / B T(I)$

$A L P C U P(I)=V \cap C(I) / D T M F(I)$

$E T A(I)=P E(I) / O T(I)$

DO $2001 \mathrm{~J}=1.8$

$\operatorname{UTF}(J, I)=C K F T \star D T(J, I)$

$2001 \operatorname{TF}(J, I)=D K 2 F K(\operatorname{TEMP}(J, I))$

2006 IF (IRITE.GT.2) Gח TO 2007 
(W. Astronuclear

1994 WRITE $(6,1998) \quad(C O N D(J, N G T 2), J=1,3), T E M K F,(J, J=1,9)$,

$1(I,(T F(J, I), J=1,9), I=1, N C)$

1998 FORMAT (1HO, $10 \times, 58 H R A D I A L$ TEMPERATURE PRUF ILE FOR EACH COUPLE CALC IULATED FOR, 3A4,19H CONDITIUNS (DEGS, A1,1H)/8HO COUPLE,6X,

$29(1 H T, I 1,9 X) /(3 H 0, I 3,1 H, F 11,2,8 F 11,2))$

IF (NC,GT,7) WRITE $(6,100)(C M T(J), J=1,25)$

WRITE $(6,2009)$ TEMKF, $(1,(D T F(J, I), J=1,8), I=1, N C)$

2009 FORMAT (1HO,21X,64HRADIAL TEMPERATURE ORUP ACROSS COMPONENTS FOR E

$1 A C H$ COUPLE (DEG. IA1,1H)//BH COUPLE,1OX, ZBHINNER BORDN

2 INNER, 28X,26HOUTER BORON OUTER/19X,81HCLAD NITRIDE

3 CUNDUCTOR T/EI T/EZ CONDUCTOR NITRIDE CLADI

$4(1 H 0,15,2 H,, F 16,3,7 F 11,3))$

WRITE $(6,100)(\operatorname{CMT}(\mathrm{J}), \mathrm{J}=1,25)$

2007 WRITE $(6,2002)$ (CDNO $(J, N G T 2), J=1,3)$

2UOZ FORMAT ( 1 HO, $12 \times, 61$ HCALCULATED PARAMETERS FDR INDIVIDUAL COUPLES OP IERATING UNDER, 3A4, IIH CONDITIONS)

C - WRITE INDIVIDUAL COUPLE PARAMETERS

WRITE $(6,13)$ (CPMD $(J, 1), J=1,7), \operatorname{TEMKF,CPMD}(8,1), \operatorname{CPMD}(9,1), T E M K F$,

1 TEMKF, CPMU $(10,1), C P M D(11,1)$

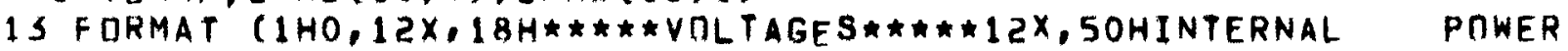

1 HEAT THERMAL EFFECTIVE, $2 A 4,1 \times, 2 A 4 / 33 H$ TH/TC VOC

$2 V M L O A D, 2 A 4,63 H$ RESISTANCE DUTPUT INPUT IMPFDANCE SEEBE

3CK FFF. ,A4,1H,IBH (DEG.,A1,24H) (VOLTS) (VILTS),

$42 A 4,35 H \quad(M=O H M S) \quad$ (WATTS) (WATTS) $(D=, A 1,12 H / K W) \quad(M V / D=$,

$5 A 1,14 H)(P C T),(, A 4, A 1,1 H))$

WRITE $(6,14)$ (TF (1,I),TF (9,I), VOC (I), VPC (I),CUR(I),RPC (I),PE(I),

1 QT (I), TICUP(I), ALPCUP(I),ETA(I),ETAC (I),I $=1, N C)$

14 FORMAT (1HO,F5,0,1H/,F4,0,2F10,5,F10,3,3PF10,4,OPF 10,4,F10,2,

1 3PF $10,2,3 P F 10,4,2 P F 10,3$, OPF 9.2$)$

C - WRITE CALCULATED AXIAL LENGTHS IF ZLP HAS BEEN DPTIMIZEN

2062 IF (IDUMZ.EQ.1) GO TO 2061

IF (NC.6T,7) WRITF $(6,100) \quad(C M T(J), J=1,25)$

WRITE $(6,2052) \quad(I, Z L N$, UPTZLP (I), ZLI, OPTCPL (I), OPTCPL $(I+100), I=1, N C)$

2052 FOKMAT (1HO// 14X, 6HCOUPLE, $18 X, 52 H A X I A L$ THICKNESSES CALCULATEO I

IN OPTIMIZATION ROUTINE/14X,6HNUMBER, $11 X, 5 H N-L E G, 10 X, 5 H P-L E G, 7 X, 12 H$

2MICA WASHERS, 6X,6HCDUPLE, 8X,7HCIRCUIT/ $(1 H 0,13 X, I 4,4 H) \quad, 5 F 15,5)$

2061 IF (NGTI.LT.3) GO TO 2005

IF (NC.GT,7,OR, IDUMZ,EQ.Z) WRITE $(6,100) \quad(C M T(\mathrm{~J}), \mathrm{J}=1,25)$

WRITE $(6,2042)$ PCMULT, $(C D N D(J, N G T 2), J=1,3)$

2042 FORMAT (// F7.0,32H COUPLE MMDULES OPERATING UNDER, 3A4,55H CUND

IITIONS WITH UNIFORM HOT ANO COLD CLAD TEMPERATURES)

RLD $=0$.

WRITE $(6,13)$ (CPMD $(J, 2), J=1,7), \operatorname{TEMKF,CPMD~}(8,2), \operatorname{CPMD}(9,2)$, TEMKF,

1 TEMKF,CPMO $(10,2)$, TEMKF 


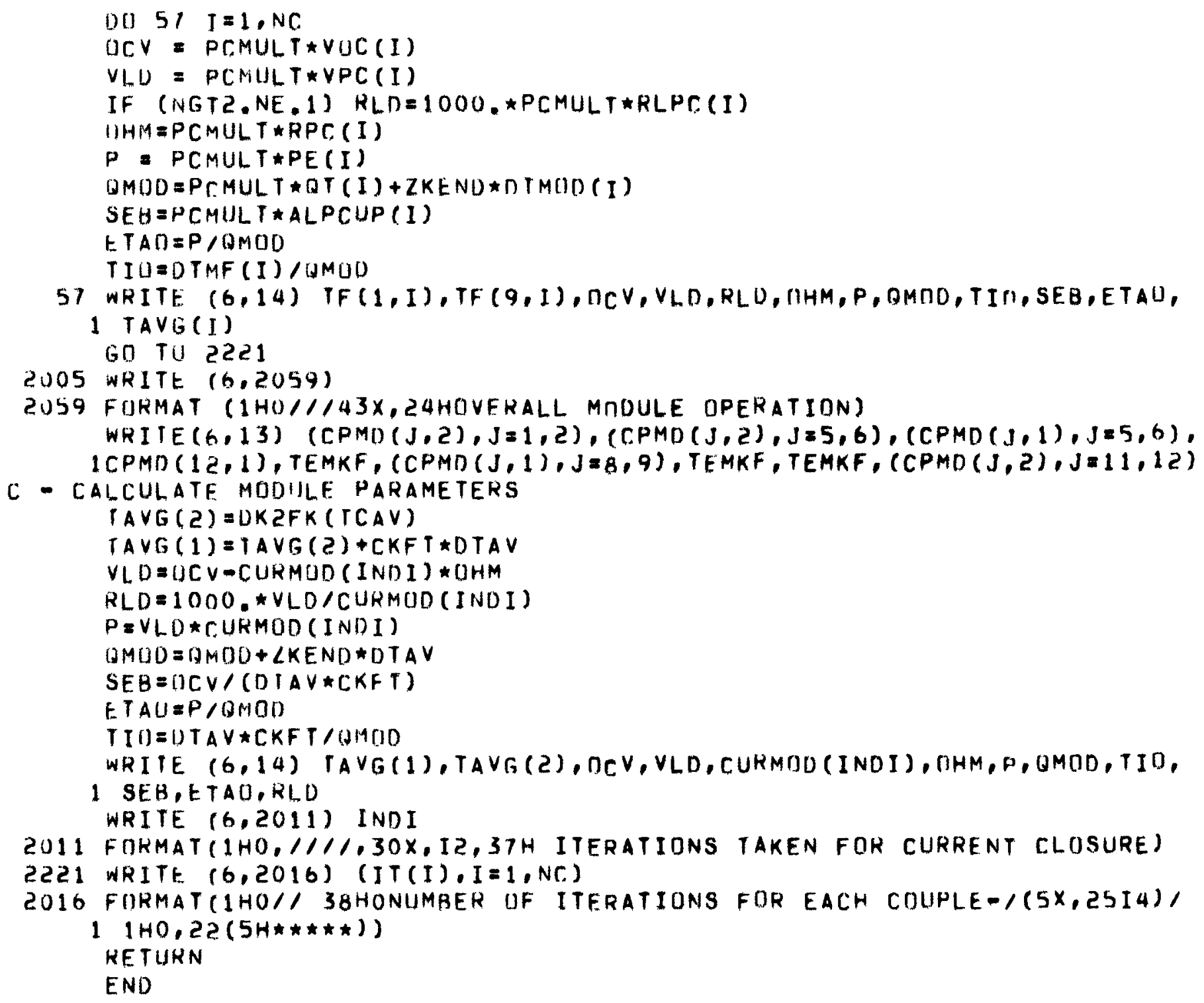


SUBRUUTINE PHIINY (DP, IPUN, HRS)

DIMENSTON FM $3 N(15), F M 2 N(15), F M 3 P(15), F M 2 P(15), D P(30)$

CUMMUN /TITLE/FETM(3), CASCAD $(8,2), \operatorname{SSIN}(3), \operatorname{CMT}(25), \operatorname{COND}(3,5)$, TEMKF,

$1 \operatorname{CRMD}(2,2), I 3 N, I 2 N, I 3 P, I 2 P$

COMMON IDATIN/TTT(15), LKMIC1 (15), ZKMICZ(15), ZKSS(15),ZKBN(16),

$1 Z K K I N(15), Z 2 N A(15), Z 2 N R(15), Z 2 N K(15), Z 2 P A(15), Z 2 P R(15), Z 2 P K(15)$,

ZL2NRK (15),ZZPRK (15),Z3NA (15),Z3NR (15),ZSNK (15),Z3NRK (15),Z3PA (15),

3 Z3PK(15), 23PK (15),23PRK (15), ZKCRH(15), ZKCRC (15),RCRH (15),RCKC (15)

4. RHP (15), RPRHO

COMMON /F ODAT/ALPHA $(15,8)$, RHM $(15,8), \operatorname{ZKON}(16,8), Z K S S I N(16,3)$,

1 RFETM $(15,4), Z K F E T M(16,3), \angle K M I C A(16)$

COMMUN /FIWT/DEN ( 8), DENI, DEN3N, DENZN, DEN3P, DENZP, DCRH, DCRC

COMMON / TEF O NCLDC, NCLDH, ICRH, ICRC, IPIN, LLIBRH, ZLIBRC, TPIN, RP IN

DATA HIT/4HHOT /,COLD/4HCOLD/, NNAME/2HN-/,PNAME/ZHP-/

IF (NCLDH.NE, 1. AND,NCLDH.NE,3) NCLDH=2

IF (NCLDC,NE.2.AND.NCLDC.NE,3) NCLDC=1

IF (ICRH,NE, Z, AND,ICRH,NE,1) ICRH=3

IF (ICRC,NE,Z,AND,ICRC,NE,1) ICRC=3

IF $(I 3 N \cdot L T .10)$ GO TO 301

$I 3 N=13 N-10$

READ $(5,3001)$ (ALPHA $(T, I 3 N), I=1,15),(R H D(I, I 3 N), I=1,15)$,

$1(\operatorname{LKON}(I, I 3 N), I=1,16), \operatorname{CASCAD}(I 3 N, 1), \operatorname{CASCAD}(I 3 N, 2)$

3001 FDRMAT (8F9.2/7F9.2/8F9.2/7F9.2/8F9.2/8F9.2,1 $1,2 A 4)$

IF (IPUN,GT,0) WRITE $(7,401)(C A S C A D(I 3 N, I), I=1,2),($ ALPHA $(I, I 3 N)$,

$1 I=1,15),(\operatorname{CASCAD}(I 3 N, I), I=1,2),(R H D(I, I 3 N), I=1,15)$,

$2(C A S C A D(I 3 N, I), I=1,2),(2 K D N(I, I 3 N), I=1,16)$

401 FORMAT (25HC SEEBECK CDEFFICIENT OF, 2A4,?3H MATERIAL (VOLTS/DFG.K

1) $, 5 X, 1 H 1,10 X, 5(E 9,3,1 H,) / 5 X, 1 H 2,10 X, 5(E 9,3,1 H,) / 5 X, 1 H 3,10 X, 5(E 9,3$,

2 1H, $/ 17 H C$ RESISTIVITY OF, 2A4, $19 H$ MATERIAL (OHM\#CM.) /5X,1H1,10X,

$35\left(E 9,3,1 H_{1}\right) / 5 X, 1 H 2,10 X, 5\left(E 9,3,1 H_{0}\right) / 5 X, 1 H 3,10 X, 5\left(E 9,3,1 H_{1}\right) /$

$426 \mathrm{HC}$ THERMAL CUNDUCTIVITY OF, ZA4,27H MATERIAL (WATTS/CM./DEG,K)/

$55 X, 1 H 110 X, 5(E 9,3,1 H,) / 5 X, 1 H 210 X, 5(E 9,3,1 H,) / 5 X, 1 H 3,6(F 9,3,1 H)$,

301 IF (IZN.LT.10) GO TO 302

$I 2 N=I 2 N-10$

HEAD $(5,3001)$ (ALPHA $(I, I 2 N), I=1,15),(R H O(I, I 2 N), I=1,15)$,

$1(Z K O N(I, I 2 N), I=1,16), C A S C A D(I 2 N, 1), C A S C A D(I 2 N, 2)$

IF (IPUN,GT,0) WRITE $(7,401)$ (CASCAD(IZN,I),I=1,2), (ALPHA (I,IZN),

$1 I=1,15),(\operatorname{CASCAD}(I 2 N, I), I=1,2),(R H D \quad(I, I 2 N), I=1,15)$,

$2(C A S C A D(I Z N, I), I=1,2),(\angle K U N(I, I Z N), I=1,16)$

302 IF (IBP.LT, 10) G0 Tח 303

I $3 P=13 P-10$

READ $(5,3001)$ (ALPHA $(I, I 3 P), I=1,15),(R H D(I, I 3 P), I=1,15)$,

$1(Z K D N(I, I 3 P), I=1,16), C A S C A D(I 3 P, 1), C A S C A D(I 3 P, 2)$ 
IF (IPUN,GT,O) WRITE $(7,401)$ (CASCAD(I3P,I),I=1,2),(ALPHAC I,I3P), $1 I=1,15),($ CASCAD $(I 3 P, I), I=1,2),(R H O \quad(I, I S P), I=1,15)$,

$2(\operatorname{CASCAD}(I S P, I), I=1,2),(Z K \cup N(I, I 3 P), I=1,16)$

303 IF (ISP.LT.10) GO TO 304

$I J P=I 5 P-10$

READ $(5,3001)$ (ALPHA $(I, I 2 P), I=1,15),(R H O(I, I 2 P), I=1,15)$,

$1(Z K U N(I, I Z P), I=1,16), C A S C A D(I ? P, 1), C A S C A D(I 2 P, Z)$

IF (IPIIN,GT,O) WRITE $(1,401)$ (CASCAD(I PP,I),I=1,2), (ALPHA $(I, I 2 P)$,

$1 I=1,15),(\operatorname{CASCAD}(I 2 P, I), I=1,2),(\operatorname{RHO}(I, I 2 P), I=1,15)$,

$2(C A S C A D(I Z P, I), I=1,2),(Z K U N(I, I Z P), I=1,16)$

$504 \angle L I R H 1=1.0-Z L I B R H$

$\angle L I B C I=1.0-Z L I B R C$

PNSN $=1.0$

PNZN $=1.0$

IF (I3N,EQ.I3P) $P N 3 N=-1.0$

IF (IZN,EQ.IZP) PNZN=-1.0

HKP $=1, \cap E-5 * H R S$

$0 \angle S N A=(1 .+H R P \star D P(I 3 N)) \star P N 3 N$

$D Z 2 N A=(1 .+H R P \star D P(T 2 N)) \star P N Z N$

UZSPA $=1.0+H R P \star O P(I 3 P)$

$D Z Z P A=1.0+H R P * D P(I Z P)$

DZ $S N R=1.0+H R P \star D P(I 3 N+10)$

D) $Z 2 N R=1.0+H R P * 1) P(I 2 N+10)$

$0 Z S P K=1,0+H R P \star D P(13 P+10)$

$D \angle 2 P R=1.0+H R P \star D P(12 P+10)$

$H R P=.01$

D) $\angle 3 N K=1, U+H R P * 1) P(I 3 N+20)$

$D Z 2 N K=1.0+H K P \star D P(I 2 N+20)$

D) $Z 3 P K=1.0+H R P \star D P(I 3 P+20)$

$U Z 2 P K=1.0+H R P * D P(12 P+20)$

$I=16$

$\operatorname{DEN}(1)=2 K S S I N(I, N C L D H)$

$\operatorname{DEN}(2)=\angle K B N(I)$

$\operatorname{DEN}(7)=2 K B N(I)$

DEN $(8)=Z K S S I N(I, N C L D C)$

DENI $=Z K M I C A(I)$

$D C R H=Z K F E T M(I, I C K H)$

$D C R C=Z K F E T M(I, I C R C)$

DEN $3 N=Z K U N(I, I 3 N)$

UENZN=ZKON $(I, I Z N)$

$D E N 3 P=\angle K D N(I, I 3 P)$

$D F N 2 P=I K O N(I, I 2 P)$

$00249 \quad I=1,15$

$R H P(I)=R F E T M(I, I P I N)$ 
(v) Astronuclear Laboratory

$Z K M I C I(I)=\angle L I B H I * Z K M I C A(I)+Z L I B K H \star Z K F E T M(I, 2)$

$Z K M I C Z(I)=\angle L I B C I * Z K M I C A(I)+Z L I R R C * Z K F E T M(I, Z)$

$R C R H(I)=R F E T M(I, I C R H)$

$R C R C(I)=\operatorname{RFETM}(I, I C R C)$

$\angle K C R H(I)=Z K F E T M(I, I C R H)$

$\angle K C K C(I)=\operatorname{ZKFETM}(I, I C R C)$

$\operatorname{LKIN}(I)=\operatorname{ZKSSIN}(I, N C L D H)$

ZKSS $(I)=Z K S S I N(I, N C L D C)$

$Z 3 N A(I)=D Z 3 N A \star A L P H A(I, 13 N)$

$Z 2 N A(I)=D Z 2 N A \star A L P H A(1, I Z N)$

$23 P A(I)=D 23 P A \star A L P H A(1,13 P)$

$\angle 2 P A(I)=D Z 2 P A \star A L P H A(I, I 2 P)$

$\angle 3 N R(I)=D 23 N R * R H O(I, I 3 N)$

$Z 2 N R(I)=D Z 2 N R \star R H O(I, I 2 N)$

$Z 3 P R(I)=D 23 P R \star R H O(I, I 3 P)$

$\angle Z P R(I)=D 2 Z P R \star R H O(I, I 2 P)$

$Z 3 N K(I)=0 Z 3 N K * Z K O N(I, I 3 N)$

$Z 2 N K(I)=0 Z 2 N K \star Z K O N(I, I Z N)$

$Z 3 P K(I)=D Z 3 P K \star Z K D N(1,13 P)$

$\angle 2 P K(I)=D Z 2 P K \star Z K O N(I, I 2 P)$

Z2NRK (I)

Z2PRK (I)

$=Z 2 N R(I) *$

Z2NK (I)

- ZZPR(I)* ZZPK(I)

Z3NRK(I) $\quad$ Z3NR(I)* Z3NK(I)

$249 \angle 3 P R K(I)=Z 3 P R(I) * 23 P K(I)$

RPRHU =RPIN/SI (TTT,RHP, TPIN, 15, IND, 1,1)

IF (IPUN.LT.O) RETURN

WRITE $(6,100)$ (CMT $(J), J=1,25)$

100 FQRMAT $(1 H 1,4 X, 2 A 4,1 X, 18 A 4,2 H(, F 2,0,2(1 H /, F 2,0), 2 H), 2 A 4 /$

$1 / 138 \times, 33 H I N P U T$ MATERIALS PROPERTIES TABLES)

WRITE $(6,281)$ HOT, NNAME, (CASCAD $(I 3 N, I), I=1,2), H O T, P N A M E$, (CASCAD

$1(I 3 P, I), I=1,2)$

281 FORMAT (1HO,/16X,2(A4,6H SIDE, A2,13HLEG WASHER - ,2A4,9H MATERIAL

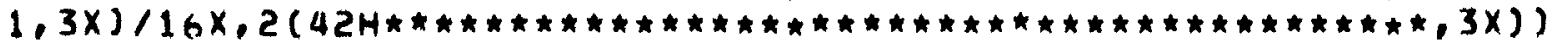
WRITE $(6,282)$

282 FORMAT (BX,5HTEMP.,6X,2(39HSEEBECK RESISTIVITY CONDUCTIVITY $1,6 \times))$

WRITE $(6,283)$

283 FORMAT $(7 \times, 6 H D E G$. $K, 3 X, 2(45 H(V O L T / D E G K)$ (OHM*CM) (WATI/C $1 M / K)$ J J

WRITE (6,253) (TTT(I),Z3NA(I),Z3NR(I),Z3NK(I),Z3PA(I),Z3PR(I), $1 Z 3 P K(I), I=1,15)$

253 FORMAT (1H0,6X,F6,1,6G15,5)

WRITE $(6,100)$ (CMT $(\mathrm{J}), \mathrm{J}=1,25)$

WRITE $(6,281)$ COLD,NNAME, (CASCAD (I 2N, I), I 1,2), COLD,PNAME, (CASCAD 
$1(I 2 P, I), I=1,2)$

WRITE $(6,282)$

WRIIE $(6,283)$

WRITE $(6,253)$ (ITT(I),Z2NA(I),Z2NR(I),ZZNK(I),Z2PA(I),ZZPR(I),

$1 \angle 2 P K(I), I=1,15)$

WRITE $(6,100) \quad($ CMT $(J), J=1,25)$

WRITE $(6,285)$

285 FORMAT (1HO, /16x, 4 (12HFIG-OF-MERIT, 3X), 2 (12HCONDUCTIVITY, 3X), /8X,

$15 H T E M P, 2(7 x, 5 H N-L E G, 10 x, 5 H P-L E G, 3 X), 3 x, 27 H B N$ INSULATIR INTER $-C$

2UUPLE, /7X,6HOEG, K, 5X,2(9HHOT SIDE,6X),2(9HCOLD SIDE,6X), Z4H SLEF

3VES INSIILAIURS/12X,4(6X,9H(1/OEG.K)), 1X, 2(4X,1IH(WATT/CM/KJ))

DO $2 \zeta 0 \quad I=1,15$

$F M 3 N(I)=\angle 3 N A(I) * \angle 3 N A(I) / \angle 3 N R K(I)$

$F M 2 N(I)=\angle 2 N A(I) \star Z 2 N A(I) / Z 2 N R K(I)$

$F M S P(I)=\angle 3 P A(I) \star Z 3 P A(I) / Z 3 P R K(I)$

$250 F M 2 P(I)=Z 2 P A(I) * \angle 2 P A(I) / \angle 2 P R K(I)$

WRITE $(6,253)$ (ITT(I),FMSN(I),FM3P(I),FMZN(I),FMZP(I),ZKBN(I),

$1 \operatorname{LKMICI}(I), I=1,15)$

WRIIE $(6,100) \quad(C M T(J), J=1,2 S)$

WRITE $(6,286)$ HOT,COLD,SSIN(NCLDH),SSIN(NCLDC),FETM(ICRH),

1 FETM(ICRH), FETM(ICRC),FETM(ICRC)

286 FORMAT (1HO, $117 x$, 25HINNER CLAD OUTEK CLAD, 5X,2(A4,21H SIDE CUN

IUUCIOR RINGS, SX)/8X, SHTEMP.,7X,6(1H(,AZ,1H),11X), /7X,6HDEG, K,

2 ?(ISH CONDUCTIVITY), $2(30 \mathrm{H}$ CONDUCTIVITY RESISTIVITY)/

$313 x, 2(15 H$ (WATT/CM/K)), 2(2BH (WATT/CM/K) ( WRITE (6,253) (TTT(I),ZKIN(I),ZKSS(I),ZKCRH(I),RCRH(I),ZKCRC(I),

$1 \operatorname{RCKC}(I), I=1,15)$

KETURN

END 
SUBRUUTINE CDUPLE

COMMUN /MDCPOP/RAD(9),DR (8), TEMP(9,300), VOC $(300), R P C(300), P E(300)$,

1 OT (300), NOPTIM, VPC (300), RLPC $(300)$, DTMOD $(300)$, CUR $(300), L N R A D(9)$,

2 ZLP, ZLN, ZLI, ZLNLP, ZLPNI, ZLTE, NGT 1, NGT2, I TPERT, PCMULT, NODUMP, IVD,

3 QGEN, DGENL, QTE, QDUT, ZID, LOD, ZKEND, ZK9, ZKR, RPPC, RPN, TOLTEM, TKEJ,

4 VREQ, PEREQ, ZLREQ, WTCON, LLPN, IDUMZ, RN, OGRF, DGTRF, DGLRF, RADK, JDUMP,

5 DP $(30), N C$

COMMON /MODCPL/CURMDD(15), IT (300), DTTE, CONRN, CONRP, ZL IP, ZNC,

1 ALR64, MAXTEM, OGAM, CGAM, INDI, RINT4, RINT6, RCONA, RCONG, CIFEH,CIFEC,

2 CONST1, CONST2, CONST3, CONST 4, CONSTS, NRSOPT, SEGTE, ICRMDL, RADC

COMMUN /DATIN/TTT(15),ZKMIC1(15),ZKMICZ(15), ZKSS(15),ZKBN(16),

1 ZKIN (15),ZZNA (15),ZZNR (15), ZZNK (15),Z2PA (15),Z2PR (15),Z2PK (15),

2Z2NRK (15), Z2PRK (15), Z3NA (15), Z3NR (15),Z3NK (15), Z3NRK(15), Z3PA (15),

3 Z3PR (15),Z3PK(15),Z3PRK (15),ZKCRH (15), ZKCRC (15), RCRH (15),RCRC (15)

4, RHP (15), RPRHO

CIIMMUN /TITLE/FETM(3), CASCAD $(8,2), \operatorname{SSIN}(3), \operatorname{CMT}(25), \operatorname{CDND}(3,5), \operatorname{TEMKF}$,

1 CKMO $(2,2), I 3 N, I 2 N, I 3 P, I 2 P$

COMMON /CPLRIT/OT (B,300), UPTLLP(300), OPTCPL (300)

DIMENSION XZK(9),ZK(9),TCON(11),ZKEQ(8),B(100)

REAL LNRAD

DATA X/K/9*0./,LNDUMP/O/, LKTEP/0./,ZKTEN/0,/,T5OP/670,/,ZKEQ/8*0.1

DATA A/ GHTFEH , GHZKPI

16HRINT6, GHQSAVE, GHFERH

26HZKNZ, GHTCLDC, GHQGAM

36HALPZ, GHZKIZ

46HOTOMN1, 6HALN2

S6HTOLTEM, GHQTOM

66H2KECPC, GHALT1

76HKHONZ, GHZLN

BGHQOUT, GHRHON

. GHTBNC

.6HZKTEN

GHRHOP 1

, GHQP

, 6HRINT4, 6HLKDT , GHTFEC

. 6 HZKNI

, GHTCLDH, GHQGEN

, 6HALPI , 6HZKII, GHTBNH

.6HZKPZ,

, GHOTOMP2, GHALN1 , GHZKTEP , GHDTMOD,

, GHDTTE , GHOTOMN2, 6HZKR

.6HALNH1

, $6 \mathrm{HZKTEQ}, 6 \mathrm{HTCON}, 6 \mathrm{HQC}$

. 6HRHON1 . 6HZLP

, GHALTZ

, GHZKTE,

96HALNC2, 6HRPC

, GHRP

, 6HQIN

- GHRHDP

- GHZLTE

, GHRHOPZ,

A6HRFEC, 6 HALPHE , GHCUR, GHCONST4,6HRINTFH, GHALPCI

16HZKHOT , GHRINTFC, GHALPCZ

26HQT . GHQEOL . GHOBOL

- GHOTE

- 6HZKCOLD, GHRPPC

. 6 HQJ

TOLTEM = AMAX1 (TOLTEM,.OO1)

, GHTREUL , GHTRBOL , GHPCMULTI

NSEG $\cong S E G T E$

$Y N C=Z N C$

IF (NGT1,GE,3) YNCEPCMULT

ZKECPC $=2 K E N D / Y N C$

CONST $6=0.5 * Z L R E Q /(Z L I * Y N C)-1.0$

DO $6010 \quad I=1, N C$

QSAVE=0.

ITNOW $=0$ 
C INIIIALIZF RADIAL TEMPERATURES

IF (INDI.GT.1) GI) TO4053

If $(I . F 0.1) 60$ TO 4045

$I 1=I-1$

IF (GGEN.LE.0.) G0 TO 5005

$D T M O D(I)=D T M U D(I 1)$

$\operatorname{TEMP}(1,1)=\operatorname{TEMP}(9,1)+D T M D D(I)$

5005 DTMODR=DTMOD(I)/DTMDD(II)

OT $(1, I)=D T(1, I 1) \star D T M O D R$

$004041 \mathrm{~J}=1.7$

$J 9=J+1$

$\operatorname{TEMP}(J 9, I)=\operatorname{TEMP}(J, I)-D T(J, I)$

4041 DT $(J 9, I)=D T(J 9, I 1) * D T M O D R$

GO $10 \quad 4040$

4045 IF (WGEN,LE.O.) GO TU 5004

DTMUD (I $)=0,5 \star D G E N \star C O N R N / S I(T T T, 22 N K, \operatorname{TEMP}(9, I), 15, I N D, 1,1)$

$\operatorname{TEMP}(1, I)=\operatorname{TEMP}(9, I)+D \operatorname{TM} D(I)$

$5004 \operatorname{TEMP}(5, I)=\operatorname{TEMP}(1, I)-\operatorname{LNRAD}(4) \star D T M O D(I) / A L R G 4$

OU $4051 \mathrm{~J}=2,4$

$\operatorname{TEMP}(J, I)=\operatorname{IEMP}(1, I)$

$4051 \operatorname{TEMP}(J+4, I)=\operatorname{TEMP}(9, I)$

DO $4052 \mathrm{~J}=1,8$

4052 DT $(J, I)=\operatorname{TEMP}(J, I)-\operatorname{TEMP}(J+1, I)$

GO 104040

4053 IF (NGT1.LT.3,OK. ITPERT.FT.1) GO TO 4040

IF (ITPERT,EQ.0) GD TO 4055

I TPERT $=0$

$\operatorname{DTMDD}(1)=\operatorname{TEMP}(1,1)-\operatorname{TEMP}(9,1)$

DTMOOR = DTMUD (1)/DTMDD (3)

DO $6013 \mathrm{JI}=1, \mathrm{NC}$

ט0 $4054 \mathrm{~J}=1.7$

DT $(J, J 1)=0 T(J, J 1) * D T M O D R$

$4054 \operatorname{IEMP}(\mathrm{J}+1, \mathrm{~J} 1)=\operatorname{TEMP}(\mathrm{J}, \mathrm{J} 1)-\pi T(\mathrm{~J}, \mathrm{~J} 1)$

6013 DT $(8, J 1)=D T M O D R * D T(8, J 1)$

4040 DTTE = TEMP $(4, I)-\operatorname{TEMP}(6, I)$

IF (DTTE.GT.DTMUD (I)) DTTE $=$ DTMOD(I)

IF (NRSOPT,EQ.0) GO TO 4060

$\operatorname{TEMP}(5, I)=\operatorname{AMIN} 1(\operatorname{AMAXI}(\operatorname{TSUP}, \operatorname{TEMP}(4, I)), \operatorname{TEMP}(5,1))$

$\operatorname{UT}(4, I)=\operatorname{TEMP}(4, I)-\operatorname{TEMP}(5, I)$

$\operatorname{UT}(5, I)=\operatorname{IEMP}(5, I)-\operatorname{TEMP}(6, I)$

4060 DELTI=DT $(4, I) / S E G T E$

DELT $=\Pi T(5, I) / S E G T E$

TT1 $=\operatorname{TEMP}(5, \mathrm{I})+.5 \star D E L T 1$

$T T 2=\operatorname{TEMP}(6,1)+.5 \star D E L T 2$ 


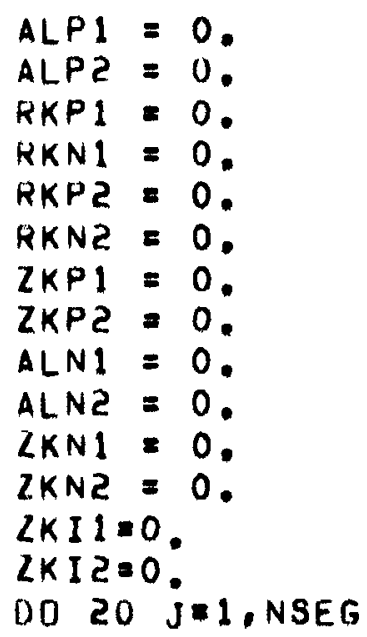




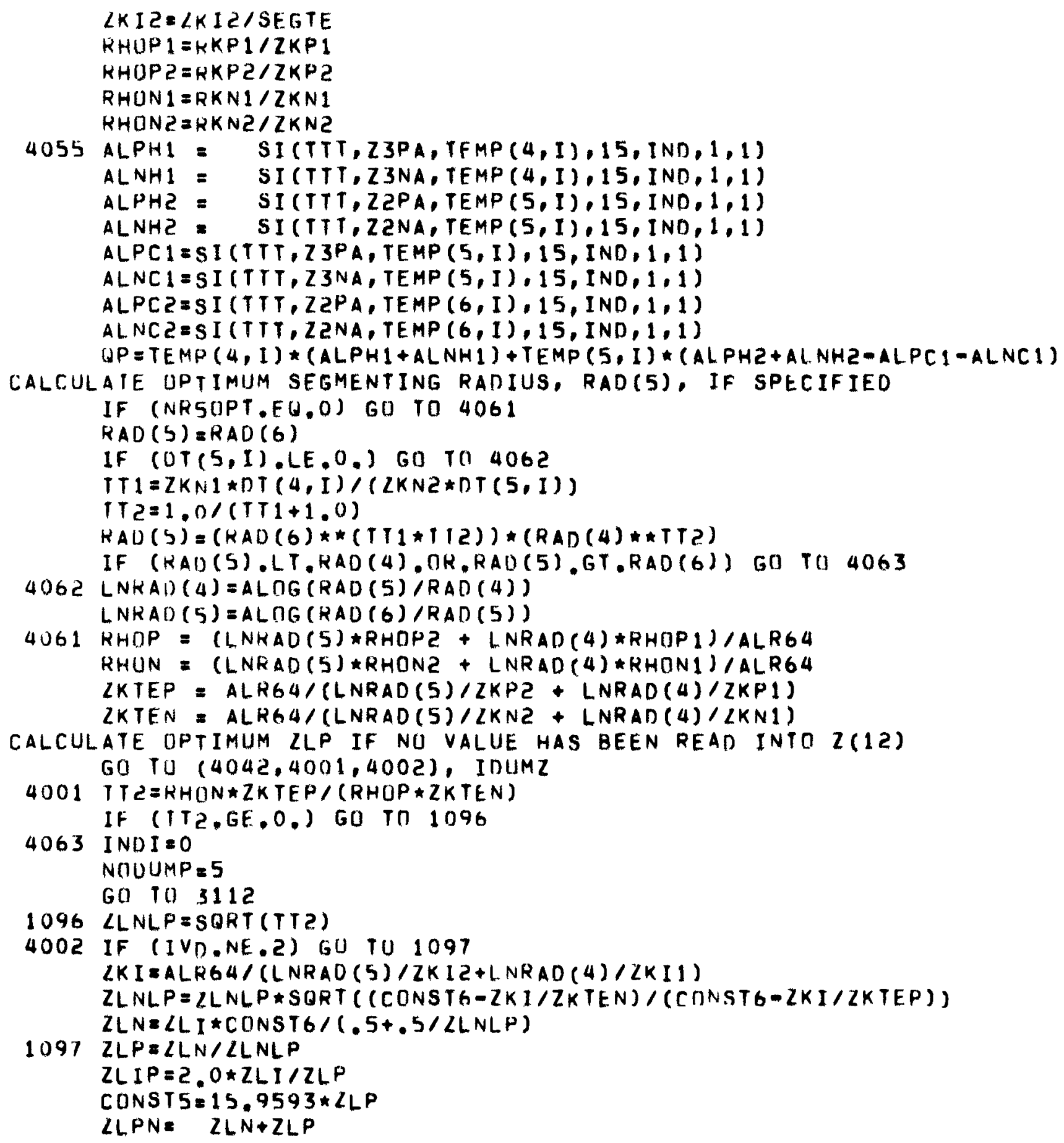




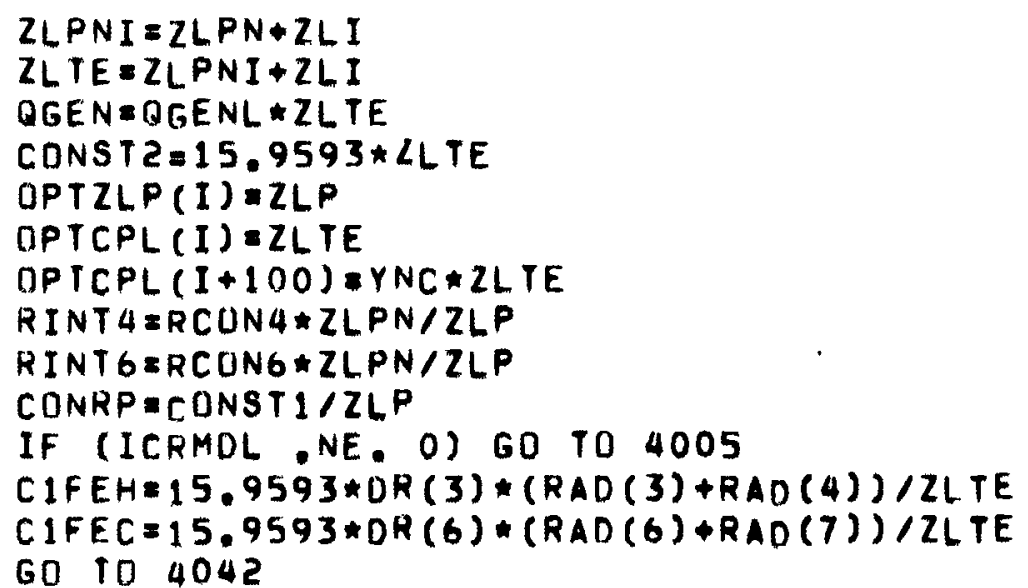

CALCULATE RADIUS OF CIRCULAR CONDUCTOR RING ELECTRICAL STREAMLINE 4005 RCHOT $=\triangle M I N I(O R(3), Z L N, Z L P)$

RCOLDEAMIN $1(D R(6), Z L N, Z L P)$

$C 1 F E H=5.08 * R A D(4) * A L O G(3.14159 * R C H O T / Z L I+1.0)$

$C 1 F E C=5.08 * R A D(6) \star A L D G(3.14159 * R C D L D / 2 L I+1.0)$

CALCULATE COUPLE RESISTANCE

4042 RINTFH=RINT4*TEMP $(4, I) * \operatorname{TEMP}(4, I)$

RINTFC $\approx$ RINT6*TEMP $(6, I) \star \operatorname{TEMP}(6, I)$

TFEC $=\operatorname{TEMP}(7, I)+.5 \star D T(6, I)$

TFEH = TEMP $(4, I)+.5 * D T(3, I)$

FERC = SI (TTT, RCRC, TFEC, 15, IND, 1,1)

FERH = SI (TTT,RCRH, TFEH, 15, IND, 1,1)

RFEH $=F E R H / C 1 F E H$

RFEC $=F E R C / C 1 F E C$

$R N=C O N R N \star R H O N$

$R P=C I I N K P \star R H O P$

$R P N=R P+R N$

$T T E=.5 *(T E M P(4, I)+\operatorname{TEMP}(6, I))$

$R P P C=R P R H O \# S I(T T T, R H P, T T E, 15, I N D, 1,1) / Y N C$

$U J=R F E H+R I N T F H+.5 * R P N$

$R P C(I)=Q J+.5 * R P N+R F E C+R I N T F C+R P P C$

CALCULATION OF THERMAL CONDUCTANCES

$\operatorname{TBNH}=\operatorname{TEMP}(3, I)+.5 * D T(2, I)$

$\operatorname{TBNC}=\operatorname{TEMP}(8,1)+.5 * D T(7, I)$

$\operatorname{TCLDH}=\operatorname{TEMP}(2, I)+.5 * 0 T(1, I)$

$\operatorname{TCLDC}=\operatorname{TEMP}(9,1)+.5 * D T(8,1)$

$X Z K(1)=S I(T T T, Z K I N, T C L D H, 15, I N D, 1,1)$

$X Z K(8)=S I(T T T, 2 K S S, T C L D C, 15, I N D, 1,1)$

$X Z K(Z)=S I(T T T, Z K B N, T B N H, 15, I N D, 1,1)$

$X Z K(7)=S I(T T T, Z K B N, T B N C, 15, I N D, 1,1)$ 
$X Z K(3)=(S I(T T I, Z K C R H, T F E H, 15$, IND, 1,1)*ZLPNI+SI (TTT,ZKMICI,TFEH,

1 15, IND, 1,1)*ZLIJ /ZLTE

$x \angle K(6)=(S I(T T T, \angle K C K C, T F E C, 15$, IND, 1,1) ZZLPNI+SI (TTT,ZKMICZ,TFEC,

$1 \quad(5,1 N D, 1,1) * Z L 1) / Z L T E$

$\angle K(1)=C O N S T 2 * \times Z K(1) / L N R A D(1)$

$\angle K(2)=C O N S T 2 * \times Z K(2) /($ LNRAD $(2) *(1.0 * \times Z K(2) *$ CONST 3$))$

$\angle K(3)=$ CONST $2 * \times Z K(3) / L N R A D(3)$

$\angle K(4)=$ CONST5*(ZLNLP*ZKNI + LKPI+ZLIP*ZKII)/LNRAD (4)

IF (LNRAD(4) .LE.0.) ZK(4)=1.0F30

$Z K(5)=C O N S 15 *(Z L N L P * Z K N Z+Z K P Z+Z L I P * Z K I 2) / L N R A D(5)$

IF (LNRAD(5).LE.0.) $Z K(5)=1.0 E 30$

$Z K I E=2 K(4) * Z K(5) /(2 K(4)+2 K(5))$

$\angle K(6)=C D N S T 2 * X Z K(6) / L N R A D(6)$

$Z K(7)=C$ CNST $2 * X Z K(7) /(\operatorname{LNRAD}(7) *(1.0+\times 2 K(7) *$ CDNST 4$))$

$\angle K(8)=C O N S T 2 \star X Z K(8) / L N K A D(B)$

IF $(\angle K G, G T, 0) Z K,(8)=Z K(8) \star \angle K 9 \star Z L T E /(Z K(8)+Z K 9 \star Z L T E)$

$A L T I=A L P I+A L N I$

$A L 12=A L P Z+A L N 2$

CALCULATION OF VOLTAGES AND CURRENT

$\operatorname{VUC}(I)=\operatorname{DT}(4, I) \star A L T I+D T(5, I) \star A L T 2$

$I T(I)=T T(I)+1$

$I T N U W=[T N \cap W+1$

I TCON $=$ ITNOW-MAX TFM

ITCUN=MAXO(ITCUN, 1)

$U C=D T T E \star Z K T E$

QEND $=2 K E C P C \star D T M U D(I)$

4047 CUR (I) $=0$.

[G) TU $(4047,4048,4049,4044,4050)$, NGT2

GOTTO 4046

4049 RLPC (I) $=$ KPC (I)

Gก TO 4048

$4050 R L P C(I)=R P C(I) * S Q R T(1,+V D C(I) *(Q P * V \cap C(I) * B J / R P C(I)) /(R P C(I) *(B C+$

$\{$ (QEND)) )

GO TO 4048

4044 OTE $=$ PCMULT $* V O C$ (I) - VREQ

$R L P C(I)=1.0 E 30$

IF (QTE.GT.O.) RLPC (I) = VREOネRPC (I)/OTE

4048 CUR ( 1 ) $=$ CURMOD (INDI)

IF (NGT1,GE, 3, UR, INDI,ER,1) CUR(I) =VUC(I)/(RPC (I)+RLPC (I))

$4046 V P C(I)=V D C(I)-C U R(I) \star R P C(I)$

CALCULATE ENHRGY TERMS

UTOMP $1=\operatorname{CUR}(I) *(A L P H I * \operatorname{TEMP}(4,1)-A L P C 1 * \operatorname{TEMP}(5,1)-A L P 1 \star D T(4,1))$

GTOMN $1=C U R(I) *(A L N H I \star \operatorname{TEMP}(4, I)-A L N C I * \operatorname{TEMP}(5, I)-A L N I \star D T(4, I))$

QTOMPZ $=C U R(I) *(A L P H Z \star T E M P(5, I)-A L P C Z \star \operatorname{TFMP}(6, I)-A L P Z \star U T(5, I))$ 
OTOMNZ $\Rightarrow C U R(1) *(A L N H 2 * T E M P(5, I)-A L N C 2 * T E M P(6,1)-A L N Z * D T(5,1))$

QTOM $\approx$ QTOMN1 + QTOMNZ+QTDMP 1 + QTOMPZ

IF (QTOM,GT,O.) DTOM=,5*QTOM

$Q P=C U R(I) \star Q P$

$Q J=C U R(I) * C U R(I) * Q J$

$Q T E=Q P-Q J-Q T D M-Q G A M \star C G A M$

$Q I N=Q C+Q T E$

$P E(I)=V P C(I) \star C U R(I)$

CALCULATE EFFICIENCY

QT $(I)=B I N+Q G A M$

DOUT $\cong$ DT (I) $-P E(I)$

$Z K H U T=1.0 /(1 . / Z K(1)+1 . / Z K(2)+1.1 Z K(3))$

$\angle K C O L D=1 . /(1 . / 2 K(6)+1 . / 2 K(7)+1 . / 2 K(8))$

IF (QGEN.GT,O..ANO,VREQ.GT.0..AND.DGRF.EO,O.) OIN=.5* (QGEN-DEND $1+Q I N)$

CALCULATE TEMPERATURE DROPS AND NEW RADIAL TEMP. PROFILE

$\angle K D T \triangle Q I N / O C$

ZKTEQ $=7 K T E \star Z K D T$

$\operatorname{ZKEO}(1)=Z K(1)$

$\operatorname{ZKEQ}(2)=2 K(2)$

$Z K E Q(3)=Z K(3)$

$Z K E Q(4)=Z K(4) * Z K D T$

$Z K E Q(5)=Z K(5) \star Z K D T$

$Z K O T=Q I N / Q O U T$

$Z K E Q(6)=Z K(6) * Z K D T$

$Z K E Q(7)=Z K(7) * Z K D T$

$Z K E Q(8)=Z K(8) * Z K O T$

IF $(Z K R, G T, 0,) \operatorname{TEMP}(9, I)=(Z K R * T R E J * Q O U T+Z K E C P C * T E M P(1, I)) /$

$1(Z K R+Z K E C P C)$

IF (RADC.LE.0.,OR, INDI.EQ.1.OR.NOPTIM.LT.4) GO TO 5008

5008 IF (QGEN.GT.0.) GD TO 5001

ZKDT =DTMOD $(I) /(1.0 / Z K H D T+1.0 / Z K T E Q+Q D U T /(Q I N * Z K C O L D))$

$\operatorname{DT}(1, I)=Z K D T / Z K E B(1)$

DO $5006 \quad J=2,8$

$J 1 \cdot J-1$

$\operatorname{TEMP}(J, I)=\operatorname{TEMP}(\mathrm{J} 1, I)=D T(J 1, I)$

5006 DT $(J, I)=Z K D T / Z K E Q(J)$

$T C O N(I T C O N)=A B S(1$. DSAVE/OT (I))

QSAVE $=$ QT (I)

GD TO 5007 


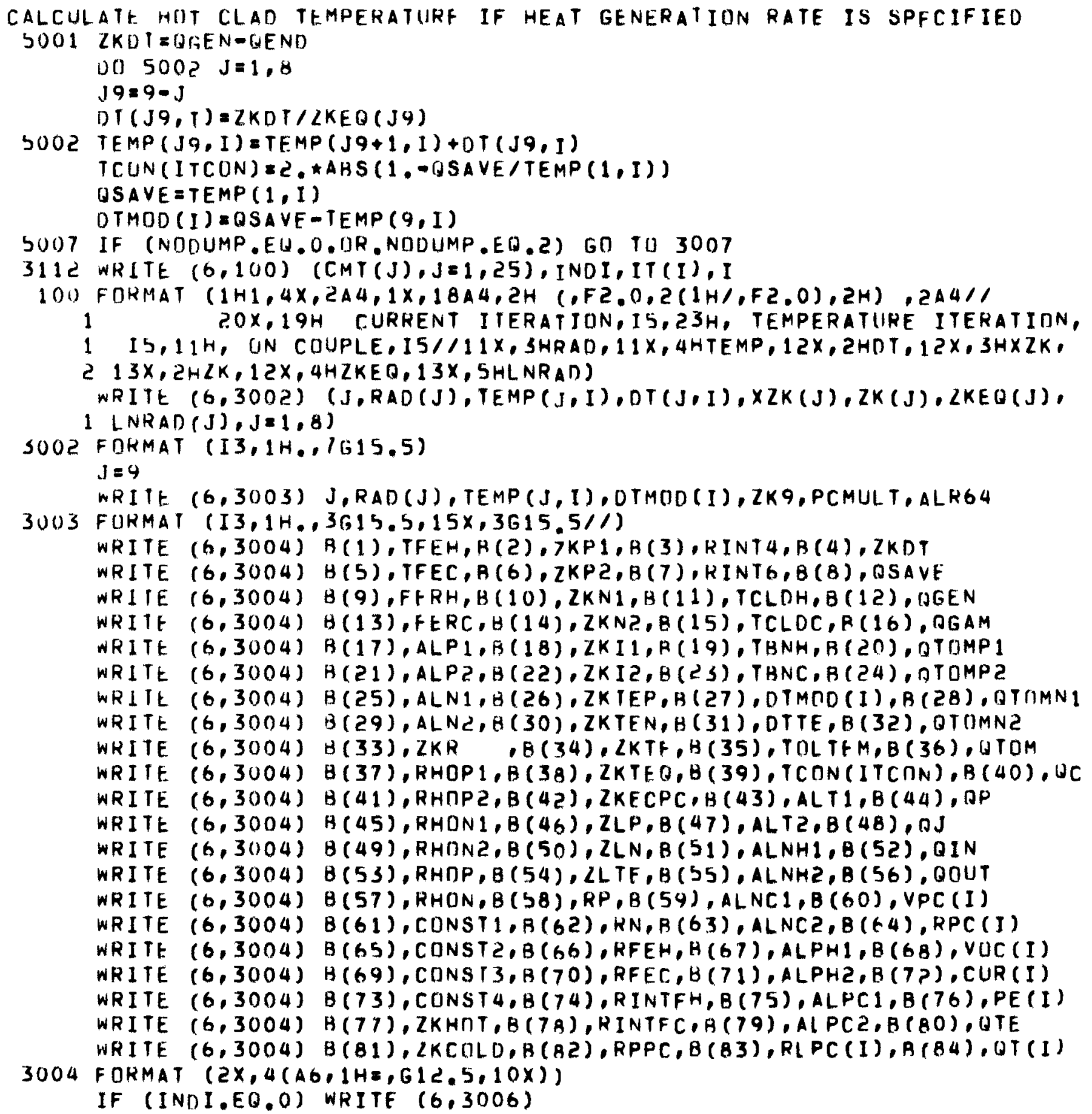



(2) Astronuclear

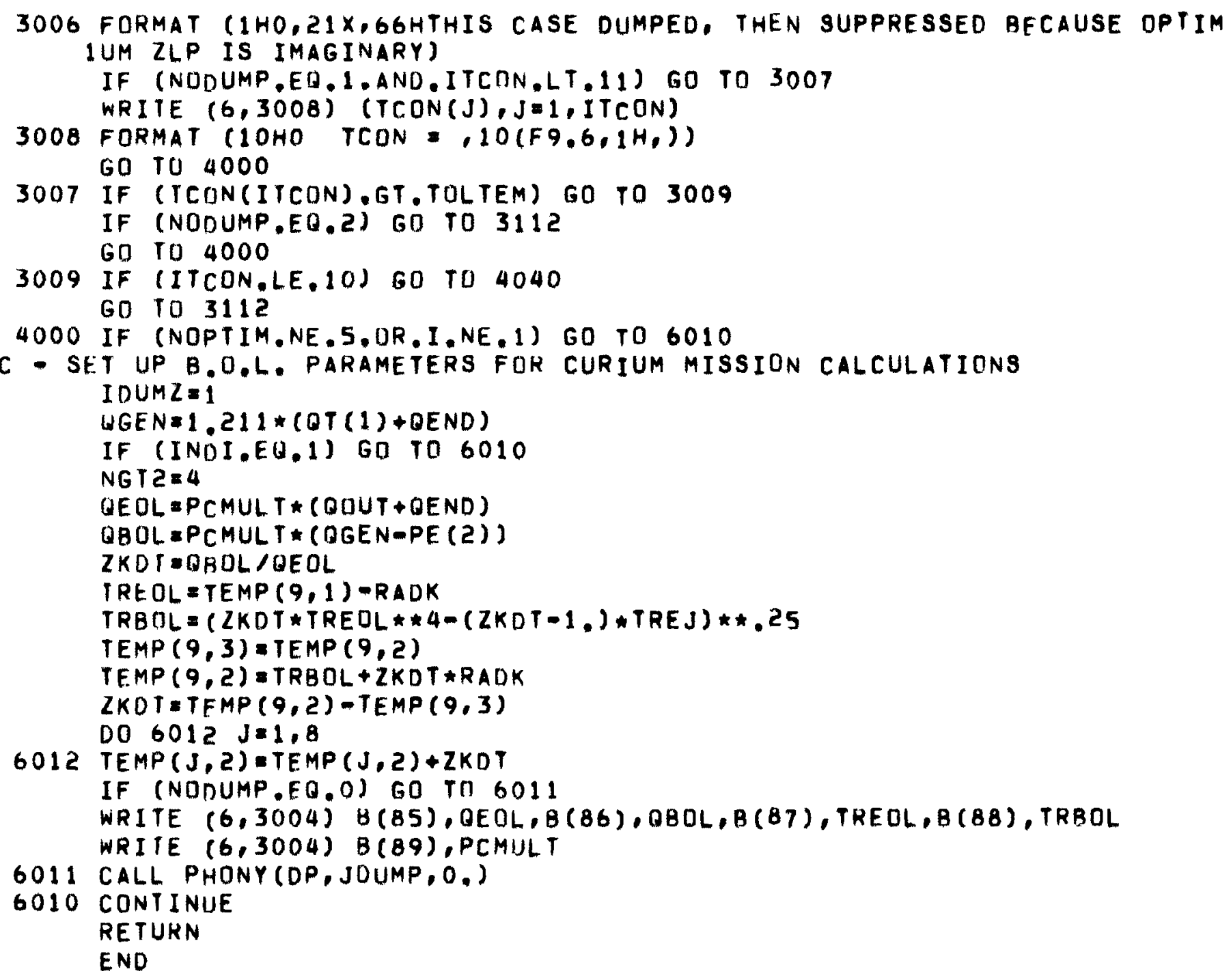


BLUCK DAIA

COMMON IDATIN/TTT(15),ZKMIC1 (15),ZKMICZ(15), ZKSS(15),ZKBN(16),

$1 \angle K I N(15), Z 2 N A(15), Z 2 N R(15), Z 2 N K(15), Z 2 P A(15), 7 Z P K(15), Z 2 P K(15)$, ZZZNRK (15),Z2PRK (15),Z3NA (15),Z3NR (15), L3NK(15),Z3NKK (15),Z3PA (13),

5 ZSPK (15),Z3PK(15),Z3PRK (15), ZKCRH(15), ZKCRC (15),RCRH (15),RCRC (15)

4. RHP (15), RPRHO

CIMMON /FOUAT/ALPHA $(15,8)$, RHO $(15,8), \operatorname{ZKUN}(16,8), 2 K S S I N(16,3)$,

1 RFETM(1ל,4), ZKFETM(16,3), ZKMICA (16)

COUMMUN /IITLE/FETM(3),CASCAD $(8,2), \operatorname{SSIN}(3), \operatorname{CMT}(25), \operatorname{COND}(3,5), T F M K F$,

$1 \operatorname{CRMU}(2,2)$, I $3 N$, I $2 N$, I 3P, I $2 P$

C IHMPERATURF AT WHICH EACH PARAMETER IS EVALUATED (DEG.K)

DATA TTT 1300..350..400..450.,500..550..600.,650..700.. $1 \quad 750 ., 800 ., 850 ., 900 . .950 .11000 .1$

C SEEBECK CHFFF ICIENT DF TEGS-3N MATERIAL (VILTS/DFG.K)

DATA AIPHA/ 8.526E-05,1.058E-04,1.254E-04,1.411E-04,1.656E-04,

? $\quad 1.803 E-04,1.960 E-04,2.097 E-04,2.205 E-04,2.254 E-04$,

$3 \quad 2.254 E-04,2,185 E-04,2.009 E-04,1.735 E-04,1.303 E-04$,

C SEERECK COEFFICIENT OF TEGS-ZN AND GE-NL MATERIAL (VDLTS/DFG.K)

$1 \quad 1.150 E-04,1.369 E-04,1.587 E-04,1.806 E-04,2.005 E-04$,

$1 \quad 2.176 E-04,2.338 E-04.2 .452 E-04,2.509 E-04.2 .490 E-04$,

$1 \quad 2.386 E-04,2.205 E-04,1.977 F-04,1.730 E-04,1.464 E-04$,

C SEEHECK COFFFICIENT OF IEGS-3P MATERIAL (VOLTS/DEG.K)

$1 \quad 5.01$ SE-05,5.807E-05,8.974E-0S.1.140E-04.1.394E-04,

$1 \quad 1.668 F=04.1 .911 E-04,2.122 E=04,2.281 E-04,2.407 E-04$,

$1 \quad 2.502 F=04,2.555 E-04,2,544 E=04,2.460 F-04,2.281 F-04$,

C SEEBECK COFFFICIENT OF TEGS-2P MATFRIAL (VDLTS/DEG.K)

$14.940 E-05.7 .980 E-05,1.102 E-04,1.387 E-04,1.748 E-04$,

$1 \quad 2.090 E-04.2 .375 E-04.2 .594 E-04,2.698 F-04,2.726 E-04$,

$1 \quad 2.708 E-04,2.660 E-04,2.594 E-04,2.508 E-04,2.394 E-04$,

C SFEBECK COEFFICIENT UF RCA-NB MATERIAL (VOLTS/DEG.K)

$1 \quad 1.030 E-04.1 .210 E-04.1 .410 E-04.1 .610 E-04.1 .820 E-04$,

$2 \quad 2.020 E-04.2 .230 E-04.2 .450 E-04.2 .600 E-04.2 .660 E-04$,

$3 \quad 2.620 E-04.2 .530 E-04.2 .430 E-04.2 .300 E-04.2 .140 E-04$,

$C$ SEEHECK CUEFFICIENT OF RCA GE-TE P-TYPE MATERIAL (VILTS/DEF.K)
1
$0.52 E-04,0,78 F-04,1.05 E-04,1.35 E-04,1.73 t-04,2,05 F-04$,

$2.38 E-04,2.66 E-04,2.83 E-04,2.98 E-04,3,11 E-04$,

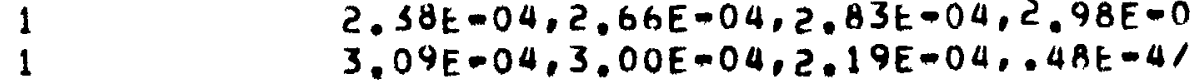

C RESISTIVITY OF TEGS-3N MATERIAL (OHM-CM)

DATA RHO, .0002628,.0003623,.0004967,.0006722,.0008992,

$1 \quad .0011785, .0015277, .0019206, .0023658, .0028198$,

1 .0032476, .0035880,.0037714,.0037452,.0036142,

C RESISTIVITY UF TEGS-ZN AND GE-NL MATERIAL (OHM-CM)

1 .0004132,.0005932,.0008393,.001170?,.0015737, 
(2) Astronuclear Laboratory

1

1

C RESISTIVITY OF

1

C RESISTIVITY OF
1
1

C RESISTIVITY

C RESISTIVITY

1
$.0020822, .0026552, .0032685, .0038738, .0043984$,
$.0046728, .0047615, .0046082, .0042209, .0037124$, TEGS-3P MATERIAL (OHM-CM)

$.0009940, .0010799, .0012395, .0014972, .0018408$, $.0022090, .0026753, .0031539, .0036939, .0043811$, $.0051542, .0057310, .0061360, .0063814, .0064428$, TEGS-2P MATERIAL (OHM-CM)

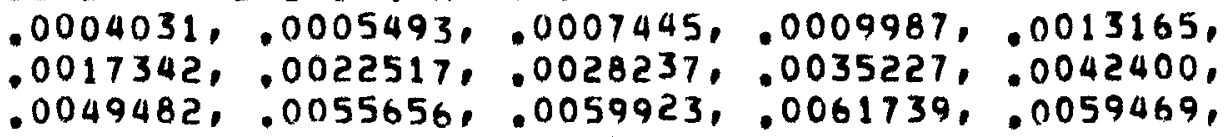

ISTIVITY OF RCA-NB MATERIAL (OHM-CM.)

4.750E-04,6.300E-04,8.250E-04,1.070E-03.1.390E-03,

$1.820 E-03,2,360 E-03,3,040 E-03,3,800 E-03,4.570 E-03$,

$5,300 E-03,6.000 E-03,6.450 E=03,6.800 E-03,6.750 E-03$,

ITY OF RCA GE-TE P-TYPE MATERIAL (OHM*CM)

1

$3.7 E-04,4,8 E-04,6,8 E-04,9.7 E-04,13.8 E-04,19.4 E-04$,

$25,5 E-04,32.8 E-04,40,5 E-04,48,5 E-04,58.0 E=04,67.0 E=04$,

$77.5 E-04,86,0 E-04,98,0 E-041$

C THERMAL CONDUCTIVITY OF TEGS-3N MATERIAL (WATTS/CM./DEG.K)

DATA ZKON, .0428220,.0375516,.0332035,.0289872,.0250344,

$1 \quad .0213451, .0181829, .0262065, .0148889, .0150206$,

1 .0162065,.0176558,.0191052,.0210816,.023058,.298,

C THERMAL CONDUCTIVITY DF TEGS-ZN AND GE-NL MATERIAL (WATTS/CM/DEG.K)

$1 \quad .0286942, .0244433, .0208299, .0180668, .0157287$,

$1 \quad .0139220, .0127530, .0122216, .0128593, .0141346$.

$1 \quad .0159412, .0178542, .0204048, .0233805, .0260374, .298$,

C THERMAL CONDUCIIVITY OF TEGS-3P MATERIAL (WATTS/CM./DEG.K)

$\begin{array}{lll}1 & .0375000, .0305000, .0246000, .0199000, .0160000, \\ 1 & .0130000, .0114000, .0110000, .0112000, .0119000,\end{array}$

C THERMAL CONDUCTIVITY DF TEGS-ZP MATERIAL (WATTS/CM./DEG.K)

$1 \quad .0428878, .0348821, .0281344, .0227591, .0182988$,

$1 \quad .0148678, .0130379, .0125804, .0128092, .0136097$,

$1 \quad .0154396, .0189850, .0235597, .0303074, .0400286, .298$,

C THERMAL CONDUCTIVITY OF RCA-N (A) MATERIAL (WATTS/CM./DEG.K)

$1.0200, .0179, .0161, .0143, .0127, .0111, .0101, .00971, .00974 .00101$,

$2.0106, .0113, .0122, .0133, .0147, .296$.

C THERMAL CONDUCTIVITY OF RCA-P(A) MATERIAL (WATTS/CM,/DEG,K)

$1.0345, .0270, .0222, .0189, .0156, .0135, .0118, .0108, .0103, .0103$,

$2.0109, .0128, .0181, .0303, .0653, .2981$

C THERMAL CONDUCTIVITY OF BORON NITRIDE (WATT/CM/DEG,K)

DATA ZKBN $1.303, .301, .299, .296, .294, .291, .289, .286, .284$

$1 \quad, .282, .279, .277, .274, .272, .270, .081 /$

C THERMAL CONDUCTIVITY OF IRON (WATT/CM/DEG,K) 
DATA ZKFETM $\quad 1.725, .696, .664, .635, .608, .574, .540, .510, .479$

$1 \quad . .449, .420, .390, .360 . .335, .313, .280$,

C THERMAL CINDUCTIVITY OF TUNGSTEN (WATT/CM/DEG.K) - TPRC DATA

$2 \quad 1.78,1.70 .1 .62,1.56,1.51 .1 .46,1.41 .1 .31 .1 .34$

$3 \quad, 1.31,1.29,1.26,1.24,1.22,1.20, .700$,

C THEKMAL CUNDUCTIVITY IF MOLYBDENUM (WATT/CM/DEG,K) - TPRC DATA

$4 \quad 1.37 .1 .35 .1 .33 .1 .31 .1 .30 .1 .27 .1 .26 .1 .24 .1 .22$

$5 \quad, 1.20,1.19,1.17,1.15,1.14,1.13, .3681$

C RESISTIVITY OF IRUN (OHM\#CM)

DATA RFETM /1.15E-5,1.40E-5.1.73E-5,2.08E-5,2.52E-5,

$1 \quad 2.97 F-5,3,52 F-5,4.12 E-5,4,88 E-5,5,60 E-5,6,34 E-5,7,10 E-5$,

? $7.91 E-5,8.80 E-5,9.82 E-5$,

C RFSISTIVITY OF TUNGSTEN (OHM\#CM)

TPRC DATA

$5 \quad 5.00 E-6,6,25 E-6,7,50 E-6,8,70 E-6,1.00 E-5,1.12 F-5,1.25 E-5,1,38$

$4 \quad E-5,1.53 E-5,1.67 E-5,1.82 E-5,1,98 F-5,2,15 E-5,2,29 E-5,2.43 E-3$,

C RESISTIVITY IJF MOLYBDENUM (DHM*CM) TPRC DATA

$5 \quad 5.50 E-6,6,50 E-6,7.50 E-6,8,50 E-6,9.50 E-6,1.04 E-5,1.13 E-5,1.25$

$6 \quad E-5,1.37 E-5,1.47 E-5,1.58 E-5,1.69 E-5,1.80 E-5,1.90 E-5,2.00 E-5$,

C RESISIIVITY UF NICKEL (OHM*CM)

$7 \quad .000011, .000013, .000015, .0000173, .0000198 .000002261 .0000257$.

$8.000029, .0000319, .0000346, .000037, .0000592, .000041, .0000427$.

$9.000044 \%$

C IHERMAL CONDUCTIVITY TF STAINLESS STEEL (WAIT/CM/DEG.K)

UATA IKSSIN $1.145, .157, .165, .172, .179, .184, .192, .198, .205$

$1 \quad . .212, .219, .225, .232, .259, .246, .285$,

C THERMAL CONDUCTIVITY OF INCONNEL (WATT/CM/OEG,K)

$3 \quad .117, .126, .135, .143, .152, .161, .170, .179, .188$

$1 \quad . .197, .203, .215, .223, .230, .240, .296$,

C THERMAL COADUCTIVITY OF T-111 (TPRC PURDUE UNIV.)

$1.018 . .431 .0439 . .452 . .464 . .481, .490 . .502, .5150 .527, .540 . .552$,

$2 \quad .565 . .577, .586 . .600 \%$

C THEKMAL COHDUCTIVITY OF MICA (WAIT/CM/OEG,K)

DATA ZKMICA $, .0290, .0310, .0330,00342, .0336, .0306, .0282, .0268, .0262$

$1, .0262, .0268, .0268, .0268, .0268, .0268 . .1051$

DATA CASCAD/4HTEGS, 4H GE, $2 \star 4 H T E G S, 2 \star 4 H K C A-, 2 \star 1 H, 4 H \quad 3 \mathrm{~N}, 4 H \mathrm{NL}$,

$14 H$ 3P, 4H 2P, 4H N, 4H P, 2 1H/,COND/4HOPEN,4H CIR,4HCUIT,

$24 H$ FIX, 4HED L, 4HOAD, 4HMATC, 4HHED, 4HLUAD, 4HFIXE, UHD V-, 4HLDAD,

3 4HOPTI, 4HMUM, $4 \mathrm{HL}$ OAO/, FETM/2HFE, IHW, ZHMO/, SSIN/2HSS, 2HIN, ZHTA/.

$4 \mathrm{CMI/25 \star 4H \star \star \star \star //CRMD/4H} \mathrm{CIR,} \mathrm{4HCUIT,} \mathrm{4H} \mathrm{MOD,} \mathrm{4HULE} \mathrm{/}$

END 
We Astronuclear

SUBROUTINE DPTIM(ISECT,IRTRN)

DIMENSIUN VPL $(4,5), O M H D(4), \operatorname{DRCP}(2,2), P D W T(2,4), \operatorname{VLL} 1(3), P W C T(4)$

1 , VRL (5),DRCPI(2), SKP(12)

COMMON /MODOPT/IPDWT, DR4, DRINCR, IRITE, DRTE, JOPTIM, IZ9, IENOK, IPUN,

1 RIINC, RUINC, RIMAX, R9MAX, DIMIN, QREQ, THINC, TCINC, TCMAX, THMAX

2, NPERT, ZNPERT, CKFP, CKFT, CTEOC,CTEIC, DEL TL, RLPERT, RLMAX, ZNMIN, Z9SAV COMMON /TITLE/FETM(3), CASCAD $(B, 2), \operatorname{SSIN}(3), \operatorname{CMT}(25), \operatorname{COND}(3,5), \operatorname{TEMKF,}$

1 CKMO $(2,2), I 3 N, I 2 N, I 3 P, I 2 P$

COMMON IMDCPOP/RAD (9), DR (8), TEMP(9,300), VOC (300),RPC (300),PE(300),

1 OT (300), NOPTIM, VPC (300), RLPC $(300)$, DTMOD (300), CUR (300), LNRAD (9),

2 ZLP, ZLN, ZLI, ZLNLP, ZLPNI, ZLTE, NGT1, NGT2, ITPERT, PCMULT, NQDUMP, IVD,

3 QGEN, QGENL, QTE, QDUT, ZID, ZOD, ZKEND, ZK9, LKR, RPPC, RPN, TOLTEM, TREJ,

$4 V R E Q, P E R E Q, Z L R E Q, W T C O N, Z L P N, I D U M Z$, RN, DGRF, DGTRF, DGLRF, RADK, JDUMP,

5 DP $(30), N C$

DATA VPL/4H V, $4 H D C, 4 H$ (VD, 4HLTS), 4H CUR, 4HRENT, 4H (AM, 4HPS),

$14 H C K T, 4 H L E N$, 4H (I, 4HN.), 4H RL, 4HOAD, 4H (OH, 4HMS), 4H RL,

2 4HUAD, 4H(M-D, 4HHMS)/,POWT/4HPDEN, 4HW/CC, 4H WT, 4HLBS, $4 \mathrm{HH}$ CUR, 4HA

3MPS, 4H TS , 4HDEG,/,OMHU/SH M-, IH, IHC,1HH/,DRCP/AH DR5, 4HDRTE,

4 4H ND. $4 H C P L S /, S K P / 1 H, 1 H O, 8 * 1 H, 1 H \star 1 H * /$

ERUIVALENCE (VPLI $(1)$, nCV), (VPLI (3),ZCIR)

REAL LNRAD

IF (ISECT.EQ.Z) GO TO 3051

C - INITIALIZE VARIABLES USED IN OPTIMZATION ROUTINE

IRTRN 1

IF (JOPTIM.NE. O) GO TO 4014

JOPTIM $=1$

IPERT $=0$

PCPERT =NPERT

PCSAVIPCMULT

RLOAD $=P C M U L T * R L P C(1)$

IR I TE $=4$

C IVDE1, TEMPERATURE PARAMETRIC WITH SPECIFIED GEOMETRY

C IVD=2, TEMPERATURE PARAMETRIC WITH SPECIFIED LENGTH AND VOLTAGE

C IVD=3, TEMP. PARAMETRIC WITH SPECIFIED LENGTH AND NO. OF COUPLES

C IVD=4, PARAMETRIC ON NO, COUPLES WITH SPECIFIED VLOAD AND LENGTH

C IVD=5, PARAMETRIC ON NO, COUPLES WITH SPECIFIED VLOAD AND POWER

RLOM 1000 .

$I D R C P=?$

I PDWT $=1$

ISKPA2

ZCIR EPCMULT *ZLTE

C - INITIALIZE PARAMETERS FOR CURIUM STUDY CALCULATIUNS NOPZ $=$ NOPT IM/Z 


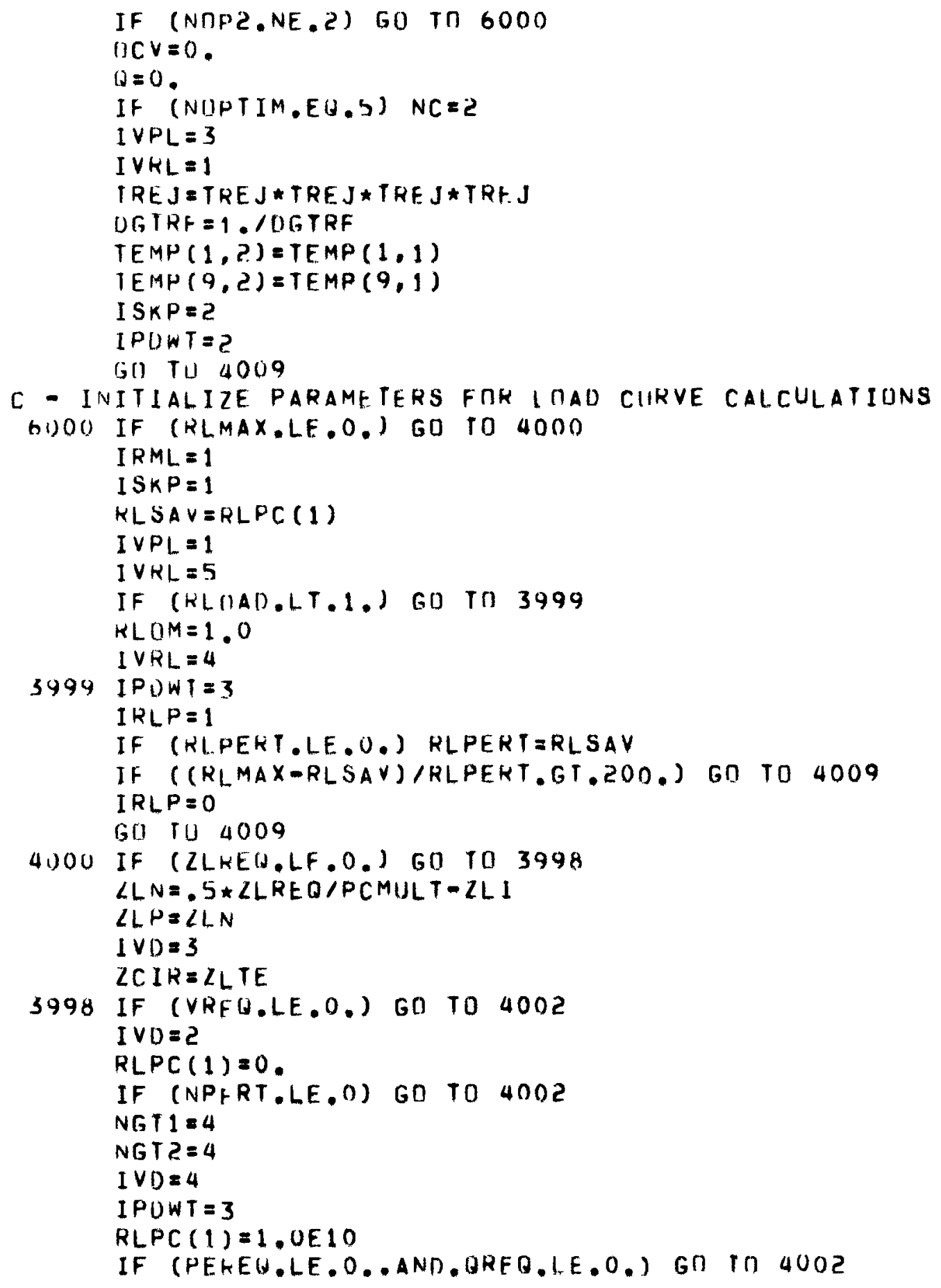




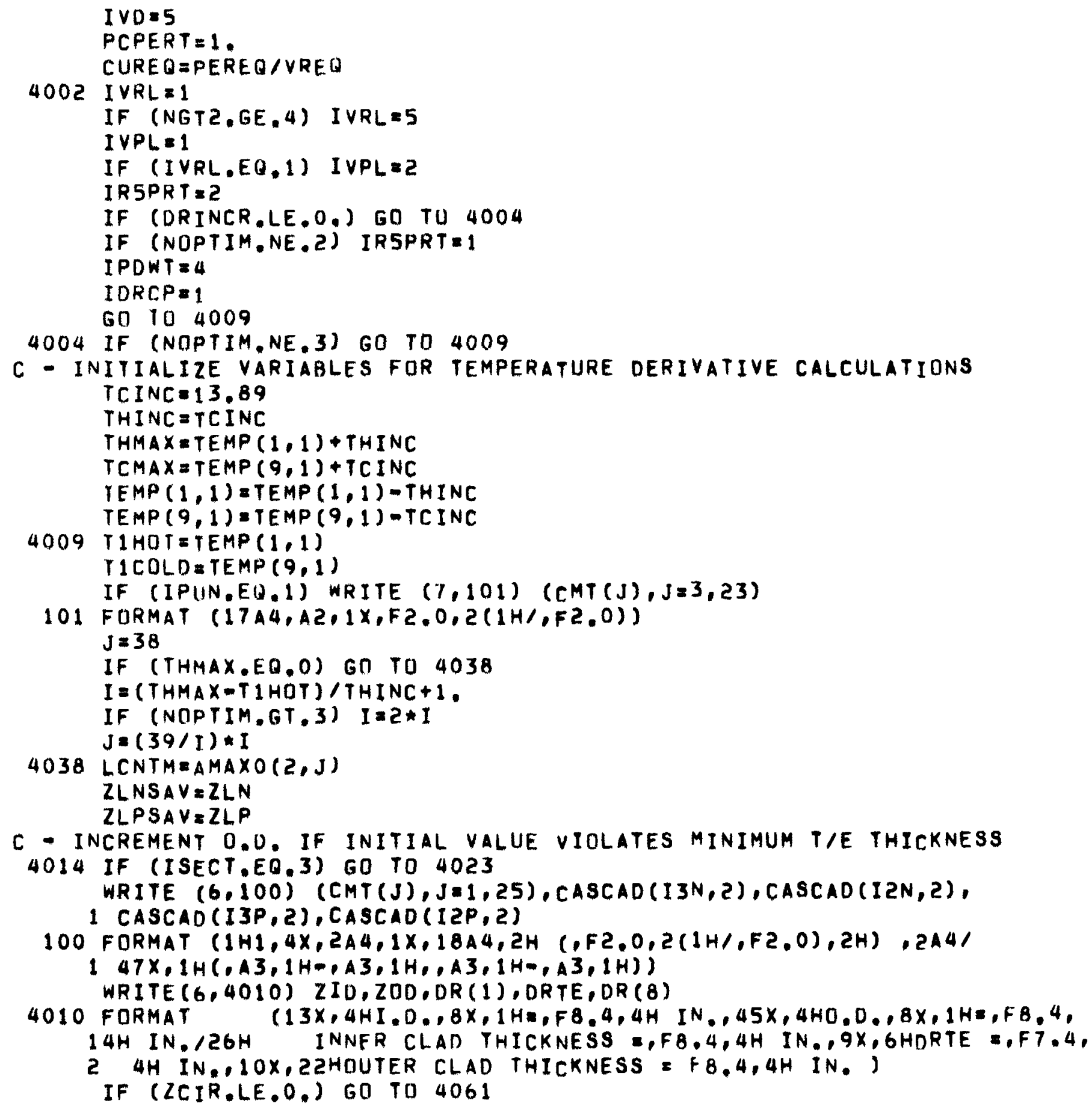


$Z L P N I=Z L P+Z L N+Z L I$

$W T=W A T E(P)$

$J=1$

IF (WTCON,GT,O.) J $\mathrm{J}=2$

IF (NGT2,NE, Z, UR,RLPERT,GT.0.) GO TO 4040

$1=2$

IF (RLIIAU.GE.1,) GO TU 4045

$R L U A D=1000 * R L O A D$

$I=1$

4U4S WRITE $(6,4041)$ ZCIR,RLOIAD, OIMHD (I),CRMD $(1, J), C R M D(2, J), W T$

4041 FORMAT (10X,16HCIRCUIT I.ENGTH =,F8,3,4H IN, ,6X,7HRLMAD $=, F 9,3$,

1 A3,4HחHMS, $11 X, 2 A 4,9 H$ WEIGHT $=, F 8,3,5 H$ LBS.)

(B) TH 4042

4040 WRITE $(6,4043) \quad \angle C I R,(C O N D(I, N G T 2), I=1,3), C R M D(1, J), C R M D(2, J), W T$

4043 FUKMAT (10X,16HCIRCUIT LENGTH =,FB,4,4H IN, $11 \times, 3 A 4,18 \times, 2 A 4$,

$19 H$ NFIGHT $=$, FB.3, SH LAS, )

GOI TO 4042

4061 IVPL $=3$

WRITE $(6,4063) \quad(C \cap N D(I, N G T 2), I=1,3)$

$4 U G 3$ F TRMAT $(49 \times, 3 A 4)$

4042 WRIIF $(6,4044)$ DRCP(1, IDRCP), (VPL (I,IVPL),I=1,2), (VPL (I,IVRL),

I I $=1,2),($ CKMD $(1$, IENDK), I $=1,2), P D W T(1, I P O W T)$, TEMKF, TFMKF,ORCP( 2 ,

? IDRCP), (VPL (I, IVPL),I=3,4), (VPL (I,IVRL),I =3,4), PDWT ( 2, IPDWT)

4044 FORMAT (17HO THOT TCMLD, 4X,A4,14H ZLN ZLP, 4X, 2A4,2X,

1 2A4, 4X,3OHRGEN VLOAD P-OUT $Q, A 4,5 X, 3 H E T A, A 2,6 X, A 4 /$

2 2(7H (DEG,.A1,1H)),3X,A4,18H (IN,) (IN.) , 2A4,2X,2A4,

$354 \mathrm{H}(\mathrm{M}-\mathrm{OHMS})$ (VOLTS) (WATTS) (WATTS) (PCT,) (,A4,IH))

LCNT $=0$

$I Z L P=1$

I THINC $=1$

IT T INC $=0$

T TAMAX $=0$.

REIURN

3051 IF (NDP2.NE.Z) GOT TO 6001

ITPERT $=2$

C - ITERATE ON NU. OF COUPLES AND ZI.N FOR CURIUM MISSION CALCULATIONS

IDUM $L=2$

NGT T2 $=5$

$\operatorname{QGEN}=0$.

IRTRN=?

$P=P C M U L T * P E(1)$

$V L D=P C M U L T * V P C(1)$

IF $((A R S(1,-O C V / V L D)+A B S(1,-13 / P)), L T \ldots 01, U R, I P E R T, G T, 10)$ GOTO 4001 IPER $\mathrm{T}=\mathrm{I} P E R T+1$ 


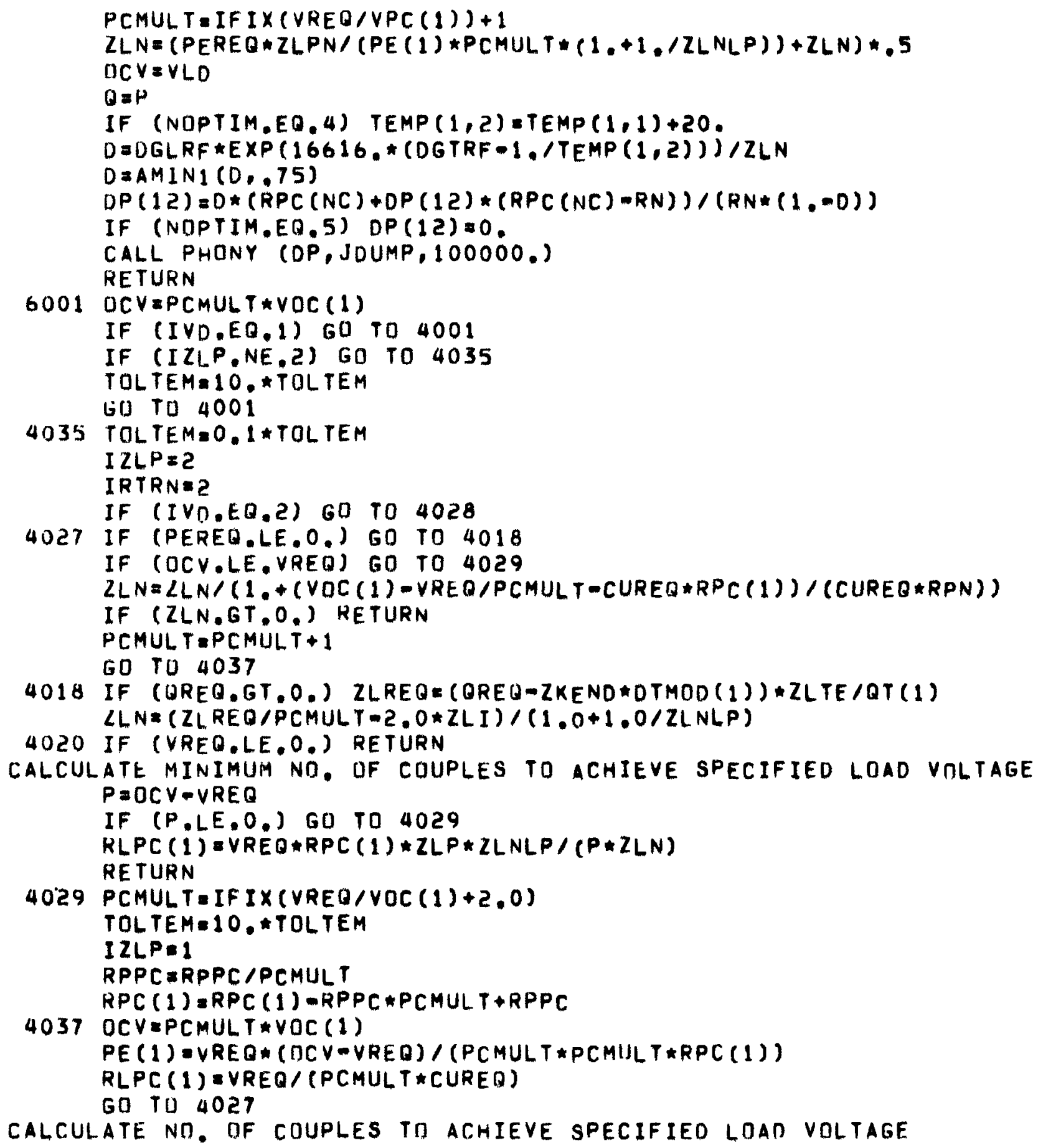




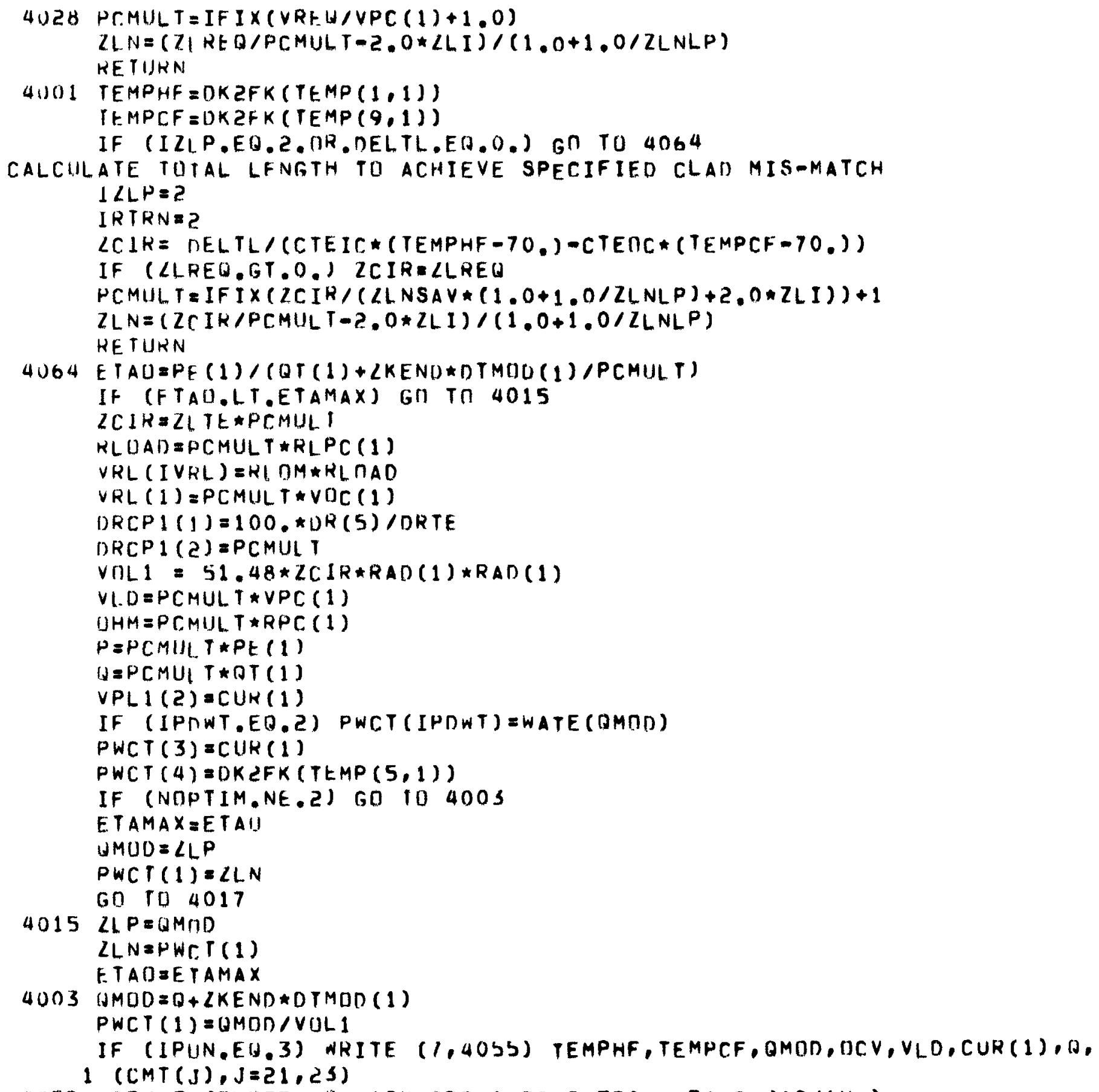


IF (IPUN,EQ,1) WRITE $(7,4050)$ ZID, ZOD, TEMPHF, TEMPCF, ZCIR, VLD, OHM, 1 ETAO,P

4050 FDRMAT $(1 \times, 2 F 7,3,2 F 7,1,5 E 10,3)$

IF (NOPTIM.NE.3) GO TO 4031

JOPT IM $=$ JOPT IM+1

$V O C(J O P T I M)=O C V /(D T M O D(1) \star C K F T)$

$R P C(J O P T I M)=O M M$

OT ( JOPTIM) $=$ DTMOD $(1) * C K F T / O M O D$

4031 LCNT $=L C N T+I S K P$

IF (LCNT.LE.LCNTM) 60 TO 4033

WRITE $(6,100)$ (CMT $(J), J=1,25), C A S C A D(I 3 N, 2), C A S C A D(I 2 N, 2)$,

1 CASCAD $(13 P, 2), C A S C A D(I 2 P, 2)$

WRIIE $(6,4010)$ ZID,ZOD,DR(1),ORTE,DR(8)

IF (RLMAD.LT.1.) GO TD 4034

$R L Q M=1.0$

$I Y R L=4$

VRL $(4) \equiv R L O A D$

4034 WRITE $(6,4044)$ DRCP $(1, I D R C P),(V P L(I, I V P L), I=1,2),(V P L(I, I V R L)$,

$1 I=1,2),($ CRMD $(1, I E N D K), I=1,2), P D W T(1, I P D W T), T E M K F, T E M K F, O R C P(2$,

2 IDRCP), (VPL (I,IVPL),I=3,4), (VPL $(I, I V R L), I=3,4), P D W T(2, I P D W T)$

PCPERT $=2,0 * P C P E R T$

4033 WRITE (6,4011) SKP(ISKP), TEMPHF, TEMPCF, DRCPI (IDRCP), ZLN,ZLP,

1 VPLI (IVPL), VRL (IVRL), OHM, VLD,P, QMDD,ETAD,PWCT (IPDWT)

4011 FORMAT (A1,F7,1,F9.1,F7,0,2F8,4,2F10,3,3PF10,3,2 (OPF10,3),

1 F $10.1,2 P F 10.4,0 P F 10.3)$

LCNT:2

GO TO $(6005,4016,4025,6006,6002)$, NOPTIM

C - WRITE B.O.L. PARAMETERS FOR CURIUM MISSION CALCULATIONS

6U02 WRITE (7,4050) ZID,ZOD, TEMPHF, TEMPCF, ZCIR, VLD,PWCT (2),FTAO,P

TEMPHF $=$ DK2FK $(T E M P(1,2))$

TEMPCF $=D K 2 F K(T E M P(9,2))$

$O C V=P C M U L T * V O C(2)$

$U H M=1000 * P C M U L T * R P C(2)$

$V L D=P C M U L T \star V P C(2)$

$P=P C M U L T \backsim P E(2)$

QMOD \#PCMULT*QT (2) + ZKEND*DTMOD (2)

ETAO $=P / Q M O D$

$Q=Q M O D / V O L 1$

WRITE (6,6003) SKP(IPERT), TEMPHF, TEMPCF, D,0,PWCT(2), DCV, OHM,VLD, 1 P,OMDD,ETAQ, IPERT

6003 FORMAT $(1 X, A 1, F 11,1, F 9,1,2 P F 6,1,0 P F B, 2, F 9,2, F 10,3, F 9,1, F 10,2$,

6 F $10,1, F 11,1,2 P F 9,3,16)$

LCNT $=L C N T+1$

CALL PHDNY (DP, JDUMP, 100000.$)$ 


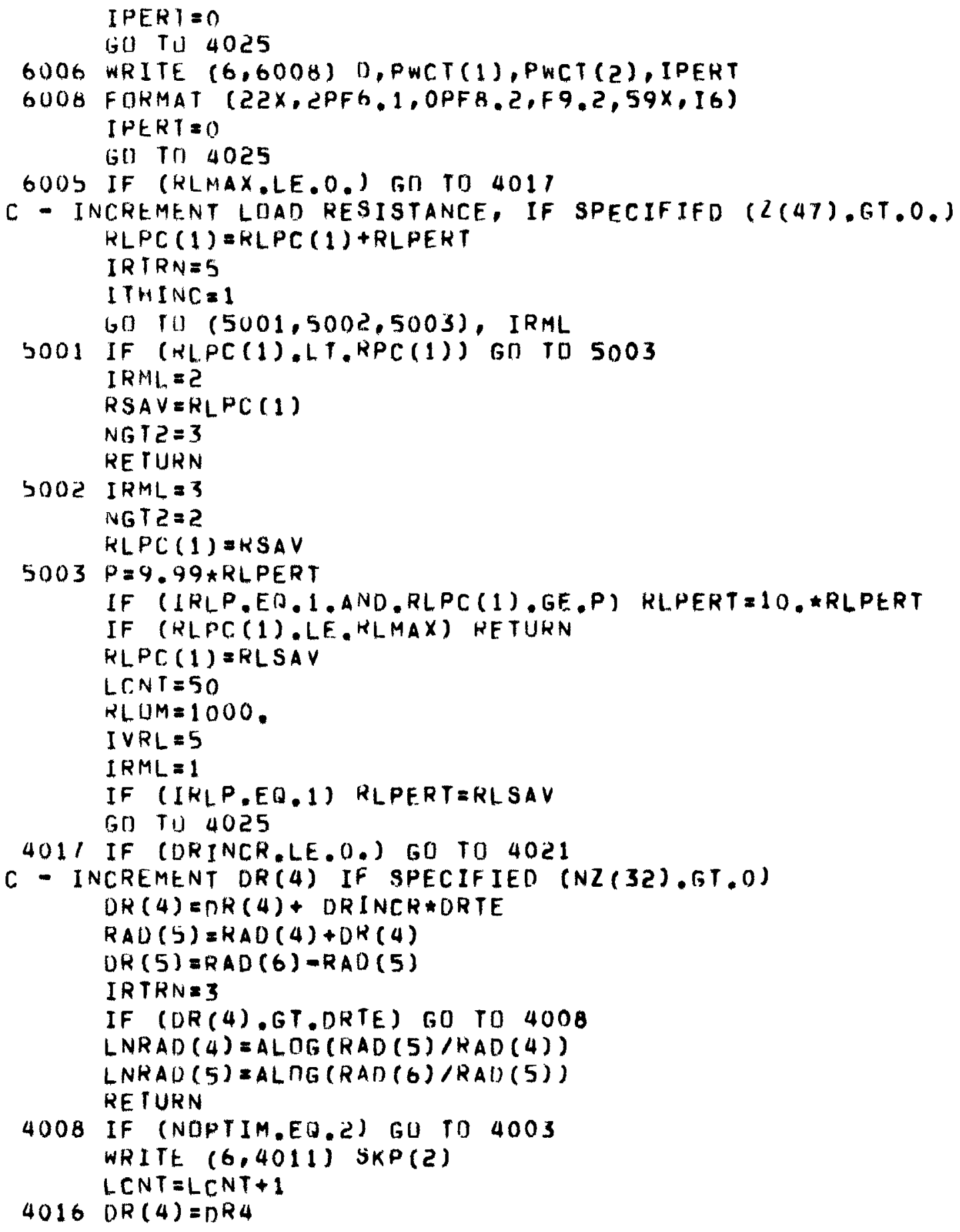




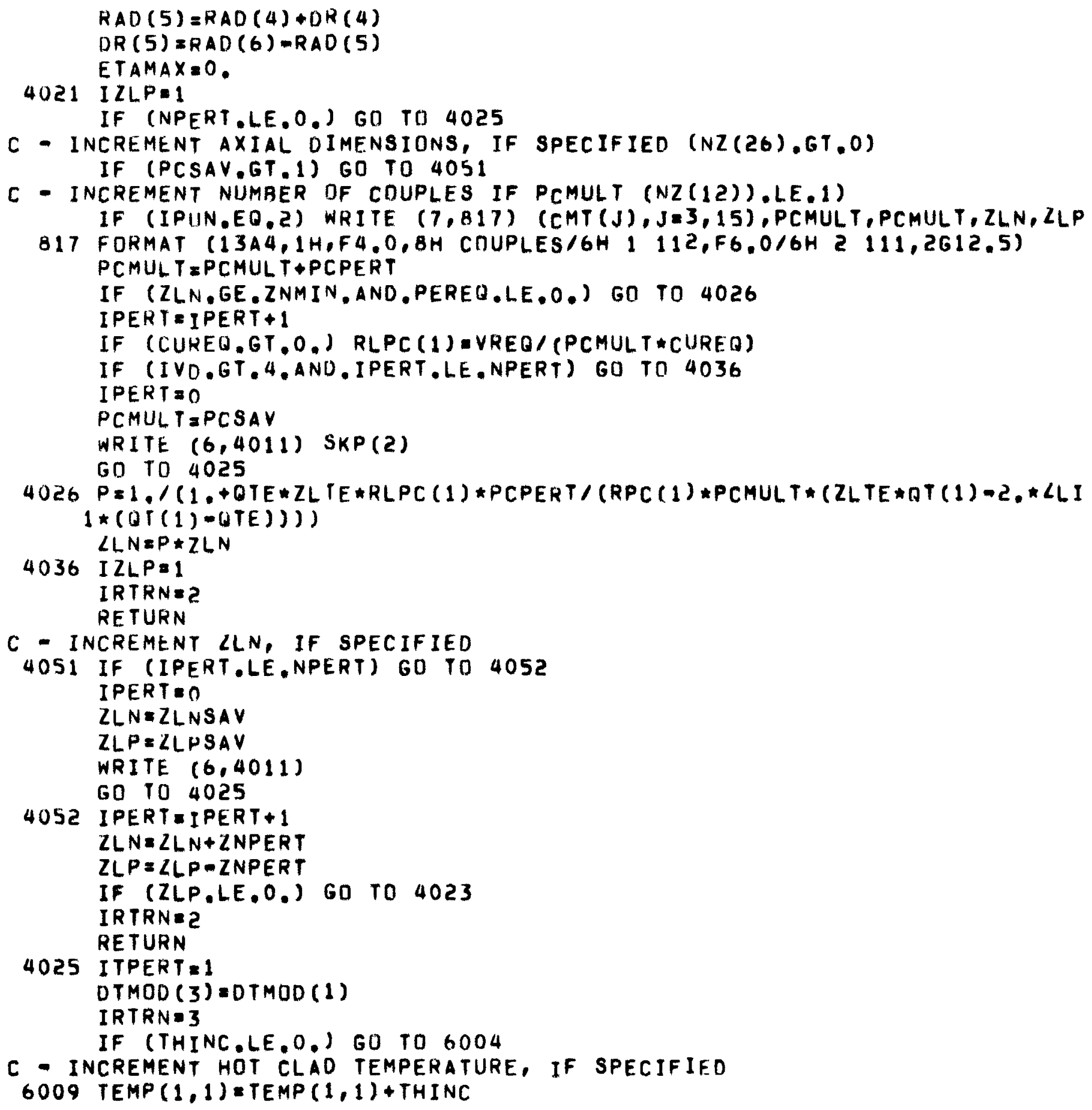




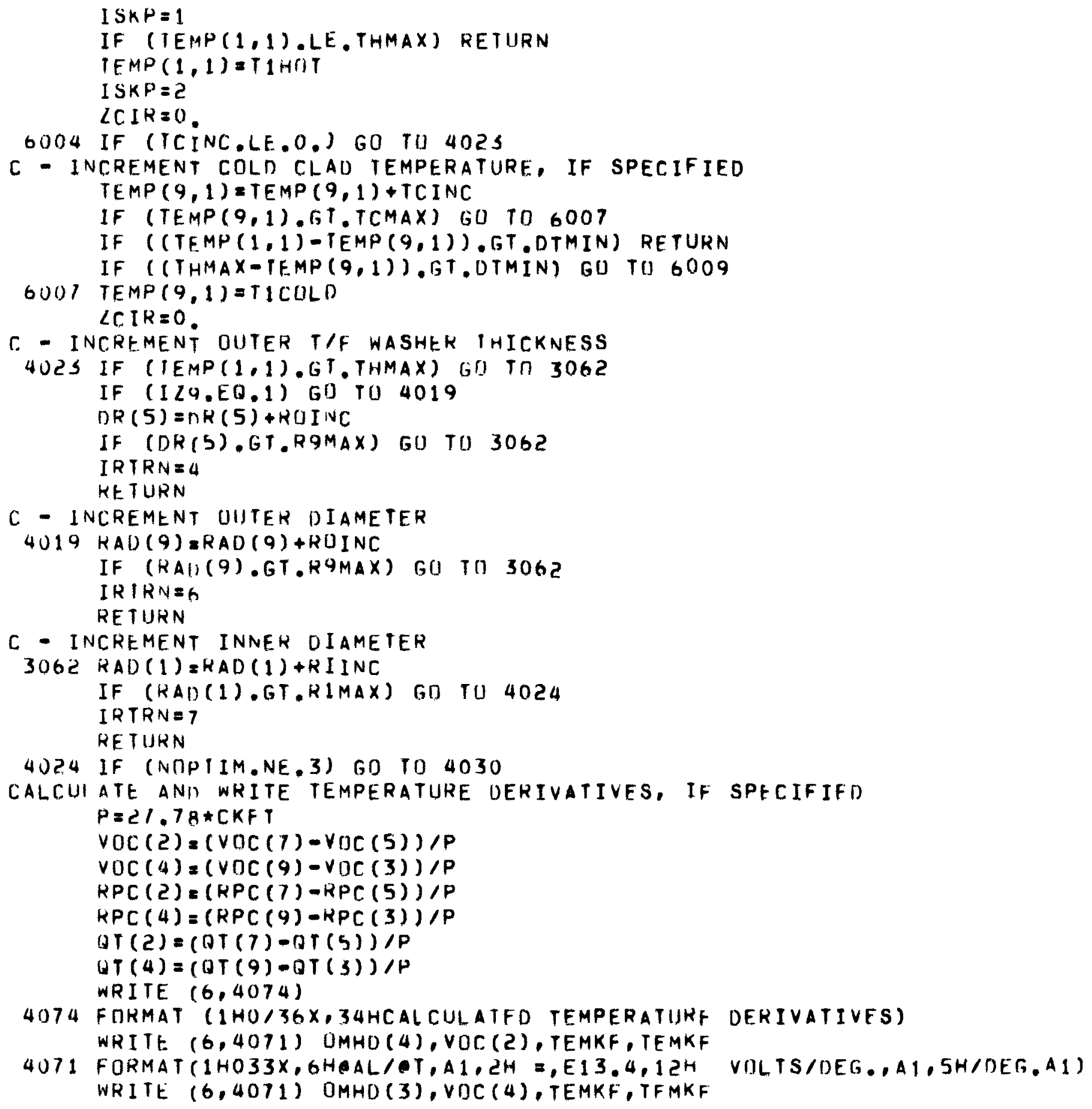




\section{(W. Astronuclear}

WRITE $(6,4072)$ OMHD (4),RPC (2), TEMKF

4072 FORMAT (1HO33X,6HARG/OT,A1,2H ,E13.4,11H OHMS/DEG.AA1) WRITE $(6,4072)$ OMHD (3), RPC (4), TEMKF

WRITE $(6,4073)$ OMHD (4), QT (2), TEMKF, TEMKF

4073 FORMAT (1HO33X,6HOTI/ET,A1, 2H =,E13,4,6H DEG.,A1,1OH/WATT/DEG.,A1) WRITE (6,4073) DMHD (3), QT (4), TEMKF, TEMKF

$\operatorname{TEMP}(1,1)=\operatorname{TEMP}(1,1)+\operatorname{THINC}$

$\operatorname{TEMP}(9,1)=\operatorname{TEMP}(9,1)+\operatorname{TCINC}$

4030 IRTRN $=1$

RETUKN

END 
SUBRUUTINE LIFE (DP)

CUMMON /MDCPOP/RAD (9), DR (8), TEMP( 9,300$), V O C(300), R P C(300), P E(300)$,

1 OT (300), NDPTIM, VPC (300), KLPC (300), DTMOD (300), CUR(300), LNRAD (9),

2 ZLP, ZLN, LLI, ZLNLP, ZLPNI, ZLTE, NGTI, NGT?, ITPERT, PCMUI T, NODUMP, IVU,

3 UGEN, QGENL, QTE, DOUT, ZID, LDD, LKEND, ZK9, LKR, RPPC, RPN, TOL TEM, TKEJ,

4 VREQ, PEKEO, ZLREQ, WTCON, LLPN, IDUMZ, RN, DGRF, DGTRF, DGLRF, RADK, JDUMP,

$5 D P(30), N C$

COMMON /MODCPL/CURMOD (15), IT (300), DTTE,CUNRN, CONRP, ZLIP, ZNC,

1 ALR64, MAXTEM, QGAM, CGOM, INOI, RINT4, RINT6, RCON4, RCONG, CIFEH, CIFEC,

2 CONST 1, CONST2, CONST 3, CDNST 4, CONSTS, NRSOPT, SEGTE, ICRMDL, RAUC

COMMIJN /MODOPT/IPDWT, DRA, DRINCR, IRITE, DRTE, JOPTIM, IZ9, IENDK, IPUN,

1 RIINC, RUINC, RIMAX, R9MAX, DIMIN, DREQ, THINC, TCINC, TCMAX, THMAX

2, NPERT, ZNPERT, CKFP, CKFT, C TEOC, CTEIC, DEL TL, RLPERT, RLMAX, ZNMIN, Z9SAV CUMMUN /TITLE/FETM(3), CASCAD $(B, 2), \operatorname{SSIN}(3), \operatorname{CMT}(25), \operatorname{COND}(3,5)$, TEMKF,

1 CRMD $(2,2), I 3 N, I 2 N, I 3 P, I 2 P$

CUMMON /MDLIF/HRS, HRINC, HRMAX, HFLF, RADPCT, ITCR, ITHO

DIMENSIINN CIRMUO(Z)

DATA CIRMOD/AHCIR, AHMUD,

QEPC $=Z K E N D * D T M D D(1) / P C M U L T$

IF (JOPTIM.NE.O) GO TO 110

$J O P T I M=1$

$1 H S A V=T E M P(1,1)$

$\operatorname{TCSAV}=\operatorname{TEMP}(9,1)$

WRITE $(6,100) \quad($ CMT $(J), J=1,25)$

100 FIIRMAT (1H1,4X,2A4,1X,18A4,2H $(, F 2,0,2(1 \mathrm{H} /, F 2,0), 2 H), 2 A 4)$

WRITE (6,101) CIRMUD (IENDK), CIRMOD (IENDK), TEMKF, TEMKF

101 FOKMAT (//9?הD

1 VIC VLUAD

TIME THOT TCOLD RLOAD

RGEN

$29 \times$, SHHUURS, $2(8 H$

$39 \mathrm{H}$ AMPS, $2(9 \mathrm{H}$

CURRENT POWER

B-, A4,7H ETA-,A1/

DEG.,A1), 2(9H

$M-D H M S), 2(9 H \quad V D L T S)$,

$\triangle B O L=0$. WATTS), $9 \mathrm{H}$ P(T./)

IF (ITHQ,EQ, 1.AND.HFLF,EQ.0.) GO TO 102

QBUL $=O T(1)+O E P C$

UGEN $=Q B Q L$

102 IF (ITCR, NE, 1) $2 K R=(Q D U T+Q E P C) /(T E M P(9,1)-T R E J)$

110 TEMPHF $=D K 2 F K(\operatorname{TEMP}(1,1))$

$\operatorname{TEMPCF}=\operatorname{DK} 2 F K(\operatorname{TEMP}(9,1))$

RLUAD $=P C M U L T \star R L P C$ (1)

$U H M=P C M U L T * R P C(1)$

$C \equiv C U K(1)$

$O C V \equiv P C M U L T * V O C(1)$

$V L D=P C M U L T * V P C(1)$

$P=P C M U L T \star P E(1)$ 
$Q=P C M U L T *(Q T(1)+Q E P C)$

$E=P / Q$

WRITE (6,111) HRS, TEMPHF, TEMPCF,RLDAD,OHM, OCV, VLD,CUR(1),P,Q,E 1 IT (1)

111 FORMAT (1X,F13,0,2F9.1,3P2F9.3,0P4F9,3,F9.1,2PF9,3,110) JחPT IMEJOPTIM+1

PE (JOPTIM) $\cong P$

VOC ( JOPTIM) $=$ HRS

$H R S=H R S+H R I N C$

IF (HRS.GT.HRMAX) GO TU 112

IF (HFLF,GT.O.) QGENEQBOL^EXP(-HRS/HFLF)

CALL PHONY (OP,JDUMP,HRS)

RE TURN

112 JOPTIM $=-2$

IF (RADPCT,EQ,O.) RETURN

$Q=1.0 E 6 \star(1 .-P E(3) / P E(2)) / V O C(3)$

$E=1.0 E 6 *(1 . . P E(7) / P E(2)) / V O C(7)$

WRITE $(6,201) \quad V O C(3), 0, V O C(7), E$

201 FORMAT ( 1 HO//25X,F 10,0,25H HOUR POWER DEGRADATION =,F8,3,

1 2ZH PCT. PER 10,000 HOUKS)

$\operatorname{TEMP}(1,1)=\operatorname{THSAV}$

$\operatorname{TEMP}(9,1)=\operatorname{TCSAV}$

RE IURN

END 
SUHRUIITINF PUMP(IRTRN)

COMMIJN /MODOPT/IPDWT, DRA, DRINCR, IKITE, DRTE, JOPTIM, IZ9, IENDK, IPUN, 1 RIINC, ROINC, RIMAX, RGMAX, DIMIN, OREQ, THINC, TCINC, TCMAX, THMAX

2, NPERT, ZNPERT, CKFP, CKFT, CTEOC, CTEIC, OELTI, RLPERT, RLMAX, ZNMIN, Z9SAV COMMUN /MDCPOP/KAD (9),DR (8), TEMP(9,300), VOIC $(300), R P C(300), P E(300)$,

1 OT (300), NUPTTM, VPC (300), RLPC (300), DTMUD (300), CUR (300), LNRAD(9),

2 ZLP, ZLN, ZLI, ZLNLP, ZLPNI, ZLTE, NGT1, NGTZ, ITPERT, PCMUL T, NDOUMP, IVD,

3 DGEN, WGENL, IJTE, QOUT, ZID, ZUN, ZKEND, ZK9, LKR,RPPC, RPN, TOLTFM, TREJ,

4 VRFQ, PEREO, ZLREQ, WTCON, ZILPN, IDUMZ, RN, DGRF, DGTRF, DGLRF, RADK, JDUMP,

$3 D P(30), N C$

COMMON / TITLE/FETM(3), CASCAD $(8,2), \operatorname{SSIN}(3), \operatorname{CMT}(25), \operatorname{CHND}(3,5)$, TEMKF,

1 CKMD $(2,2), I 3 N, I Z N, I 3 P, T 2 P$

COMMUN / TEPMP/NPUMP,DRB, CUD2

IF (JOPTIM-1) 102,103,201

C - INIIIALIIF VARIABLES

102 JOPTIM=1

INC $3=1$

TFMPHF $=D K 2 F K(T E M P(1,1))$

IEMPCF $=$ DK ZFK $(T E M P(9,1))$

IRITE $=4$

CODP $=D R(8) / R A D(9)$

$C O U=.5 \backsim C O D 2$

$D K 8=0$.

IF (PEREO.GT.0..AND.VREQ.GT.0.) GO TO 105

IRIRN $=3$

WRITE $(6,106)$

106 FORMAT (1H//10OH VOLTAGE AND PRWER MUST BE SPECIFIED IN PUMP MOI)UL 1E. PARAMETRIC CALCULATIONS, CALCULATIONS SUPPRESSED)

RETURN

IOS CURE $(S=P E R E Q / V R E Q$

RLPC (I) $=$ VREQ/CUREO

$I Z 9=2$

LOSAV $=\cap R(5)$

$P \equiv R U 1 N C * F L U A T$ (NPUMP)

KOMAX $=Z 9 S A V+0.5 \star P$

DR $3 S A V=D R(3)$

DRGSAVEDR (6)

DR $3 M A X=D K 3 S A V+P$

DRGMAX $=$ DR6SAV +P

103 WRITE $(6,100) \quad(C M T(J), J=1,25)$

100 FOKMAT $(1 H 1,4 X, 2 A 4,1 X, 18 A 4,2 H(, F 2,0,2(1 H /, F 2,0), 2 H), 2 A 4)$

WRITE (6,101) TEMPHF, TEMKF, TEMPCF, TEMKF, ZIU,DRTE,DR(1),PCMULT,COD

101 FORMAT (26H AVERAGE HITT CLAD TFMP. IFB,1,GH DEF, ,A1,3OX, 2SHAVER 

(2) Astronuclear

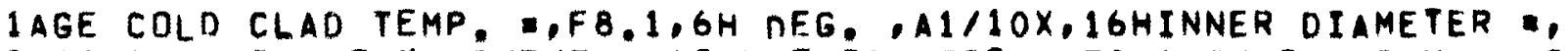
$2 F 8,4,4 \mathrm{H}$ IN, $36 \times, 22 \mathrm{HT} / \mathrm{E}$ RADIAL THICKNESS $=, F 8,4,4 \mathrm{H}$ IN, $/ 26 \mathrm{H}$ INNE $3 R$ CLAD THICKNESS $=, F 8,4,4 H$ IN, $8 \times, 16 H N D$, OF COUPLES $=, F 3,0,4 X$, 4 2THCLAD THICKNESS/D,D. RATIO $=, F 8,5$ )

$J=1$

IF $(W T C D N, G T, 0,) \mathrm{J}=2$

WRITE $(6,104)$ CRMD $(1, \operatorname{IENDK}), \operatorname{CRMD}(1, \operatorname{IENDK}), \operatorname{CRMD}(1, \mathrm{~J})$

104 FORMAT $(95 H O$ DR(3) DR(6) D.D. ZLN RLP RGEN 1 VOC VLUAD CURRENT POWER AA4,5X,3HETAA2,3X,A4,3HWT, $2 / 119 H$ (IN.) (IN.) (IN.) (IN.) (IN.) (M-OHMS) (VDLT 3S) (VOLTS) (AMPS) (WATTS) (WATTS) (PCT.) (LBS.))

201 JOPTIMEJOPTIM+1

IRTRN $=1$

IF (ARSCCUREQ-CUR(1))/CUREQ.LE.TOLTEM.OR.JOPTIM.GT.10) GO TO 210 $R C P C=(V O C(1)-V R E Q / P C M U L T) / C U R E Q-R P P C$

$R C O N D=R P C(1)=R P P C=R P N$

$P=R C P C \star R C P C-4, \star R P N \star R C U N D$

IF $(P . L T .0$.$) GO TO 209$

$\angle L N=.5 \star Z L N \star(R C P C-S Q R T(P)) / R C O N D$

RETUKN

$209 Z L N=\angle L N * S Q R T$ (RPN/RCOND)

JOPTIM $=10$

RETURN

210 OHM $=$ PCMULT $\star R P C(1)$

$W T=W A T E(P)$

NCV $=P C M U L T * V O C(1)$

$V L D=P C M U L T * V P C(1)$

$P=V L D \star C U R(1)$

$Q=P C M U L T \star Q T(1)+Z K E N D \star D T M O D(1)$

$E=P / Q$

IF $(I N C 3, E Q, 0)$ GO TO 212

WRITE $(6,211)$ DR(3), DR (6), ZOD,ZLN,ZLP,OHM, OCV,VLD,CUR (1),P,Q,E,WT

211 FORMAT (2HO, 3F8,4,2F9.4,3PF9,4, OP2F10,4,F9,2,F9,3,F9.1,2PF10.4,

1 OPF 9.3)

INC $3=0$

60 TO 214

212 WRITE $(6,213)$ DR (6),ZOD,ZLN,ZLP,OHM,OCV,VLD,CUR(1),P,O,E,WT

213 FDRMAT $(10 X, 2 F 8,4,2 F 9,4,3 P F 9,4,0 P 2 F 10,4, F 9,2, F 9.3, F 9,1,2 P F 10.4$,

1 OPF9,3)

C - INCREMENT OUTER CONDUCTOR RADIAL THICKNESS

214 JDPTIM=2

IRTRN=Z

$D R(6)=D R(6)+R O I N C$

IF (DR (6).LE.DRGMAX) RETURN 


\section{INC $S=1$}

DR $(6)=$ NRGSAV

C- INCKEMENT INNER CONDUCTOR RADIAL THICKNESS

$D R(3)=O R(3)+R O I N C$

IF (DR(3).LE.DK3MAX) RETURN

JUPT I $M=1$

$D R(3)=1) R 3 S A V$

C- INCREMENT T/E WASHER RADIAL THICKNESS

$Z 9 S A V=Z 9 S A V+0.25 * R U I N C$

$D R(4)=n R(4)+0.25 * R \Pi I N C$

IF (Z9SAV.LE.RYMAX) RETURN

IRTRN $=3$

RETURN

ENU

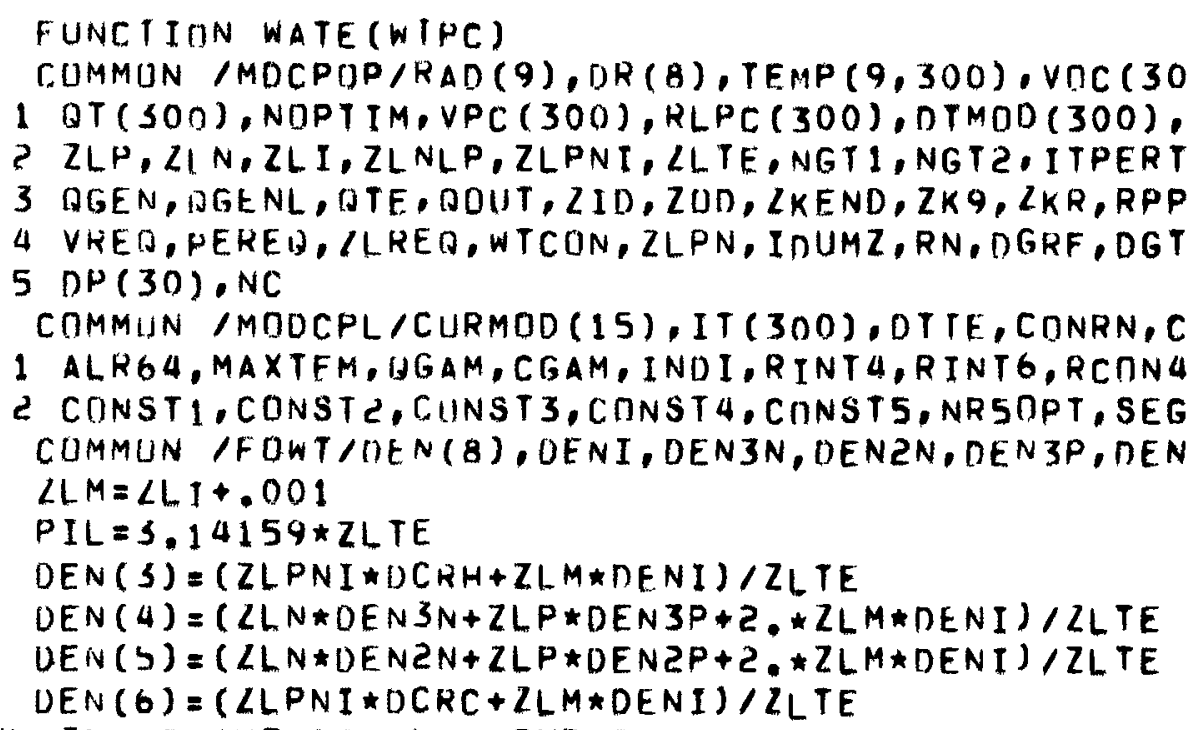

CALCULATE WEIGHT OF UNE COUPLE

$W T P C=0$.

DO $10 \quad \mathrm{I}=1,8$

$10 W T P C=W T P C+P I L \star D R(I) \star(R A D(I)+R A D(I+1)) * D E N(I)$

CALCULATE TOTAL MODULE WEIGHT

WATE =WTCON* (RAD(9) +RAD(1)) *(RAD(9) -RAD(1)) +PCMULT*WTPC

REIURN

END

FUNCTION DKZFK (I)

CUMMON /MODOPT/IPDWT, DR4, DRINCR, IRITE, DRTF, JOPTIM, I $\angle 9$, IENOK, IPIIN,

1 RI INC, RUINC, RIMAX, RQMAX, OIMIN, QREO, THINC, TCINC, TCMAX, THMAX

2, NPERT, ZNPERT, CKFP, CKFT, CTEOC, CTEIC, DFLTL, RLPERT, RLMAX, ZNMIN, 29SAV CONVERTS KELVIN TO FAHRFNHEIT DEGREES (IF $N Z(0)=1$ )

$D K 2 F K=T \star C K F T-C K F P$

REIURN

ENO 
FUNCTION SI (XTBL, YTBL, XX, NN, IND, INDLE, INDUE)

DIMENSIDN XTBL(2), YTBL (2)

$X=X X$

$N=N N$

c

C

C

C

C

C

C

C

c

C

C

C

C

C

C

C

C

C

C

C

c

C

IND

$=$

(IND=O INDICATES NQ EXTRAPOLATIDN WAS NEEDED DN $X$ )

(IND $=1$ INDICATES LOWER EXTRAPRLATION WAS NEEDED DN $X$ )

(IND $=2$ INDICATES UPPER EXTRAPOLATION WAS NEEDEN ON $X$ )

INDLE = INDICATES TYPE-DF-LOWER-EXTRAPOLATION TO BE USFD ON $X$

(INDLE 1 INDICATES LOWER EXTRAP. ON $X$ IS TO BE LINEAR)

(INDLE $=2$ INDICATES LOWER EXTRAP, ON $X$ IS TD BE PARABOLIC)

(INDLE 3 INDICATES LOWER-LINEAR EXTRAP. ON X AND ERROR PRI

(INDLE 4 INDICATES LOWER PARABOLIC EXTR, ON X AND ERROK PR

(INDLE $=5$ INDICATES LOWER EXTRAP. ON X IS TO BE FIRST TABLF

INDUE = INDICATES TYPE-DF-UPPER-EXTRAPDLATION TD BE USED ON $X$

(INDUF 1 INDICATES UPPER EXTRAP. ON $X$ IS TO BE LINEAR)

(INDUE 2 INDICATES UPPER EXTRAP. ON $X$ IS TO BE PARABOLIC)

(INDUE $=3$ INDICATES UPPER-LINEAR EXTRAP, ON $X$ AND ERROR PRI

(INDUE 4 INDICATES UPPER PARABOLIC EXTR, ON X AND ERROR PR (INDUE 55 INDICATES UPPER EXTRAP. DN $X$ IS TO BE LAST TABLE

XTBL = NAME DF INDEPENDENT VARIABLE TABLES

YTBL = NAME OF DEPENDENT VARIABLE TABLES

$N$ = NUMBER-OF-POINTS IN EACH TABLE

$X \quad=$ PARTICULAR VALUE DF INDEPENDENT VARIABLF.

$S I=Y T B L(1)$

$I N D=0$

IF (NN,LE.1) RETURN

CHECK TO SEE IF LOWER OUT-OF-RANGE EXTRAPOLATION WILL BE NEEDED

IF $(X-X$ TBL (1)) 120, 130, 150

LUWER DUT-OF-RANGE EXTRAPOLATION WAS FOUND NECESSARY (SET IND=1)

$I N D=1$

IF (INDLE,EQ, S) RETURN

C

150 IF (X.LT.XTBL $(N))$ GO TO 210

C UPPER DUT-OF-RANGE EXTRAPOLATION WAS FOUND NECESSARY (SET INDIZ) $I N D=2$

$I I=N$

GO TO $(254,180,254,180,131)$. INDUE

131 SI:YYBL(N)

RETURN 


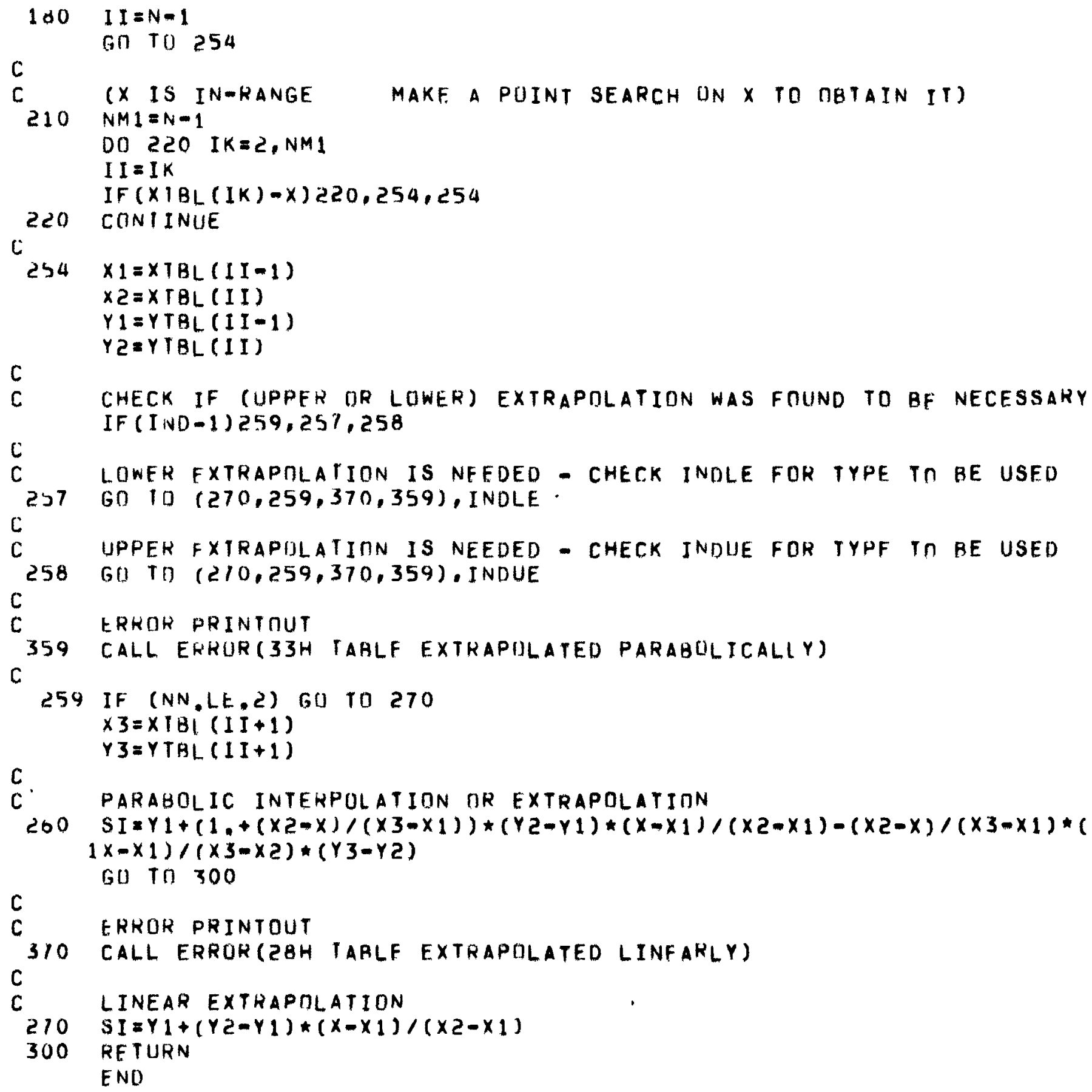

